\title{
Análise de instrumentos de apoio ao monitoramento dos serviços de atenção básica
}

\section{Paulo de Tarso Puccini}

Tese apresentada ao Programa de Pós-Graduação em Saúde Pública da Faculdade de Saúde Pública da Universidade de São Paulo para obtenção do título de Doutor em Saúde Pública.

Área de concentração: Serviços de Saúde Pública. Orientadora: Profa. Dra. Vitória Kedy Cornetta

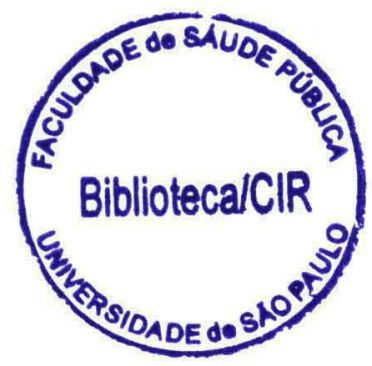

São Paulo

2005 


\section{5 doc}

Autorizo, exclusivamente para fins acadêmicos e científicos, a reprodução total ou parcial desta tese, por processos fotocopiadores. Para fins curriculares do autor, é solicitado que seja comunicado por e-mail: ppuccini@terra.com.br onde a tese será citada.

Assinatura:

Data: 
Dedicatória

Aos meus pais, Geraldo Puccini (em memória) e Wanda dos Santos Puccini (em memória), e aos meus irmãos, Cristóvão, Geraldo e Rita.

À Rosana e aos nossos filhos, Pedro e Renata. 


\section{Agradecimentos}

À professora Vitória Kedy Cornetta, pela amizade, pelo apoio e pela aberta e criteriosa orientação.

Aos professores Augusta Thereza de Alvarenga e Paulo Antônio de Carvalho Fortes, pelas sugestões na qualificação.

A Rosana Fiorini Puccini, pelo carinho, apoio e sugestões.

A Raquel Zaicaner, secretária de Saúde de Itapecerica da Serra, pela amizade e pelo apoio, e a todos os amigos e profissionais da Secretaria Municipal de Saúde de Itapecerica da Serra, pelo apoio recebido e pela possibilidade de ter compartilhado uma luta cotidiana em defesa do direito à saúde.

A Fernando Lefèvre e Ana Maria Cavalcanti Lefèvre, pelo apoio.

A Edina Mariko Koga da Silva, pelas sugestões.

A Pedro Fiorini Puccini e Renata Fiorini Puccini, pela ajuda.

A Geraldo Puccini Junior e Dilma Mineko Tacahashi Puccini, pelo incentivo.

A Lauro Vicente de Oliveira Aventurato, Gizelda Monteiro da Silva, Marlene Freire da Silva e Silva, pelo apoio.

A Zenilda Gonçalves Leite e Sueli Aparecida de Paiva, pela ajuda e digitação do material.

A Cecília Vannucchi, pela revisão do texto. 


\section{RESUMO}

Puccini PT. Análise de instrumentos de apoio ao monitoramento dos serviços de atenção básica. São Paulo; 2005. [Tese de Doutorado - Faculdade de Saúde Pública da Universidade de São Paulo].

O desenvolvimento da atenção básica e a conseqüente reorganização da sua rede de serviços são processos fundamentais na reforma setorial da área, visando à consolidação do direito à saúde e do Sistema Único de Saúde. O monitoramento é uma etapa indispensável ao processo de planejamento e administração, um componente da capacidade de gestão. Considerando-se a insuficiência de instrumentos para o apoio à gestão local da atenção básica, partiu-se da hipótese de que determinadas ocorrências atendidas em pronto-socorro podem estar relacionadas a possíveis falhas da atenção básica e, assim, ser utilizadas como eventos sentinela que apóiem o monitoramento da rede básica. Objetivo: analisar ocorrências atendidas em pronto-socorro com vistas à identificação de indicadores que possam ser utilizados pela gestão local para o monitoramento da atenção básica. Método: estudo transversal com componente retrospectivo. Foram utilizados dados quantitativos e qualitativos sobre determinadas ocorrências atendidas em pronto-socorro, previamente escolhidas, que possivelmente refletem uma falha no funcionamento da rede básica. Foram exploradas as diferenças encontradas na distribuição da freqüência de cada uma dessas ocorrências, entre áreas/UBSs, utilizando-se a técnica estatística da metanálise e analisadas as motivações e circunstâncias determinantes da procura por atendimento no prontosocorro. Resultados: as freqüências das hipóteses diagnósticas escolhidas (HDEs) apresentaram valores de $30 \%$ a $42,8 \%$ do total de atendimento conforme a área/UBS de procedência dessas pessoas. Essa diferença mostrou-se estatisticamente significante $\left(\mathrm{X}^{2}=\right.$ 9,19 e p-valor $=0,027$ ). A entrevista com uma amostra de 113 das 625 pessoas atendidas e diagnosticadas com uma das ocorrências escolhidas reconstituiu os passos das pessoas na procura de assistência até serem atendidas no pronto-socorro, com interesse especial na relação mantida ou não com a unidade básica de saúde. A apreciação desses discursos sugeriu a existência de causalidade entre o motivo declarado da procura do pronto-socorro e a situação da organização e da disponibilidade de atendimentos em cada unidade básica de saúde. Conclusões: a análise das ocorrências como possíveis eventos sentinela, indicadores para o monitoramento da rede básica, sugere: 1) a freqüência das ocorrências escolhidas foi influenciada pelas áreas/UBSs de procedência das pessoas; 2) é plausivel 
que a influência detectada seja, em parte, determinada pela situação local da atenção básica em cada área/UBS; 3) a técnica de levantamento de evento sentinela em PS para o monitoramento da atenção básica mostrou-se tecnicamente possível; 4) o instrumental de monitoramento estudado pode ser produzido e mantido com uma operação simples e viável para o gestor municipal; 5) o instrumental satisfaz de forma aceitável um conjunto de requisitos desejáveis para um indicador que o qualificam para a função de monitorar a atenção básica; 6) o indicar não revela todos os aspectos e dificuldades da atenção básica, mas propicia um maior diálogo com o cotidiano mais imediato dos serviços e pode somarse a outros indicadores, propiciando a sua parte de contribuição.

Descritores: Serviços básicos de saúde. Cuidados integrais de saúde. Avaliação dos serviços. Evento sentinela. Monitoramento. Metanálise. 


\section{ABSTRACT}

Puccini PT. Analysis of support instruments for the monitoring of basic attendance services. São Paulo; 2005. [Doctoral Thesis - School of Public Health, University of São Paulo].

The development of basic attendance and consequent reorganization of the network of such services have been fundamental processes within the reform of the sector that have had the aim of consolidating the National Health System and the right to healthcare in Brazil. Monitoring is an indispensable stage in the planning and administration process and forms one component of the capacity for administrating the system. Considering the insufficiency of instruments for supporting the local administration of basic attendance, the hypothesis raised was that certain occurrences attended by emergency services might be related to possible failures of basic attendance and thus could be utilized as sentinel events that would support the monitoring of the basic network. Objective: To analyze occurrences attended by emergency services with the aim of identifying indicators that could be utilized by local administrations for monitoring basic attendance. Method: This was a crosssectional study with a retrospective component. Quantitative and qualitative data on certain previously chosen occurrences attended by emergency services were utilized. These occurrences might reflect failures in the functioning of the basic network. The differences in their frequency distribution between areas and basic healthcare units were explored by utilizing the statistical technique of meta-analysis, and the motivations and circumstances determining the demand for emergency service attendance were analyzed. Results: The observed frequencies of the diagnostic hypotheses chosen ranged from $30 \%$ to $42.8 \%$ of all attendance, according to the area and basic healthcare unit these people came from. Such differences were shown to be statistically significant $\left(X^{2}=9.19 ; p=0.027\right)$. Interviews with a sample of 113 of the 625 people attended and diagnosed with one of the chosen occurrences reconstructed the steps these people took in seeking attendance, up to the time they were attended by the emergency services, with special interest in what relationship (if any) they had with the basic healthcare unit. Examination of these conversations suggested there was a causal relationship between the declared reason for seeking the emergency services and the state of organization and availability of attendance in each basic healthcare unit. Conclusions: Analysis of the occurrences as possible indicative sentinel events for monitoring the basic network suggests: 1) the frequency of the chosen 
occurrences was influenced by the areas and basic healthcare units the people came from; 2) it is plausible that the influence detected is partly determined by the local state of basic attendance in each area and basic healthcare unit; 3) the technique of surveying sentinel events in emergency services for monitoring basic attendance has been shown to be technically feasible; 4) the monitoring instrument studied can be produced and maintained through an operation that is simple and viable for the municipal administrator; 5) the instrument acceptably satisfies a set of desirable requisites for an indicator that qualify it for the function of monitoring basic attendance; 6) the indicator does not reveal all the aspects and difficulties within basic attendance, but provides greater dialog with the most immediate day-to-day routine in the services and can be added to other indicators, thereby making its contribution.

Key words: Basic health services. Comprehensive health care. Services evaluation. Sentinel event. Monitoring. Meta-analysis. 


\section{Sumário}

1 Introdução ......................................................................................... 1

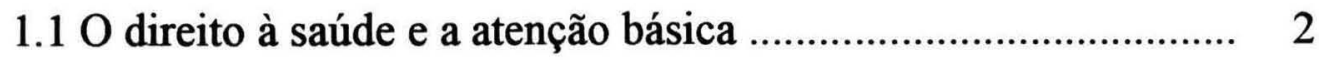

1.2 Atenção primária e atenção básica …………………................. 4

1.3 A atenção básica no SUS e a integralidade ............................... 7

1.4 A integralidade do cuidado e a humanização dos serviços ....... 10

1.5 A atenção básica e as mudanças no modelo assistencial ........... 13

1.6 Mudança do modelo assistencial e capacidade de gestão .......... 16

1.7 Monitoramento da atenção básica, marcadores e eventos

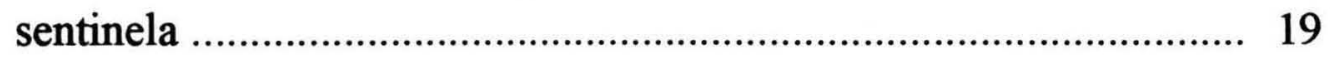

1.8 Sintetizando: o problema e a hipótese da pesquisa .................. 22

2 Objetivos .......................................................................................... 24

3 Método ........................................................................................ 25

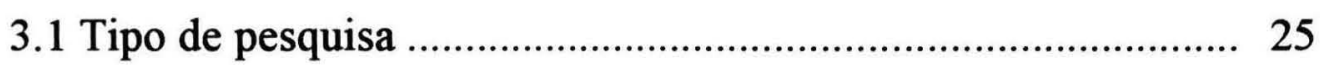

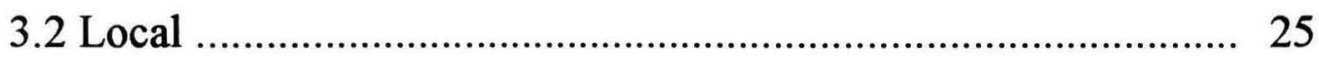

3.3 População e amostra ………………………………............. 30

3.4 Principais variáveis de estudo e levantamento dos dados.......... 33

3.5 A escolha das ocorrências para estudo.................................... 35

3.6 Análise dos dados.............................................................. 40

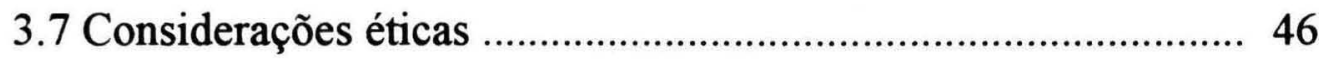


4.1 Os atendimentos no Pronto-Socorro Central .......................... 47

4.2 As entrevistas com as pessoas diagnosticadas com uma das hipóteses diagnósticas escolhidas para estudo........................... 66

4.3 Algumas características das unidades básicas escolhidas para estudo.

4.4 Opinião dos médicos socorristas e dos médicos das unidades básicas de saúde.

5 Discussão

6 Conclusões

\section{Anexos}




\section{Lista de figuras}

Figura 1 - Itapecerica da Serra, na Grande São Paulo - GSP

Figura 2 - Distribuição das consultas médicas. Itapecerica da Serra, 1999

e 2003

Figura 3 - Freqüência dos casos, segundo critérios de seleção.

PS Central, Itapecerica da Serra, 2004

Figura 4 - Metanálise da contribuição de cada uma das HDEs no cálculo da medida-sumário de odds ratio, segundo comparação entre as áreas/UBSs de procedência Branca Flor e Valo Velho. Itapecerica da Serra, 2004

Figura 5 - Metanálise da contribuição de cada uma das HDEs no cálculo da medida-sumário de odds ratio, segundo comparação entre as áreas/UBSs de procedência Salvador Leone e Valo Velho. Itapecerica da Serra, 2004

Figura 6 - Metanálise da contribuição de cada uma das HDEs no cálculo da medida-sumário de odds ratio, segundo comparação entre as áreas/UBSs de procedência Parque Paraíso e Valo Velho. Itapecerica da Serra, 2004

Figura 7 - Metanálise da contribuição de cada uma das HDEs no cálculo da medida-sumário de odds ratio, segundo comparação entre as áreas/UBSs de procedência Branca Flor e Parque Paraíso. Itapecerica da Serra, 2004

Figura 8 - Metanálise da contribuição de cada uma das HDEs no cálculo da medida-sumário de odds ratio, segundo comparação entre as áreas/UBSs de procedência Branca Flor e Salvador Leone. Itapecerica da Serra, 2004

Figura 9 - Metanálise da contribuição de cada uma das HDEs no cálculo da medida-sumário de odds ratio, segundo comparação entre as áreas/UBSs de procedência Salvador Leone e Parque Paraíso. Itapecerica da Serra, 2004 
Figura 10 - Razão de Prevalência (RP) de HDs demais entre pares de áreas/UBSs.

Itapecerica da Serra, 2004

Figura 11 - Razão de Prevalência (RP) de HDEs entre pares de áreas/UBSs. Itapecerica da Serra, 2004

Figura 12 - Verificação da significância da diferença de $10 \%$ de ocorrência le HDEs em diferentes tamanhos de amostras, em dois períodos hipotéticos ta UBS Valo Velho. Itapecerica da Serra, 2004 


\section{Lista de quadros}

Quadro 1 - Ocorrências em pronto-socorro, indicadas pelos médicos socorristas como casos a serem mais adequadamente atendidos na rede básica. Itapecerica da Serra, 2004

Quadro 2 - Ocorrências atendidas em pronto-socorro, escolhidas como possíveis indicadores para o monitoramento da atenção básica.

Itapecerica da Serra, 2004

Quadro 3 - Observação de aspectos negativos na organização das UBSs em estudo, segundo situação de cada UBS diante da superação do problema. Itapecerica da Serra, 2004 


\section{Lista de tabelas}

Tabela 1 - Indicadores da situação de saúde-assistência selecionados, segundo alguns anos. Itapecerica da Serra 2004

Tabela 2 - Unidades Básicas que se utilizam preferencialmente do PS Central de Itapecerica da Serra escolhidas para o estudo e população de abrangência, 2004

Tabela 3 - Freqüência dos atendimentos, segundo dia da semana e hipótese diagnóstica. PS Central, Itapecerica da Serra, 2004

Tabela 4 - Freqüência das HDs escolhidas e demais, segundo horário de atendimento. PS Central, Itapecerica da Serra, 2004

Tabela 5 - Freqüência das HDEs e HDs demais, no horário-UBS, segundo áreas/UBSs de procedência dos usuários. PS Central, Itapecerica da Serra, 2004

Tabela 6 - Freqüência das 25 primeiras HDs dos atendimentos realizados no horário-UBS e originados nas áreas/UBSs escolhidas.

PS Central, Itapecerica da Serra, 2004

Tabela 7 - Distribuição de todas as HDs dos atendimentos realizados no horário e áreas de procedência em estudo, segundo capítulos da CID/10 PS Central, Itapecerica da Serra, 2004

Tabela 8 - Freqüência das HDs escolhidas e demais, no horário-UBS e originados nas áreas/UBSs escolhidas, segundo sexo.

PS Central, Itapecerica da Serra, 2004

Tabela 9 - Freqüência das HDEs e HDs demais, no horário-UBS e áreas/UBSs de procedência em estudo, segundo faixas etárias. 
Tabela 10 - Freqüência das HDEs e HDs demais, no horário-UBS e áreas/UBSs de procedência em estudo, segundo grupos etários.

PS Central, Itapecerica da Serra, 2004

Tabela 11 - Valores de odds ratio entre grupos de idade e HDE no horário e áreas de procedência em estudo. PS Central, Itapecerica da Serra, 2004

Tabela 12 - Freqüência de algumas variáveis e verificação da influência na ocorrência das HDEs dos atendimentos realizados no horário e áreas de procedência em estudo. PS Central, Itapecerica da Serra, 2004

Tabela 13 - Verificação da influência de algumas variáveis na ocorrência das HDEs, segundo horário e área de procedência em estudo.

PS Central, Itapecerica da Serra, 2004

Tabela 14 - Freqüência das HDEs e HDs demais, no horário-UBS, segundo áreas/UBS em estudo. PS Central, Itapecerica da Serra, 2004

Tabela 15 - Verificação da diferença entre pares de áreas/UBSs de origem dos atendimentos na freqüência das HDEs. PS Central, Itapecerica da Serra, 2004

Tabela 16 - Freqüência das HDEs e HDs demais no horário e áreas de procedência em estudo, segundo grupos etários. PS Central, Itapecerica da Serra, 2004

Tabela 17 - Freqüência de cada uma das HDEs e HDs demais no horário e áreas de procedência em estudo, segundo sexo. PS Central, Itapecerica da Serra, 2004

Tabela 18 - Freqüência de cada uma das HDEs e HDs demais no horário e áreas de procedência em estudo, segundo áreas de procedência em estudo. PS Central, Itapecerica da Serra, 2004 
Tabela 19 - Valores do qui-quadrado e valores de $p$ da diferença entre as quatro áreas/UBS de procedência e a freqüência de cada uma das HDEs.

Tabela 20 - Resumo dos valores de odds ratio de cada uma das HDEs, segundo áreas/UBSs tomadas duas a duas e valor da medida-sumário de odds ratio, calculados com a técnica da metanálise. PS Central, Itapecerica da Serra, 2004

Tabela 21 - Freqüência dos atendidos com HDE entrevistados, segundo dia da semana. PS Central, Itapecerica da Serra, 2004

Tabela 22 - Freqüência dos atendidos com HDE entrevistados, segundo área/UBS de procedência. PS Central, Itapecerica da Serra, 2004

Tabela 23 - Freqüência dos atendidos com HDE entrevistados, segundo cada uma das HDEs escolhidas para estudo. PS Central, Itapecerica da Serra, 2004

Tabela 24 - Distribuição dos entrevistados e do total de atendidos com HDE, segundo sexo. PS Central, Itapecerica da Serra, 2004

Tabela 25 - Distribuição dos entrevistados e do total de atendidos com HDE, segundo grupo etário. PS Central, Itapecerica da Serra, 2004

Tabela 26 - Distribuição das principais ocupações, média de anos de estudo e média de anos na residência atual dos entrevistados, segundo área/UBS de procedência. PS Central, Itapecerica da Serra, 2004

Tabela 27 - Freqüência de algumas características de uso dos serviços de saúde por parte dos entrevistados, segundo áreas/UBSs escolhidas.

PS Central, Itapecerica da Serra, 2004 
Tabela 28 - Freqüência das categorias discursivas dos entrevistados que procuraram atendimento na UBS pelo problema atual e dos que tiveram consulta médica durante o ano na UBS. PS Central, Itapecerica da Serra, 2004

Tabela 29 - Freqüência das categorias discursivas dos entrevistados, segundo área/UBS de procedência. PS Central, Itapecerica da Serra, 2004

Tabela 30 - Distribuição percentual do número de casos padronizados das categorias discursivas, segundo as áreas/UBSs de procedência.

PS Central, Itapecerica da Serra, 2004

Tabela 31 - Algumas características das unidades básicas de saúde escolhidas para o estudo. Itapecerica da Serra, 2004 76

Tabela 32 - Produção e índice por 1.000 habitantes de consultas médicas (CM), segundo UBSs em estudo e Pronto-Socorro Central. Itapecerica da Serra, 2004

Tabela 33 - Valores de odds ratio entre grupos de idade, dias da semana, sexo e ocorrência de HDE nas áreas/UBSs em estudo.

'S Central, Itapecerica da Serra, 2004 


\section{Lista de Abreviaturas e Símbolos}

AIS - Ações Integradas de Saúde

CONASP - Conselho Consultivo de Administração de Saúde Previdenciária

FSP - Faculdade de Saúde Pública

HAS - hipertensão arterial sistêmica

HDE - hipótese diagnóstica escolhida

HDs demais - demais hipóteses diagnósticas

IBGE - Instituto Brasileiro de Geografia e Estatística

MDB - Movimento Democrático Brasileiro

MS - Ministério da Saúde

NOAS - Norma Operacional de Assistência à Saúde

NOB - Norma Operacional Básica

OMS - Organização Mundial da Saúde

OPAS - Organização Pan-Americana de Saúde

$\mathrm{OR}$ - odds ratio

PS - Pronto-Socorro

SUDS - Sistema Unificado e Descentralizado de Saúde

SUS - Sistema Único de Saúde

UBS - Unidade Básica de Saúde

UERJ - Universidade do Estado do Rio de Janeiro

UNICAMP - Universidade Estadual de Campinas

USP - Universidade de São Paulo

URRS - União das Repúblicas Socialistas Soviéticas

$\mathrm{X}^{2}$ - qui-quadrado 


\section{Introdução}

“O sucesso e a viabilidade do Sistema Único de Saúde dependem da instalação de uma rede básica eficaz", "A atenção básica é precondição para o funcionamento de um sistema de saúde eficaz, eficiente e eqüitativo", "A atenção básica é a principal estratégia do Sistema Único de Saúde para a mudança do modelo de atenção" Essas são afirmações muito freqüentes em documentos oficiais do Sistema Único de Saúde (SUS) e na elaboração teórica da área, sobre os rumos do sistema de saúde brasileiro.

Desde as primeiras mudanças provocadas pelo movimento brasileiro de reforma sanitária, iniciado, como conjunto de medidas institucionais, com a implementação dos convênios das Ações Integradas de Saúde (AIS), em 1983, a rede básica de serviços vem ocupando uma posição privilegiada nas proposições. A discussão de como mudar o modelo assistencial tem priorizado o tema da atenção básica como uma questão estratégica. Mas por que mudar o modelo assistencial e para qual direção se pretende caminhar? Essas talvez sejam as principais questões a ser tratadas para um entendimento da definição, das contribuições e dos limites da atenção básica, superando a tentação de catalogar o que constitui ou não seu rol de funções.

A história da estruturação dos serviços públicos de saúde no Brasil foi marcada desde o início do século passado por uma separação artificial, uma dicotomia entre ações preventivas, limitadas a campanhas e programas de controle de epidemias e endemias, e ações médico-curativas organizadas em torno do sistema previdenciário. As heranças desse período não são de rápida e fácil superação: fragmentação das ações e serviços, muitas vezes duplicados, com comandos paralelos; ação programática rígida e limitada, realizada em Centros de Saúde sob o comando de governos estaduais, isoladas das ações realizadas pela administração municipal ou federal; assistência curativa individual distorcida e sem eficácia; separação entre preventivo e curativo, individual e coletivo; inexistência de mecanismos de referência para continuidade e integralidade da assistência; limitação da oferta de serviços.

Todos esses aspectos restritivos articulavam-se com a definição que a sociedade tinha sobre a saúde das pessoas e sobre a abrangência dos cuidados de saúde. A marca fundamental desse período é a inexistência do reconhecimento do direito de todos à saúde. 


\subsection{0 direito à saúde e a atenção básica}

A saúde foi uma bandeira de resistência democrática por muitos anos. Ela despertava interesse, agrupava, expunha conflitos e contradições e favorecia, ainda que de forma difusa e atomizada, espaços de debate, organização e mobilização. Tais embates pela democratização viabilizaram diversas iniciativas de questionamento aos limites das concepções sobre a saúde e seus serviços, que também ocorriam internacionalmente, particularmente após a realização da Conferência de Alma-Ata, no ano de 1978 (GALLO e NASCIMENTO 1995).

Com a crise econômica e, em particular, do sistema previdenciário, nos anos finais da ditadura militar, abrem-se conflitos no interior do governo com espaços para ações de racionalização que contam com a participação de setores das forças democráticas presentes no aparelho de Estado. Assim, surge o Plano do Conselho Consultivo de Administração de Saúde Previdenciária (CONASP), que, posteriormente, vai orientar os convênios das Ações Integradas de Saúde (AIS) e o Sistema Unificado e Descentralizado de Saúde (SUDS). O relevante desse processo é verificar que ele não se realiza apenas com sua lógica interna de reparos funcionais no sistema nacional de saúde. O processo é intensamente politizado. Infladas pela vitória oposicionista nas eleições de 1982, as primeiras iniciativas com as AIS e o SUDS contribuiram para que paulatinamente fosse rompido o limite inicial de mudanças, abrindo caminho em direção ao SUS. Fortalece-se o movimento pela reforma sanitária, que contribui com muitas formulações de alternativas, as quais vão embasar as decisões da VIII Conferência Nacional de Saúde. Novas forças sociais entram em cena na disputa pela condução das políticas públicas da área de saúde: movimentos de saúde, conselhos populares criados em torno das AIS e do SUDS e a municipalização que coloca, definitivamente, a saúde na agenda do poder local, envolvendo de forma crescente e participativa prefeitos, vereadores e organizações da sociedade, assim como secretários municipais e estaduais da saúde (RODRIGUES NETO 1997).

A Constituinte foi marcada por essa conjuntura política muito singular. Ela registrou o transbordar do anseio democrático difusamente organizado, com a participação de amplo espectro de forças políticas progressistas. Na Constituinte vem à tona a pesada divida social acumulada por anos de injustiças, desigualdades e obscurantismo. Numa sociedade fragilmente organizada, setores mais estruturados e combativos puderam ampliar suas conquistas. Pelas particularidades da luta contra a ditadura em torno de uma ampla 
frente democrática, o MDB congregou e expressou publicamente a maior parte dos combates e foi também crescendo seu compromisso com as teses democratizantes da saúde. Foi um momento importante na vida pública brasileira, um processo que viria fazer resplandecer a solidariedade humana expressa na marca civilizadora da "Constituição Cidadã", conforme batizada pelo seu presidente, o deputado Ulisses Guimarães, no discurso de promulgação da nova Carta Magna.

Todo esse processo produz uma nova condição para as futuras políticas de saúde e, definitivamente, converte a saúde de questão social (já assim manifesta no século XIX, com o nascente Estado republicano, que, procurando afirmar sua legitimidade, desenvolve as primeiras iniciativas públicas de combate às grandes epidemias) em direitos sociais em disputa, horizontes de um projeto contra-hegemônico (HOCHMAN 1998).

O surgimento de uma questão a partir de necessidades problematizadas nem sempre produz respostas públicas voltadas para o seu substantivo equacionamento. $\mathrm{O}$ simples fato de ela ser uma questão presente numa sociedade marcada pela desigualdade suscita diferentes formas de reação, que põem em movimento tendências divergentes em torno de sua efetiva resolução. É por isso que a política de satisfação de necessidades embutidas numa questão social constitui uma situação incontestável de conflito de interesses. Daí a importância de considerar o direito à saúde, incluído na Constituição e nas Leis Ordinárias que regulam a questão, não como uma medida criada juridicamente e a ser desenvolvida por decreto ou por gestões meramente tecno-administrativas, mas, acima de tudo, como um recurso jurídico e político conflituoso, não obstante sua configuração formal (POTYARA 2000).

A saúde como direito social e a ação das forças sociais para sua efetiva realização, ou não, são, portanto, a marca fundamental deste novo período das políticas públicas de saúde. A saúde é questão assumida formalmente pelo conjunto da sociedade como direito de cidadania e, portanto, universal, coletivo, não contributivo e financiado pelos fundos públicos, configurando-se, assim, a nova conjuntura político-social. É em torno dessa questão e da disputa pelos fundos públicos que diferentes projetos passam a se articular.

As novas condições para a organização das ações de saúde no Brasil, concretizadas com a regulamentação do SUS, na Constituição de 1988 e na legislação ordinária que se seguiu (Lei 8.080/90 e Lei 8.142/90), inauguraram um novo ciclo de disputas, qualitativamente distinto das questões e problemas que tomavam conta da agenda político- 
social da área da saúde, no periodo anterior. Os problemas e equívocos do sistema de saúde então existente foram criticados em profundidade e amplitude. A reestruturação assumida pelo SUS estabelece, além de nova definição formal do sistema, um novo conceito de saúde, ampliado, não reduzido a ações assistenciais, compreendendo a necessidade de maior abrangência do horizonte sanitário como busca de igualdades para a melhoria da qualidade de vida.

A reconstrução do sistema de saúde em novas bases, portanto, não é tarefa simples, pois ultrapassa um questionamento conceitual interno da área, restrito apenas aos seus técnicos e profissionais. A saúde como direito social é a mudança fundamental anunciada pelo SUS. Assim, para a sua consolidação torna-se gradativamente insuficiente apenas o posicionamento crítico em relação ao conceito limitado da saúde ou em relação à forma de organização dos serviços - dicotomizada entre as ações individuais e as coletivas e entre prevenção e cura, características da situação anterior. A nova arena exige mais. Tomando o conceito amplo de saúde, a nova arena exige que se criem formas que materializem social e politicamente uma ação cuidadora integral, como direito de cidadania.

As propostas técnicas e organizacionais, como, por exemplo, as formulações da Atenção Primária, que foram instrumentos importantes na luta contra a situação anterior ao SUS e na estruturação conceitual da reforma sanitária, precisam incorporar novas questões para contribuir na nova realidade da saúde como direito.

\subsection{Atenção primária e atenção básica}

É pela compreensão desse contexto histórico e social que podemos melhor entender a evolução dos significados das proposições da atenção primária e suas relações com a atenção básica no SUS.

Atenção primária foi definida na Conferência de Alma-Ata, em 1978, e confirmada pela Assembléia Mundial de Saúde em reunião subseqüente, em maio de 1979, como (STARFIELD 2002, p.30-31):

Atenção essencial à saúde baseada em tecnologia e métodos práticos, cientificamente comprovados e socialmente aceitáveis, tornados universalmente acessíveis a individuos e famílias na comunidade por meios aceitáveis para eles e a um custo com que tanto a comunidade como o país 
possa arcar em cada estágio de seu desenvolvimento, um espírito de autoconfiança e autodeterminação. É parte integrante tanto do sistema nacional de saúde, no que constitui a função central e o núcleo principal, como do desenvolvimento social e econômico global da comunidade. É o primeiro nível de contato dos indivíduos, da família e da comunidade com o sistema nacional de saúde, levando a atenção à saúde o mais próximo possível do lugar onde as pessoas residem e trabalham, constituindo o primeiro elemento de um processo de atenção continuada à saúde.

De fato, se formos analisar as proposições aprovadas na Conferência sobre a atenção primária e expressas na Declaração de Alma-Ata e no documento "As 22 Recomendações de Alma-Ata", não veremos grandes contradições em relação ao que agora se discute quanto à atenção básica. Mas as propostas ganham significado na prática social e aí se caracterizam como estratégias no interior da disputa sobre a abrangência e os limites das políticas públicas. Foi nos embates de interesses de sua operacionalização que a atenção primária transformou-se em serviços mínimos para populações marginalizadas. Esse mesmo embate ainda hoje permanece com muito vigor, apesar do espírito das leis que defendem o direito à saúde no SUS.

Como afirma Mario Testa:

[...] não é possível considerar a atenção primária de saúde como um conceito totalizante, com a mesma validade em qualquer país e circunstância [...] A contextualização da atenção primária de saúde é dada, em primeira instância, pelo sistema de saúde em que está inserida. Esse sistema é o que concretiza a significação de tal atenção no nível da organização setorial (TESTA 1992, p.160).

Pontos fundamentais das proposições de Alma-Ata foram colocados de lado, e um dos seus itens, o qual faz referência a um conjunto de ações que ao menos deveriam ser implementadas, foi elevado por diversas circunstâncias e interesses diversos à categoria de objetivo final das proposições da Conferência. É importante lembrar que, repercutindo um momento de luta político-ideológica internacional, em Alma-Ata, delegações de 134 governos, sob a coordenação do Professor B. Petrovsky, Ministro da Saúde da URSS, eleito presidente da Conferência, firmou-se na "Declaração de Alma-Ata - 1978" que a saúde é um direito humano fundamental; que a saúde não é somente ausência de doença 
mas algo cuja concretização exige ação dos setores econômico e social; que a grave desigualdade existente no estado de saúde das populações, especialmente entre a população dos países desenvolvidos e a dos demais, é política, social e economicamente inaceitável; que o desenvolvimento econômico e social baseado em uma Nova Ordem Econômica Internacional é de importância fundamental para a saúde de todos; que o povo deve ter direito de participar e que os governos têm a obrigação de cuidar da saúde de sua população e, finalmente, que a atenção primária de saúde é a chave para alcançar melhor nível de saúde como parte de um desenvolvimento no espírito da justiça social.

Analisando a evolução da atenção primária, TESTA (1992) observa que, nos países que conseguiram direcionar o sistema de saúde, segundo esse conjunto articulado de princípios e valores sociais, ela é um elemento da cadeia de atenção, onde são resolvidos alguns problemas, orientando os restantes pelos níveis sucessivos. Em países que não conseguiram estabelecer um sistema com essas características, isto é, regionalizado e com um adequado sistema de referência, a atenção primária de saúde se transformou em atenção primitiva de saúde, em um serviço de segunda categoria. Não há uma rede de estabelecimentos interligados por claros procedimentos de referência e de transmissão da informação pertinente, que ordenem a circulação interna das pessoas atendidas no sistema, e não há um ordenamento territorial regionalizado. $\mathrm{O}$ tipo de atenção prestado nesses estabelecimentos não tem a qualidade necessária para realizar a distribuição indicada. $O$ pessoal destinado a prestar esses serviços, nos países capitalistas dependentes, é, em geral, o de menor nível de capacitação: estudantes ou médicos recém-formados, sem a necessária experiência para desempenhar a função que tem a maior responsabilidade no funcionamento do sistema.

Foi com uma orientação restritiva que a atenção primária foi significada e orientada no Brasil, na primeira metade da década de 1980. Capturada pelo enfoque da Medicina Comunitária, que se baseava em iniciativas voltadas para populações negras e pobres dos Estados Unidos, os cuidados primários, nos países periféricos, foram induzidos no limite de ações focais da medicina comunitária, com farta munição articulada por fundações norte-americanas que já apoiavam, desde a década de 1970, experiências pontuais em universidades e instituições filantrópicas (ASSIS et al.1993; MARSIGLIA 1995).

O característico desses programas marginais complementares aos limites do próprio sistema então existente - que não reconhecia o direito universal e integral à saúde - era oferecer serviços de baixa resolubilidade e de baixo custo, providos por pessoal de baixa 
qualificação profissional, sem possibilidades de referências para outros níveis, incluindo uma retórica de participação comunitária (ASSIS et al.1993).

Ao assumir esse caráter de medicina simplificada para os pobres, a atenção primária deixou de ser privilegiada enquanto tal nas proposições elaboradas na VIII Conferência Nacional de Saúde; entretanto, o ideário de Alma-Ata (direito fundamental, dever de Estado, integralidade, eqüidade, intersetorialidade, participação da comunidade, regionalização, hierarquização, descentralização) foi amplamente incorporado no corpo doutrinário da Reforma Sanitária Brasileira (PAIM 1999).

Em 1998, no processo de implantação do SUS, o Ministério da Saúde aprovou a Portaria n 3925 (Manual de Organização da Atenção Básica do SUS), contendo uma orientação geral aos gestores municipais sobre o conteúdo e a organização das ações de atenção básica. Adota-se nesse Manual a definição de atenção básica como sendo "um conjunto de ações, de caráter individual ou coletivo, situadas no primeiro nível de atenção dos sistemas de saúde, voltada para a promoção, a prevenção de agravos, o tratamento e a reabilitação" (BRASIL 1998). Essa definição evidencia importantes questões: Qual seria a dimensão e a abrangência desse conjunto de ações? Como a atenção básica se situa e se articula com o sistema?

\subsection{A atenção básica no SUS e a integralidade}

No Brasil, a transição por que passam as práticas de saúde, de mercadoria/benefício contributivo para a nova conceituação como direito social de cidadania, é certamente um processo dificultado por velhos problemas herdados pelo SUS e por novos que vão se colocando nas disputas pela organização dos serviços e das ações de saúde, segundo os princípios do SUS.

As heranças recebidas pelo SUS e os interesses que mantiveram a saúde também como mercadoria/benefício colocam a atenção básica numa posição estratégica, num centro de tensão entre forças, numa disputa entre o SUS para pobres e o SUS como direito de cidadania de todos os brasileiros. Na perspectiva do SUS como um subsistema público seletivo para os pobres, a conseqüência mais provável será a tendência ao subfinanciamento e à restrição de serviços assistenciais ao mínimo (MENDES 2004). 
No processo de busca da superação do modelo médico-privatista, com todo o seu corolário de mazelas articuladas com os interesses econômicos do "complexo médicoindustrial", e também da saúde pública campanhista e controlista, enfrentam-se polêmicas recorrentes com as concepções restritivas representadas pelas propostas de provimento mínimo do direito à saúde, focadas na rede básica simplificada, com equipe mínima, cumpridora de uma "oferta organizada" unilateral e "tecnicamente" definida, oriundas de uma concepção distorcida da "atenção primária à saúde", e, também, com as "modernas" concepções da "Gestão pela Qualidade", a qual, comprometida com a funcionalidade do "Estado Gerencial", tende a dissolver as arenas de disputa política pela abrangência dos direitos sociais e pela qualidade de vida (OLIVEIRA 1998). Assim, ao se evidenciarem momentos de forte conflito com os interesses hegemônicos na implementação do SUS, que se manifestam em variados aspectos objetivos observáveis, não se deve propor uma forma de equacionamento da questão sugerindo mudanças nos serviços que desconsiderem o fortalecimento de um bloco de forças capaz de defendê-lo. A desconsideração da correlação de forças pode induzir à criação de propostas apenas submetidas à lógica das racionalidades técnicas ou extremamente voluntaristas, sem nenhuma viabilidade e, sobretudo, descentrar prioridades e desarmar a constituição dos mecanismos de ação política contra-hegemônicos (PUCCINI 2002).

Na dimensão da organização dos serviços e das práticas, os princípios do SUS, em especial o da integralidade das ações, são qualificadores do direito social, são elementos que impulsionam a expressão de novas necessidades. Isto é, se no plano mais geral da política o embate dos projetos da saúde concentra-se na disputa pelos princípios da universalidade, da autonomia crítica do controle social, da formatação da eqüidade e da conseqüente política de financiamento do sistema, no plano da organização cotidiana dos serviços e das práticas é sobre a integralidade do cuidado que se trava a disputa entre o mínimo e o básico. No ato de reconhecer e valorizar novas necessidades está a fundamental diferença entre o provimento mínimo e o básico do direito à saúde. É um momento privilegiado no qual se constituem alianças sociais para que o alcance e a abrangência das políticas públicas não sejam reduzidos ao mínimo (PUCCINI e CECÍLIO 2004).

O ótimo no provimento de um direito social é, certamente, um ponto sempre em fuga, mas o mínimo e o básico não são a mesma coisa; do ponto de vista prático, conceitual e político, são noções assimétricas. O mínimo se vincula ao menor, ao menos, 
identifica-se com patamares de satisfação de necessidades que beiram a desproteção; é acompanhado por supressão ou cortes de atendimento. Já o básico diz respeito a algo fundamental, principal, primordial, que serve de base de sustentação indispensável ao que a ela se acrescenta. $\mathrm{O}$ básico requer investimentos sociais de qualidade que preparem o terreno para o surgimento de outras necessidades, que questionem os limites da própria estrutura social e das relações sociais vigentes (POTYARA 2000).

A reforma sanitária reconhece que cada região, na sua grande diversidade social e zpidemiológica, tem um perfil de necessidades e prioridades. A descentralização com Ìnfase na municipalização, a hierarquização e a regionalização são estratégias de rganização do SUS para, com a ação do controle social, tirar do papel os princípios da sidadania e transformá-los em prática social. Nessa direção, são questões estratégicas, já implamente reconhecidas, para a remontagem do sistema de saúde brasileiro, o papel, a əxtensão e a organização que a rede básica deve assumir. Desenvolver uma organização de ierviços e uma prática comprometida com a integralidade do cuidado é um problema :entral. É impossível um gestor local ou regional conseguir articular uma cidade saudável :om foco na promoção de saúde, se continua refém de um modelo assistencial antigo.

Os municípios que combateram as atividades distorcidas da assistência e investiram ıa ampliação da assistência básica resolutiva, lutando pela integralidade, conseguiram ıeutralizar as heranças do complexo médico-industrial. Foram esses que mais acertaram na ntersetorialidade e nas ações de promoção. Já aqueles que se deram por vencidos e ıcharam que não podiam mais perder tempo com interesses malignos da assistência e jastaram o seu tempo gerencial e o entusiasmo exacerbando as possíveis contribuições das ıções intersetoriais e de promoção, não fizeram nem a promoção, nem a reversão estrutural la assistência (SANTOS 2002).

É fato que para que uma rede básica possa ser responsável pela saúde de uma dada ıpulação, não pode se omitir na hora da demanda, da doença, do sofrimento, ocultando ua insuficiência de recursos ou sua maneira limitada de funcionar com um discurso que estrinja o papel da atenção básica ao mínimo, ao atendimento primário e à promoção da aúde. A dificuldade em responder aos problemas concretos que aparecem na porta dos erviços gera muitas críticas, insatisfações, e, assim, toda a credibilidade dos serviços e a lecessária intenção de ampliar o conceito de saúde-doença são arrastadas, em conjunto om o não-acolhimento das demandas, para o mundo das intenções irrealizadas. 
Compreende-se, assim, que não há futuro para o SUS sem a presença ativa dos interessados na transformação da saúde em direito social e, portanto, sem o reconhecimento do cidadão, com expectativas e necessidades, como agente político de sua concretização. Assim, o que importa em cada momento da luta pelo direito à saúde é a adequação do projeto coletivo do SUS, que transcende os regramentos técnicos, enfrentando, no terreno onde apareça, a tendência de limitar ao mínimo o financiamento e as ações de um sistema que, por ser solidário, universal e um direito financiado por fundos públicos, encontra-se na contramão do ideário e dos interesses da acumulação de capital.

\subsection{A integralidade do cuidado e a humanização dos serviços}

A concretização do princípio da integralidade precisa superar o entendimento da rede básica como sinônimo de equipe mínima, profissionalmente capenga, simplificada, com baixa resolubilidade, sem trabalho de equipe multiprofissional; precisa superar a exacerbação do discurso da promoção de saúde em contraposição às ações assistenciais, que num típico exemplo de "idéias fora de lugar" perde o foco da luta brasileira entre o mínimo versus o básico e se torna incapaz de acolher as pessoas e de assumir a responsabilidade pela saúde da população de uma área, oferecendo cuidados integrais e contínuos.

As proposições de humanização da assistência têm contribuído para uma melhor compreensão da prática da integralidade, ao induzirem a pensar uma nova rede básica, ao defenderem que é impossível equacionar a questão da integralidade sem valorizar um encontro muito além de soluções com modelos técnicos rígidos de programação de "oferta organizada" de serviços. A integralidade, para concretizar-se, depende do reconhecimento e da valorização do encontro singular entre os indivíduos, que se processa no necessário convívio do ato cuidador. Esse reconhecimento contamina a atmosfera do convívio cotidiano com uma nova força estruturante e de defesa dos princípios do direito à saúde. Integralidade e cuidado reúnem, portanto, em um mesmo princípio ampliado, uma nova tendência de reconhecimento do outro, um direcionamento da materialização do direito à saúde que não é mais a simples soma aritmética de aspectos técnicos das ações de saúde (PUCCINI e CECÍLIO 2004).

O novo modelo assistencial não se resolve com uma necessária, porém insuficiente, justaposição das dicotomias entre individual e coletivo, entre preventivo e curativo. É 
preciso compreender a integralidade do cuidado para além da disponibilidade e da articulação de serviços. O processo integrador de ações depende da interação entre as pessoas para o encaminhamento dialógico de interesses comuns e, para assim, superar-se a fragmentação tecno-burocrática. Esse é um dos sentidos que embasam a atual ênfase na humanização dos serviços de saúde.

A valorização do encontro cuidador é uma exigência particularmente forte na área da saúde pelas suas características próprias. Toda a assistência se funda numa inter-relação pessoal muito intensa. A saúde, mais do que outros serviços, depende de um laço interpessoal forte e decisivo para a própria eficácia do ato. $\mathrm{O}$ usuário é um fornecedor de valores de uso substantivos, de tal modo que é co-participante do processo de trabalho e co-responsável pelo êxito ou malogro da ação terapêutica (NOGUEIRA 1997).

Em termos gerais, o movimento de humanização pode ser entendido como uma crítica a essa condição da vida humana em sociedade. $O$ homem estranha seu próprio trabalho e os produtos de seu trabalho. Recusa aceitar que as coisas são assim porque sempre foram assim. $\mathrm{O}$ movimento pela humanização questiona os limites impostos pela organização social vigente, procura ir além do fazer fixado e regulamentado na estrutura social, busca interromper o fluxo imaginado como o natural dos acontecimentos, escapar da tirania da aparência de "normalidade" e refletir criticamente sobre a realidade. Nesse sentido é que HELLER (1978), discutindo as imposições da organização social, alerta que os homens prisioneiros do fazer pelo fazer e do consumismo entregaram-se ao domínio das coisas sobre eles, e nessas condições as relações inter-humanas aparecem como desejos de coisas, e as necessidades não são governadas pelas necessidades de desenvolvimento e de auto-realização dos indivíduos.

$\mathrm{Na}$ área da saúde, um movimento humanizador também vem se desenvolvendo e se traduz em muitas proposições: melhorar a relação médico-paciente; organizar atividades de convívio amenizadas e lúdicas, como as "brinquedotecas" e outras ligadas às artes plásticas, à música e ao teatro; garantir acompanhante na internação da criança e horários de visita mais amplos para adultos e idosos; implementar novos procedimentos na atenção psiquiátrica, na realização do parto - o parto humanizado - e na atenção ao recém-nascido de baixo peso - programa da mãe-canguru; amenizar as condições do atendimento às pessoas em regime de terapia intensiva; denunciar a "mercantilização" da medicina; criticar a "instituição total". 
Entretanto, a humanização efetivamente transformadora exige ultrapassar o limite da pregação moral, da vontade individual de alguns profissionais, e ir além da amenização de aspectos isolados da prática social. No caso da saúde, a atitude transformadora expressa-se na crítica e na superação das heranças negativas do SUS, da visão da saúde como mercadoria e não como direito social; na superação da visão da saúde como caridade ou filantropia, da pessoa em atendimento como um ser sem nome, opinião e expectativas; na valorização das relações interpessoais como aspectos fundamentais da ação cuidadora integral; no reconhecimento do cidadão, do usuário do serviço e dos profissionais como agentes do processo de cuidado, como portadores de um direito e de necessidades.

Concebe-se, assim, uma linha de identidade das diferentes experiências desse movimento como tentativas de ruptura, de ir além das necessidades "necessárias", de valorizar a autonomia dos sujeitos e as diferenças (HELLER 1978, 2000). Isto é, uma opção de entendimento que transforma a doutrina humanista clássica atravessando-a com o pulsar histórico dos carecimentos humanos concretos construídos socialmente.

Com base em algumas experiências concretas de processos de humanização (PUCCINI 2002), podem-se destacar certas questões e princípios que têm marcado sua ação transformadora, em especial para a reorganização da atenção básica:

- reconhecer que a integralidade do cuidado pressupõe ouvir e compreender o outro, considerar a pessoa atendida como agente do processo de cuidado;

- acolher a todos os que procuram os serviços, garantindo uma continuidade do cuidado conforme a necessidade;

- favorecer o diálogo e o processo pedagógico na relação profissionalusuário;

- ampliar canais de participação da população e de controle social, visando reconhecer novas necessidades e incluir a opinião dos usuários na definição de prioridades;

- ampliar a participação dos profissionais no planejamento e no gerenciamento das unidades, debatendo a situação da organização dos serviços e as prioridades de mudança; 
- valorizar o saber de cada profissão e do trabalho em equipe, incentivando e capacitando em especial o enfermeiro, para que ele retome seu papel assistencial na rede básica;

- substituir o "balcão recepção", com seu papel limitado a uma ação burocrático-administrativa, por uma recepção técnica acolhedora que possibilite melhor condição ao trabalhador da saúde de dialogar, escutar o problema que motivou a pessoa a procurar o serviço e, assim, definir, em conjunto com ela, a continuidade do seu cuidado;

- capacitar os médicos, sem o objetivo restrito de transformá-los em “generalistas", a terem uma compreensão da atenção básica receptiva, cuidadora, crescentemente resolutiva, respeitosa do direto do cidadão, que atende pessoas agendadas e não-agendadas e realiza ações em equipe dentro e fora da unidade de saúde;

- articular o desenvolvimento de novas atividades na unidade e fora dela (extramuros) em conjunto com a comunidade, para que as atividades, num novo patamar de integralidade, superem a visão restrita da saúde como sinônimo de consulta médica, exames e medicamentos.

A humanização assim compreendida pode contribuir para a atribuição social de sentidos e finalidades ao princípio da integralidade na atenção básica, favorecendo uma contraposição à tendência restritiva das políticas públicas mínimas na área da saúde, agrupando interesses num projeto de defesa do direito à saúde (PUCCINI 2002).

\subsection{A atenção básica e as mudanças no modelo assistencial}

As dificuldades do processo de mudança não são poucas. Além das heranças negativas que fundamentam a história da saúde e as práticas cujos valores são permanentemente revigorados no funcionamento da ordem social e sua reprodução, novas dificuldades são evidenciadas na disputa do novo com o antigo no processo de mudança. Como toda mudança, a reorganização dos serviços desloca interesses, questiona certos equilíbrios, certa maneira de funcionar acordada entre grupos de interesses, e esses são motivos de resistência. 
Assim, é necessário reconhecer que há uma integração entre as ações realizadas na esfera pública e a lógica do sistema social e sua reprodução, mas, também, que a luta social tem conquistado a ampliação da ação pública na prestação de serviços sociais, segundo princípios do bem comum, como "antimercadorias e antivalores", a despeito dos interesses imediatos do capital (BRAVERMAN 1987; OLIVEIRA 1998). Essa situação, sempre muito instável e cheia de avanços e reveses, apresenta-se nos dilemas e nas dificuldades que envolvem a implementação do SUS, na disputa pelo provimento mínimo versus o básico do direito à saúde, na disputa pelos fundos públicos.

Uma mudança na saúde, ainda que setorial, está de forma permanente interagindo com a disputa dos valores gerais da sociedade na qual se insere e é dependente dela. Isto é, novos fins do trabalho em saúde, e na rede básica em especial, sob a ótica do direito social, só encontram sua afirmação democrática com a incorporação do cidadão na definição de projetos, na afirmação do tipo de sociedade que se deseja, na ação política como materialização das possibilidades de gestação de projetos de interesse geral.

A atenção básica é um componente fundamental desse projeto geral, que, para contar com a disposição de todos os envolvidos na condução dos seus rumos, precisa buscar atingir um grau mais elevado de clareza e organização. A atenção básica, como algo a ser priorizado pelos sistemas de saúde, tem sido defendida por diversas propostas para a conformação de um sistema de saúde, entretanto, tal importância atribuída às ações básicas não tem a mesma abrangência de concepção. Há conflitos presentes, o que continuamente tem causado dificuldades para o estabelecimento de parâmetros e instrumentos de avaliação e monitoramento gerencial dessas ações.

Uma rede básica mínima cria um ciclo vicioso na utilização dos serviços, resulta em grande e desnecessária procura da população por unidades de urgência/emergência e de ambulatórios de especialidades e, em conseqüência, as unidades básicas perdem sua condição de local onde se privilegiam os cuidados contínuos, perdem a credibilidade para realizar ações de promoção e prevenção, mergulham no equívoco de avaliar que o problema é a população que não entende ou resiste em aceitar que a porta de acesso aos serviços de saúde é a unidade básica.

A idéia de que a rede básica é a porta de entrada do sistema de saúde, embora corretamente preocupada com a integração sistêmica, traz duas grandes armadilhas: 
- considerar que de forma regulamentar e tecnocrática os gestores são capazes de definir uma porta obrigatória ou preferencial que a população deverá procurar;

- considerar que, como é porta de entrada, o fundamental do trabalho da rede básica seria garantir o acesso a outros níveis, descaracterizando, assim, a integralidade como parte da ação de cada serviço. Pois, de forma gradativa e crescente, isso vai desqualificando a atenção básica, reduzindo-a ao discurso de promoção e limitando-a a uma triagem para a assistência realizada em outros níveis do sistema (MERHY e QUEIROZ 1993; CECíLIO 1997).

O fato é que a população só usará a rede básica como acesso privilegiado se esta se preparar para isso. Tal situação reforça a idéia de que o acesso, a integralidade com humanização dos serviços e a continuidade do cuidado não são atributos do sistema concretizados apenas na existência de uma cadeia de níveis de assistência, mas estão presentes na concepção e nas funções de cada um dos níveis e de cada serviço, com os respectivos profissionais.

A concepção de básico é dinâmica, é a capacidade de aprender com a realidade e incorporar de forma permanente novas necessidades. Trabalhar com o básico é trabalhar com um caminho sempre a percorrer, e não com um ponto de chegada. Assim, uma definição de rede básica, mais do que estabelecer um conjunto fixo de funções nacionalmente pré-definidas, precisa ser capaz de, no cotidiano, ensinar e aprender com os outros níveis do sistema e com as necessidades apresentadas pelo usuário, pelo cidadão e pela comunidade.

Sobre essa tentativa de fixar o elenco de funções pertinentes à atenção básica, importante para um processo avaliativo e de monitoramento, RIBEIRO (2002) afirma que, considerando o diversificado elenco de conceitos e definições, talvez não seja necessário, ou mesmo possível, um consenso, mas apenas que cada processo avaliativo ou de monitoramento das mudanças defina com nitidez o que se pretende avaliar ou monitorar. 


\subsection{Mudança do modelo assistencial e capacidade de gestão}

A reorganização da rede básica representa um processo fundamental na reforma setorial e é fortemente dependente da capacidade de gestão (BODSTEIN 2002). A capacidade de governo, que é revelada como capacidade de direção, administração e controle, refere-se, segundo MATUS (1997), ao acervo de técnicas, métodos, destrezas e habilidades de um gestor e sua equipe para conduzirem o processo social a objetivos declarados, dados a governabilidade do sistema e o conteúdo propositivo do projeto de governo. Assim, toda equipe de governo está sempre limitada por sua capacidade de gestão, que será desafiada em medida proporcional à ambição do projeto de governo e à dificuldade para mudar expressa pela governabilidade do sistema.

Avaliação e monitoramento são etapas essenciais do processo de planejamento e administração, são componentes da capacidade de gestão que possibilitam a tomada de decisão de maneira mais racional e atenta aos problemas enfrentados. Apesar do intenso debate, poucos estudos e pesquisas de caráter avaliativo tratam de qualificar as mudanças em curso no sistema de saúde brasileiro. Tais estudos adquirem, portanto, um papel imprescindível em um contexto democrático, de construção social de um direito. Isso porque, quanto maior a capacidade de gestão, de planejamento, de monitoramento e de avaliação de seus resultados, tanto maior o espaço para a participação e o controle social (BODSTEIN 2002).

CESAR e TANAKA (1996), seguindo a tríade defendida por DONABEDIAN (1980) - estrutura, processo e resultado -, propõem uma definição de avaliação como um conjunto de atividades voltadas para medir as condições existentes, o processo de trabalho e os resultados obtidos, fazendo as comparações tanto com as condições e as tecnologias previstas, quanto com os resultados e as metas a serem alcançados, para a emissão de um juizo de valor. A avaliação seria, assim, constituída de etapas que podem ser agrupadas nas ações de medir, comparar e emitir juízo de valor.

A essencialidade de uma avaliação se localiza no julgamento de valor de um programa, projeto, intervenção ou sobre qualquer um de seus componentes, com o objetivo de ajudar na tomada de decisões. Esse julgamento pode ser resultado da aplicação de critérios e de normas (avaliação normativa) ou se elaborar com base em um procedimento cientifico (pesquisa avaliativa) (HARTZ e CAMACHO 1996; HARTZ 2000a). 
Atentos a possíveis armadilhas a que a supervalorização recente de avaliações poderia levar, CARVALHO e BARREIRA (2001) chamam a atenção para alguns aspectos norteadores de uma melhor compreensão do que seja avaliar:

- A avaliação não tem um valor em si, não substitui a política ou programa nos processos e resultados que move e persegue.

- Avaliação é oportunidade de reflexão crítica da ação e possibilidade de disputa e conquista dos resultados idealizados.

- Avaliação é imperativo ético, desconstrói e reconstrói a política ou programa na sua intencionalidade, resultados e efeitos quanto à alteração da qualidade de vida - enquanto proteção, inclusão e cidadania - dos envolvidos na ação pública.

Avaliar é estabelecer um juízo de valor. A idéia de valor vai além do julgamento de mérito como tal. Pressupõe um posicionamento do avaliador e do avaliado sobre o conteúdo das conclusões, que serão incorporadas, interagindo com o contexto no qual a avaliação se desenvolve (NOVAES 2000). Assim, é forçoso reconhecer que não há neutralidade num processo avaliativo. O juízo de valor depende da visão de mundo de quem o executa, e toda avaliação pressupõe uma opção clara sobre o que se vai avaliar, sobre as características que se vai observar e medir e sobre o que se fará com o juízo de valor emitido nesse processo (SALA 1998).

No caso da avaliação e do monitoramento da atenção básica e sua rede de serviços, a diversidade de situações apresenta-se como uma dificuldade adicional à necessidade de uma objetivação do que avaliar e monitorar. Essa condição sempre será um desafio metodológico, pela própria natureza dinâmica desse tipo de serviço, particularmente num momento turbulento de superação do legado da situação anterior ao SUS.

Destacando que a avaliação de sistemas de saúde e, em particular, da atenção básica enfrenta desafios metodológicos - determinação multifatorial da saúde, julgamento de valor, natureza dos processos de trabalho que visam a mudanças sociais -, CONILL (2002) reforça as proposições de BODSTEIN (2002), sugerindo três questões, que poderiam ser utilizadas como categorias analíticas em torno das quais mais se articulam as transformações pretendidas pela reforma brasileira: o acesso, a integralidade e o controle social. 
A expressão da luta cotidiana pela abrangência e extensão da saúde para todos, em contraposição à tendência do provimento seletivo segundo a estratégia dos mínimos sociais, estabelece para construção e funcionamento do novo modelo assistencial a necessidade de articulação dos princípios do SUS, pois eles se esclarecem e se reforçam mutuamente (CECÍlIO 2001). Assim, acesso, conceito ampliado de saúde, integralidade com humanização dos serviços e controle social são rumos gerais e são as categorias fundamentais adotadas neste estudo para a avaliação e o monitoramento do processo de mudança. Para tanto, esses rumos gerais precisam ser traduzidos em categorias mais operativas. $O$ desafio está então na necessidade de definir variáveis que traduzam avanços no sentido proposto e que não desconsiderem inovações que estão transformando os princípios e o processo de trabalho dos serviços, mas que nem sempre aparecem refletidos nos indicadores clássicos, já que estes raramente dão conta de mudanças contextuais, do desempenho institucional e dos processos na gestão da rede e dos serviços (SILVA e FORMIGLI 1994; HORTALE 1999; BODSTEIN 2002).

Objetivando orientar o processo de implementação da atenção básica, o Ministério da Saúde formulou a proposta do Pacto de Indicadores da Atenção Básica (BRASIL 1999), regulamentando um processo de acompanhamento e avaliação. Assim, concebeu um grupo inicial de 17 indicadores. No ano de 2003, após reunião da Comissão Intergestora Tripartite, o elenco inicial passou para 34 indicadores, que compõem um conjunto de metas a serem pactuadas pelos municípios e estados, como um instrumento nacional de avaliação das ações e serviços de saúde, referentes à atenção básica no âmbito do SUS (BRASIL 2003). Sem dúvida, foi uma iniciativa importante, que tem contribuído para o avanço da avaliação e da gestão do SUS. Mas, pela sua própria origem e vocação principal, essa estratégia tem uma contribuição limitada na gestão cotidiana dos serviços e no reconhecimento dos problemas mais imediatos ao alcance dos gestores municipais.

MEDINA et al. (2000), reconhecendo a potencialidade do Pacto de Indicadores e observando que muitos gestores presos a um tratamento burocrático deixam de aproveitar sua contribuição para a gestão, destacam, por outro lado, a necessidade de desenvolver novas ferramentas para conferir agilidade ao processo de monitoramento e maior possibilidade de direcionamento das ações em tempo real.

Segundo HARTZ (2000b), a análise de componentes inovadores de um sistema não é bem representada nem captada em estratégias baseadas em metas. Indicadores tradicionais utilizados, ainda que necessários, tornam-se insuficientes para apreender as 
mudanças desejáveis. A mesma autora destaca a importância e os desafios metodológicos para integrar a avaliação em um sistema organizacional de modo a ser efetivamente capaz de influenciar o seu funcionamento, ligando as atividades analíticas às de administração. Assim, busca clarear as diferenças entre as atividades de avaliação e as de monitoramento, enfatizando aspectos desta última. Enquanto a avaliação poderia ser entendida como um conjunto de atividades, desenhadas seqüencialmente, para determinar o valor ou o mérito de um programa, projeto ou intervenção, o monitoramento estaria mais focado na geração de informações de fácil apropriação e utilidade para o dia-a-dia dos gestores, gerando informações mais relevantes para a tomada de decisão e aperfeiçoamento dos programas. O monitoramento está articulado, mas não se confunde com as funções da avaliação das políticas e programas de saúde (HARTZ 2002).

Observa-se, entretanto, que essa não tem sido a principal tendência, e complexos instrumentos e sistemas computacionais tornaram o monitoramento muito mais uma ferramenta de controle e acompanhamento de instâncias centrais do sistema ou de organismos financiadores. Não surpreende, portanto, o fato de os gestores locais não os considerarem úteis e criticarem a sobrecarga da coleta de informações (BODSTEIN 2002; HARTZ 2002). Em geral, esses sistemas, embora ofereçam informações importantes para uma avaliação mais global, têm obedecido a uma lógica centralizadora e vertical, o que dificulta ou impossibilita a futura desagregação de informações para o acompanhamento das ações e para a tomada de decisão, resultando em reduzida utilidade para a gestão local dos serviços (TEIXEIRA et al. 2003).

\subsection{Monitoramento da atenção básica, marcadores e eventos sentinela}

Monitoramento e investigação avaliativa são ferramentas de gestão. O monitoramento é voltado para a análise continuada, para o acompanhamento dos procedimentos e dos produtos. Sua utilidade é maior para o gestor local dos serviços. A avaliação, diferentemente, focaliza a efetividade ou o impacto das mudanças produzidas e, em geral, tem utilidade maior para a instância central e os organismos de financiamento. A atividade de monitoramento é uma etapa imprescindivel na avaliação dos programas de saúde (HARTZ 1996; 2000).

Em síntese, monitoramento pode ser definido como um conjunto de atividades de coleta e análise de informações pré-definidas (indicadores), visando acompanhar de forma 
sistemática e contínua o comportamento de serviços assistenciais, com o objetivo de detectar problemas e avanços. É uma atividade voltada para o cotidiano dos serviços e seus resultados, subsidiando o planejamento e a gerência local (PENNA 1997).

Um exemplo clássico de monitoramento na área de saúde é a vigilância epidemiológica. Ela tem como estratégia trabalhar com as informações de todos os casos suspeitos ou confirmados de determinado grupo de agravos escolhidos. Entretanto, muitos problemas de saúde prescindem do conhecimento de todos os casos para subsidiar as intervenções, demandando outras formas de coleta de dados e de monitoramento operacionalmente mais ágeis, que permitam a identificação dos problemas em uma escala temporal mais próxima da ocorrência dos eventos, problemas esses que muitas vezes estão fora do alcance de indicadores tradicionais (TEIXEIRA et al. 2003).

Nesse sentido, duas técnicas são freqüentes: o uso de marcadores/traçadores e de eventos sentinela. Marcadores ou traçadores, como instrumentos para a avaliação da atenção à saúde, foram propostos inicialmente por KESSNER et al. (1973). Baseiam-se no pressuposto de que, com base na avaliação da assistência prestada às pessoas, por Jeterminada condição ou doença escolhida e acompanhada, seria possível detectar e inferir problemas e pontos de estrangulamentos de um serviço (PENNA 1997).

Por exemplo, poderiam-se tomar como marcador os cuidados de pré-natal rrestados, verificando como foi o pré-natal, a média de consultas realizadas, o início do Jré-natal, os exames realizados ou outras atividades previstas. Já o evento sentinela difere to marcador, por ter como idéia básica a coleta de informação a partir do fato negativo, lefinido previamente como o que não deveria ocorrer. Nesse exemplo, um evento sentinela evaria a investigar retrospectivamente a cadeia de fatos que determinou que um grupo de nulheres parturientes não tivesse realizado o pré-natal. São exemplos típicos de eventos sentinela da qualidade da assistência as investigações do óbito infantil e materno realizadas selos Comitês de Mortalidade. A área da saúde ambiental também se apropriou da sstratégia de eventos sentinela, a exemplo de malformações congênitas, visando investigar 1 associação dessas ocorrências com riscos ambientais. Também o Unicef, em 1986, ıtilizou a técnica de eventos sentinela para estudar a tendência da mortalidade infantil na Juatemala e na Nicarágua (TEIXEIRA et al. 2003).

Evento sentinela foi inicialmente conceituado por RUTSTEIN et al. (1976) como scorrência de agravo, invalidez ou morte desnecessária, isto é, como ocorrência de 
condições que poderiam ser evitadas, já que há tecnologia de saúde suficiente para isso. Com base nesse conceito, eventos sentinela vêm sendo utilizados para a avaliação de sistemas de saúde. Assim, são conceituados como algo que não deveria ocorrer se os serviços de saúde funcionassem adequadamente (PENNA 1997).

Definido o evento e detectada sua ocorrência, desencadeia-se uma investigação para o esclarecimento das falhas que levaram à ocorrência desse evento, a fim de propiciar sua correção e melhorar o funcionamento do sistema. A idéia básica, portanto, é fazer a coleta sistemática de informação a partir do fato negativo e, por meio da investigação dos casos, avaliar a articulação, o acesso, a integralidade, a resolubilidade $e$ as falhas que estão ocorrendo nos serviços e na integração do sistema. Assim, o evento sentinela trabalha com o pressuposto de que uma informação de um evento escolhido, possível de ser coletada com certa facilidade, permita monitorar um certo universo de fenômenos (PENNA 1997).

O uso de evento sentinela tem importantes características (HARTZ 1996; PENNA 1997; TEIXEIRA et al. 2003):

- obriga a uma definição clara dos objetivos dos serviços, na medida em que trabalha com o fato definido como negativo, que não deveria ocorrer;

- viabiliza, na exploração retrospectiva da ocorrência, a incorporação de outros elementos, como a percepção de profissionais e usuários sobre os serviços e seus problemas;

- favorece a deteç̧ão de insuficiências de acesso, resolubilidade e continuidade do cuidado;

— pode incluir no monitoramento a população não coberta pelos serviços;

- tem natureza mais especifica que indicadores mais voltados para a avaliação, com menor dificuldade na operacionalização do monitoramento, em especial de processos de mudança.

Mas é sempre bom lembrar que eventos escolhidos podem ser apenas indicadores de condições dos serviços, e não da saúde da população. 


\subsection{Sintetizando: o problema e a hipótese da pesquisa}

A reorganização da rede básica representa um processo fundamental na reforma setorial da área da saúde. Apesar do intenso debate, poucos são os estudos sobre as mudanças em curso no sistema de saúde brasileiro que têm como perspectiva oferecer instrumentos de apoio à gestão local da atenção básica.

Essa necessidade, amplamente reconhecida, delimita questões para uma pesquisa: como entender, atualmente, o que é atenção básica integral no SUS e como monitorar o processo de mudança e a reversão do modelo assistencial? Seria possível definir indicadores que contribuíssem objetivamente para o monitoramento da atenção básica, que comportassem diferenças de momentos da sua reorganização e que fornecessem subsídios para a gestão cotidiana dos serviços? Que instrumentos de avaliação e monitoramento poderiam contribuir para ampliar a capacidade de gestão local de modo articulado com os rumos gerais propostos.

Há diversos trabalhos de análise sobre demanda ambulatorial e de pronto-socorro, mas eles não se direcionaram para a análise de eventos sentinela com vistas a monitorar a atenção básica. Neles são comuns conclusões como: "os dados levantados indicam que o estrangulamento de serviço de emergência se deve à desestruturação dos serviços básicos" (MARTINS e PASKULIN 1992, p.26); o pronto-socorro estudado "não é apenas um serviço de urgência, mas também, uma 'válvula de escape' dos serviços públicos de saúde [...]" (SALLA et al. 1989, p.79); "um considerável número de pacientes poderia ter sido atendido nas respectivas unidades básicas, sugerindo a sua excludência dos niveis primário e secundário" (GUTIERREZ e BARBIERI 1998, p.81).

Alguns estudos que tomaram como objeto de análise, especificamente, a demanda de unidades de emergência/urgência têm observado alta proporção de pessoas com problemas de saúde que se avaliam como passiveis de serem resolvidos mais apropriadamente em UBSs (YAMADA et al. 2000; CASTRO et al. 2001; YAMADA et al. 2001; CASTRO et al. 2002; YAMADA et al. 2002; MENDES 2003). Esses estudos, embora de natureza geral sobre a demanda atendida, sugerem importantes informações criticas sobre possiveis problemas da rede básica que poderiam estar determinando tal característica de demanda nos serviços estudados. Entretanto, eles não tinham o objetivo de explorar retrospectivamente determinados tipos de ocorrência e relacioná-los com 
características da organização e do funcionamento da rede básica, de modo a propiciar instrumentos para o monitoramento.

No presente trabalho parte-se da idéia de que seja necessário avançar na capacidade de monitoramento das mudanças da atenção básica, segundo princípios e categorias analíticas estabelecidas. Para tanto, elege-se a técnica da identificação e da exploração de eventos sentinela em unidade socorrista, pois se caracterizam como ocorrências negativas em uma dimensão mais imediatamente relacionada a possiveis falhas do processo de trabalho da atenção básica.

A hipótese do presente estudo, portanto, é que determinadas ocorrências em unidades socorristas, utilizadas como eventos sentinela, podem ser relacionadas a possíveis falhas da atenção básica, convertendo-se, assim, em instrumentos que colaborarão com o monitoramento da rede básica, visando à concretização dos rumos gerais pretendidos. 


\section{Objetivos}

\section{Objetivo geral}

Analisar ocorrências atendidas em pronto-socorro para identificar eventos sentinela que possam ser utilizados na gestão local como indicadores para o monitoramento da atenção básica.

\section{Objetivos específicos}

- Eleger ocorrências nosológicas de pessoas atendidas em pronto-socorro para a verificação de possíveis eventos sentinela.

- Verificar a existência de diferenças entre áreas/UBSs de procedência das pessoas atendidas no pronto-socorro quanto à freqüência das ocorrências previamente escolhidas.

- Analisar a possível influência da situação local da atenção básica na determinação dessas diferenças, incluindo, além de valores freqüenciais, o contexto das características de organização da rede básica, da repercussão das proposições de humanização dos serviços e da visão dos envolvidos, em particular dos usuários dos serviços, dos médicos do pronto-socorro e das unidades básicas de saúde.

- Discutir a viabilidade operacional da utilização desses eventos sentinela pelo gestor municipal como indicadores para apoiar o monitoramento da atenção básica.

- Discutir as limitações, as qualidades e a utilidade do indicador em estudo. 


\section{Método}

\subsection{Tipo de pesquisa}

Trata-se de um estudo transversal com componente retrospectivo (PEREIRA 2002, p.283). Foi realizada análise com dados quantitativos e qualitativos sobre ocorrências atendidas em um serviço de pronto-socorro, a fim de verificar a potencialidade da utilização dessas ocorrências como eventos sentinela para apoiar o monitoramento da rede básica de saúde. Considerando a utilidade de um evento sentinela, procurou-se identificar e explorar retrospectivamente casos atendidos em unidade socorrista que não deveriam ter ocorrido e que de alguma forma refletem uma possível falha nas atividades de organização e funcionamento da rede básica. Identificado um caso, levantaram-se, portanto, as circunstâncias da sua ocorrência, a área/UBS de procedência das pessoas atendidas e a história da utilização dos serviços de saúde relacionada ao caso em questão. Para verificar as relações entre essas ocorrências, previamente escolhidas, e aspectos da organização dos serviços básicos e do seu processo de trabalho, foram levantadas também informações sobre cada uma das unidades básicas de saúde incluídas no estudo, junto aos seus médicos e diretores.

\subsection{Local}

O local do estudo foi o município de Itapecerica da Serra, localizado a $33 \mathrm{~km}$ do centro do município de São Paulo, na região sudoeste da Grande São Paulo, e limitado pelos municípios de Cotia, Embu, Embu-Guaçu, São Lourenço da Serra e São Paulo (figura 1).

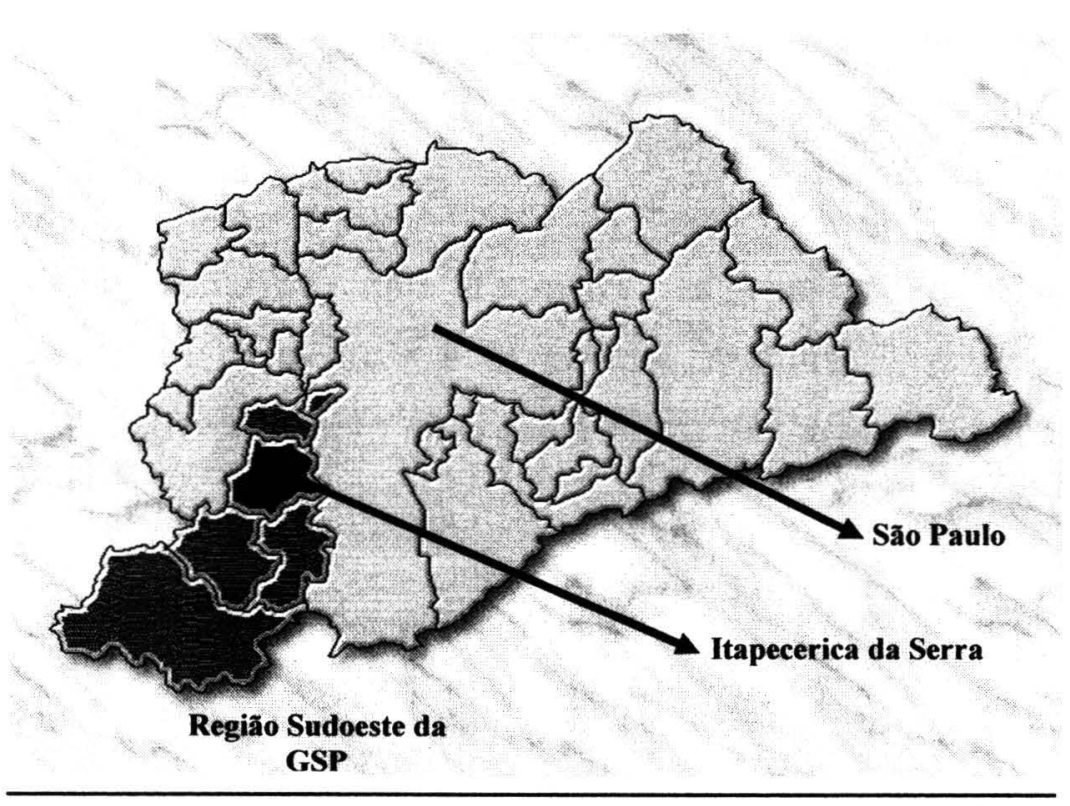

Figura 1 - Itapecerica da Serra, na Grande São Paulo - GSP 
O aldeamento de Itapecerica da Serra, com a participação dos padres jesuítas, ocorreu por volta do ano de 1690, e sua emancipação à condição de município, em 1877 . Entre 1960 e 1970, o município desmembrou-se, dando origem aos municípios de Embu, Taboão da Serra, Embu-Guaçu, Juquitiba e, em 1997, São Lourenço da Serra. As principais vias de acesso são a Rodovia Regis Bittencourt - BR 116 e a Estrada de Itapecerica da Serra. $O$ crescimento rápido e intenso da sua população, a partir da década de 1960, comum nas cidades-dormitórios da Grande São Paulo, foi motivado pela forte migração. Com um dos mais expressivos crescimentos populacionais da Grande da São Paulo, a população do município é estimada para o ano de 2004 em 147.540 habitantes. A rede de água tratada atinge $85 \%$ da população, a de esgoto $25 \%$, e a de coleta de resíduos sólidos tem cerca de $96 \%$ de cobertura; a população analfabeta corresponde a $8,9 \%$, e a renda per capita é de R $\$ 277,20$, segundo dados do IBGE para o ano de 2000. Esse quadro situa o município de Itapecerica da Serra no $288^{\circ}$. lugar, dentre os municípios paulistas, quanto ao Índice de Desenvolvimento Humano Municipal - IDHM-2000. Todo o território do município, de $136 \mathrm{~km}^{2}$, encontra-se em área de proteção de manancial, gerando o desafio adicional de promover um plano local de desenvolvimento sustentável e viável.

Quanto aos serviços de saúde, na década de 1980, a rede pública começa a expandir-se, como resultado da implementação do convênio das Ações Integradas de Saúde - AIS. Nesse processo de mudanças, iniciado com as AIS e o SUDS, ganha expressão regional uma crítica ao modelo de organização da saúde e da rede básica, em particular. Questiona-se a inexistência de compromisso dos serviços com o cidadão, realiza-se a inclusão nas UBSs de atendimento médico para as pessoas doentes, o que era malvisto pelas tradições controlistas dos antigos Centros de Saúde. São abolidas as concep̧̧ões de pré e pós-consulta como atos que fragmentam a consulta médica e prejudicam uma melhor relação entre os médicos e as pessoas atendidas. Procura-se superar a rígida e falsa separação entre prevenção e cura, em busca da integralidade das ações (SANO 1999).

$\mathrm{Na}$ região, técnicos e uma parcela da população participam ativamente na intervenção e na reorganização de alguns serviços privados, que, desapropriados pelo poder público, deram origem ao Pronto-Socorro Municipal de Embu, ao Hospital Regional de Osasco e ao Hospital Municipal de Jandira, constituindo-se, assim, os primeiros leitos públicos nessa grande área da Grande São Paulo. Conquistou-se, ainda, a construção do 
que hoje são os Hospitais de Itapecerica, Pirajussara/Embu, Carapicuíba e Itapevi. Ocorreu expansão e organização da rede básica, resultando na ampliação dos serviços e das especialidades de atendimento, com maior articulação e unificação do sistema. A região contou, também, nesse período, com importante participação da Faculdade de Saúde Pública da Universidade de São Paulo na organização de um distrito escola. A afirmação do SUDS, que no plano nacional significava uma vitória das tendências descentralizadoras e unificadoras do sistema, em contraposição às resistências centralizadoras instaladas no aparelho de Estado e articuladas com interesses econômicos da área (LUZ 1997), no plano local produziu uma inserção de novas forças sociais, redefinindo o papel do poder local na gestão das políticas públicas de saúde (PUCCINI 2002).

Em 1991, Itapecerica da Serra cria o Fundo Municipal e o Conselho Municipal de Saúde, conforme regulamentado na legislação do SUS. Desenvolvendo um modelo de distritalização e vigilância à saúde, a área de responsabilidade de cada unidade básica de saúde foi delimitada no ano de 1993, por meio de um processo de territorialização que contou com a participação de funcionários da saúde e lideranças populares. Identificam-se áreas e situações de risco, estabelecem-se programas prioritários, ampliam-se os trabalhos com a comunidade e as alternativas de cuidado. Esse processo é fortalecido com a formação de Conselhos Locais de Saúde em todas as unidades (SANO 1999).

De três unidades básicas existentes no ano de 1980, a rede pública de saúde passou a contar, no ano de 2004, com dez unidades básicas, um centro de referência para especialidades, serviço de vigilância sanitária e epidemiológica, um Centro Regional de Controle de Zoonoses, dois prontos-socorros, um laboratório regional, uma maternidade municipal com 32 leitos, recém-ampliada, e um Hospital Geral Regional com 165 leitos, que iniciou seu funcionamento em 1999. Nesse processo de busca de melhoria da atenção básica, a partir de 1997 desenvolve-se uma nova prioridade para a organização do sistema local, focada na busca da humanização dos serviços e da satisfação dos usuários. Definiuse uma visão de reorganização dos serviços como a busca de uma nova inter-relação entre profissionais e usuários, que valorizasse o respeito mútuo, o reconhecimento do cidadão como portador de um direito, a atenção, o zelo e as exigências técnicas e humanas na ação profissional para a realização dos cuidados. Foram priorizadas, na implementação da diretriz de humanização, atividades voltadas para a reflexão crítica, a formação e a participação dos profissionais; atividades voltadas para a ampliação dos canais de comunicação, participação do cidadão e controle social; atividades voltadas para a 
reorganização dos serviços, procurando incorporar as opiniões, os anseios e as críticas dos profissionais e usuários (ITAPECERICA DA SERRA 1998, 2003; PUCCINI 2002).

A série histórica de alguns dados e indicadores de saúde sugere uma melhora nos serviços de saúde, em parte como resultado de maior abrangência e articulação do sistema de saúde local (tabela 1).

Tabela 1 - Indicadores selecionados da situaçăo de saúde-assistência de Itapecerica da Serra, segundo alguns anos.

\begin{tabular}{|c|c|c|c|}
\hline Indicador & 1996 & 2000 & 2002 \\
\hline coeficiente de mortalidade infantil * & 25,20 & 15,20 & 10,01 \\
\hline taxa de mortalidade materna ** & 155,30 & 50,70 & 0,00 \\
\hline CPOD *** & 3,20 & 1,57 & 1,42 \\
\hline \% da pop. com todos os dentes aos 18 anos & $\ldots$ & $\ldots$ & $87,80 \%$ \\
\hline cobertura de crianças < 1 ano & $96,00 \%$ & $125,80 \%$ & $176,92 \%$ \\
\hline cobertura de gestantes & $\ldots$ & $77,11 \%$ & $108,16 \%$ \\
\hline \% de amamentaçăo exclusiva aos 4 meses & $\ldots$ & $\ldots$ & $31,90 \%$ \\
\hline cobertura papanicolaou & $14,50 \%$ & $28,50 \%$ & $32,69 \%$ \\
\hline doses imunizantes de vacinas aplicadas & $\ldots$ & 17.687 & 22.276 \\
\hline consultas médicas & 279.337 & 402.521 & 472.417 \\
\hline tratamentos completos - bucal & 6.415 & 11.296 & 11.532 \\
\hline
\end{tabular}

Entretanto, as consultas médicas realizadas em ambiente de pronto-socorro permanecem elevadas, quando comparadas com as consultas básicas, embora apresentem uma leve diminuição na participação relativa quando se comparam os anos de 1999 e 2003 (figura 2). Mas é impossível afirmar que essa seja uma tendência estável e fruto das intervenções realizadas na alteração do modelo assistencial e da reformulação da rede básica (ITAPECERICA DA SERRA 2003). 
Certamente, muito das consultas realizadas em ambiente de pronto-socorro ainda são desnecessárias, o que permite sua análise segundo a estratégia de eventos sentinela.

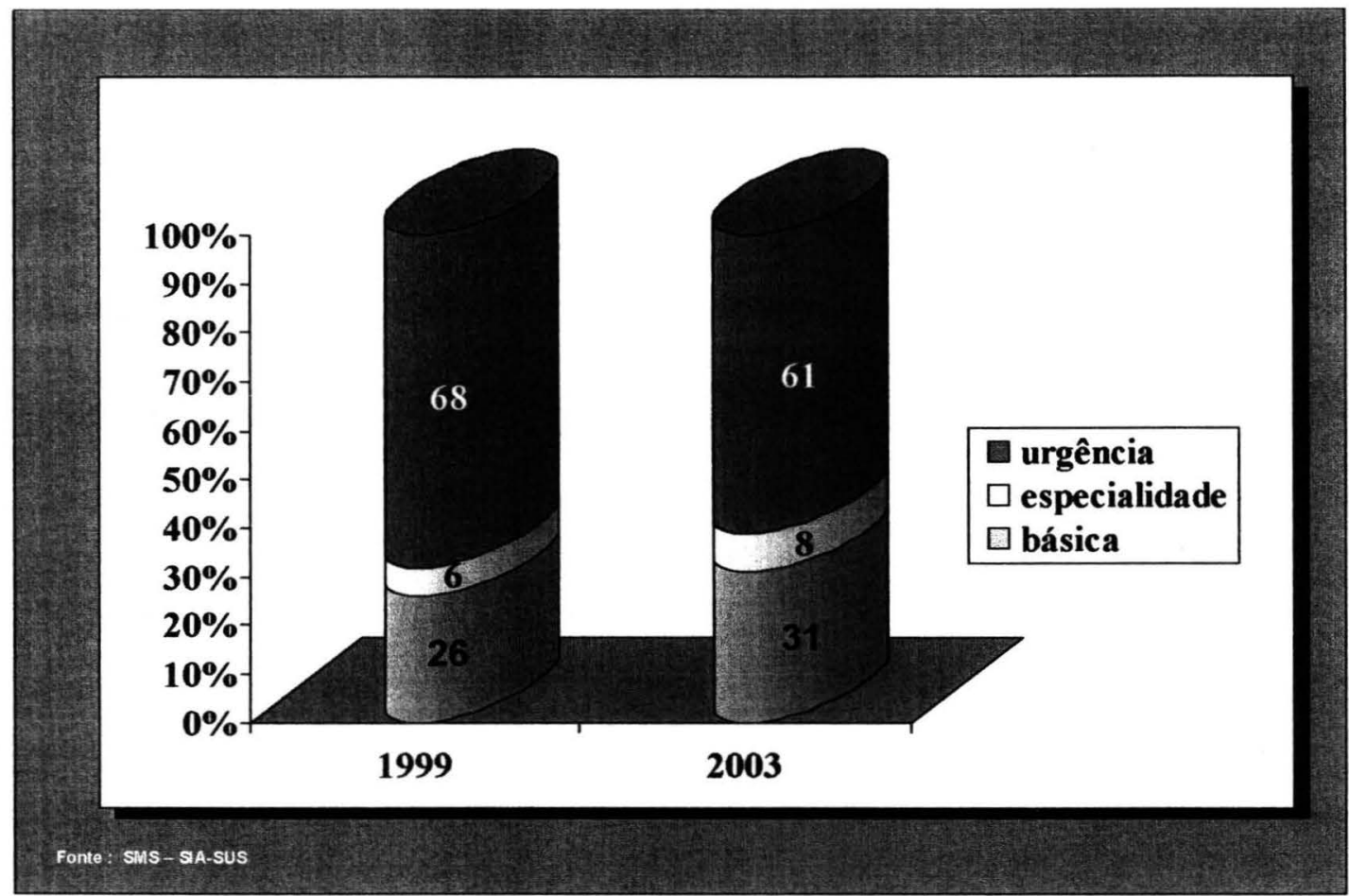

Figura 2 - Distribuição das consultas médicas. Itapecerica da Serra, 1999 e 2003.

Essas características favoreceram, portanto, a escolha do local como campo de estudo, além do fato de o pesquisador lá haver trabalhado. A priorização de estratégias de organização e humanização da rede básica, a diversidade de situações características desses processos e a desigualdade no grau de mudanças implementadas em cada unidade (por exemplo, os estágios de organização da recepção técnica acolhedora) permitem conhecer e comparar situações, com distintos problemas, possibilitando uma exploração abrangente das relações entre possíveis eventos sentinela e problemas da atenção básica. 
Considerado o desenho geral da pesquisa, a articulação e a regionalização dos serviços, foram escolhidas quatro UBSs para o estudo, com diferentes portes e cuja população $(58,6 \%$ da população total do município) utiliza, preferencialmente, o ProntoSocorro Central de Itapecerica da Serra como referência (tabela 2).

Tabela 2 - Unidades Básicas que se utilizam preferencialmente do Pronto-Socorro Central de Itapecerica da Serra escolhidas para o estudo e população de abrangência, 2004

\begin{tabular}{l|ccr}
\hline \multicolumn{1}{c|}{ Unidade } & $\begin{array}{r}\text { população de } \\
\text { abrangência }\end{array}$ & $\begin{array}{r}\text { \% da pop. do } \\
\text { município }\end{array}$ & $\begin{array}{r}\text { \% da pop. do } \\
\text { grupo }\end{array}$ \\
\hline \hline UBS Salvador Leone & 36.500 & 24,7 & 42,2 \\
UBS Parque Paraíso & 24.500 & 16,6 & 28,3 \\
UBS Valo Velho & 18.500 & 12,5 & 21,4 \\
UBS Branca Flor & 7.000 & 4,7 & 8,1 \\
Todas as quatro UBSs & 86.500 & 58,6 & 100,0 \\
\hline Total do município & 147.540 & - & - \\
\hline
\end{tabular}

Fonte: SMSIS e DATASUS

\subsection{População e amostra}

3.3.1 Médicos socorristas: formulário para auto-resposta entregue aos 16 médicos do Pronto-Socorro Central de Itapecerica da Serra, plantonistas do período diurno.

3.3.2 pessoas atendidas no pronto-socorro: foram consideradas como populaçãoalvo do estudo todas as pessoas atendidas durante um mês, no horário das 7 às 16 horas, de segunda a sexta-feira - horário e dias da semana que consideraram o funcionamento regular da rede básica -, e que tiveram procedência de uma das áreas/UBSs escolhidas para o estudo.

Essa base mensal utilizada para definir a população-alvo (universo) justifica-se pelo fato de que o presente estudo propõe-se a identificar instrumentos de monitoramento que permitam instantâneos da situação de um período, de modo a compará-los numa série histórica. Assim, é com base em ocorrências mensais que se poderão construir instrumentos mais ágeis para o monitoramento, não tendo 
sentido pensar a população-alvo como aquela formada pelas pessoas atendidas no ano ou nos semestres.

Quanto à definição do tamanho da amostra, a preocupação primeira foi fixar um procedimento de coleta de dados que fosse operacionalmente fácil de ser reproduzido no cotidiano de trabalho dos sistemas municipais de saúde. Assim, estabeleceu-se como pressuposto não ultrapassar duas semanas de coleta de dados, comprometendo a pesquisa com a simplicidade de um procedimento de levantamento de dados que possa ser repetido cerca de quatro vezes ao longo de um ano, tornando-o viável no processo de monitoramento da atenção básica.

Considerando-se esse pressuposto, o tamanho da amostra depende do volume global de atendimentos de um pronto-socorro e da parcela correspondente ao atendimento realizado para as pessoas com procedência de cada uma das áreas/UBSs escolhidas para serem monitoradas. Mas, dessa parcela de atendimentos correspondente às áreas de procedência de interesse, as HDEs (hipóteses diagnósticas escolhidas) para estudo, com pretensões de serem eventos sentinela, são, ainda, uma parcela menor. Nessas condições, o que se coloca em questão é saber até que freqüência de uma determinada ocorrência atendida no PS há significância estatística para as análises e comparações. Note-se que intencionalmente está se invertendo a pergunta comumente formulada para a definição do tamanho de uma amostra. A partir de um tamanho dado pelas condições operacionais, pergunta-se até onde é possível ir com a análise com uma certa margem de segurança. Essa preocupação é necessária dado que a tendência é trabalhar com freqüências muito pequenas, sobretudo pelo fato de que uma freqüência geral no PS terá que ser redistribuida segundo as áreas/UBSs de procedência das pessoas atendidas, pelo interesse nessa dimensão local da análise.

No cálculo das possibilidades da amostra considerou-se, portanto, como pergunta a ser respondida: qual o valor da menor freqüência que pode ser aceito para incluir uma dada ocorrência no estudo?

Dados utilizados nos cálculos:

- População de estudo: atendimentos diários de segunda a sexta-feira, no horário das 7 às 16 horas, originados em uma das áreas/UBSs escolhidas: média de 3.000 pessoas atendidas por mês.

- Tamanho da amostra (duas semanas) $=1.500$ pessoas atendidas

- Considerando-se que a menor área/UBS corresponde a $8,1 \%$ do total da população das quatro áreas em estudo (tabela 2) e procurando identificar uma freqüência mínima geral para que determinada ocorrência (hipótese 
diagnóstica) tenha chance de estar representada com ao menos um caso em todas as áreas/UBSs, temos que:

$$
\begin{aligned}
& -1 \text { caso }=1500 \text { x Freqüência Mínima Geral (FMG) x 8,1\% } \\
& -1=1500 \text { x FMG } \times 10,092 \\
& -1=138 \text { x FMG } \\
& -\quad \text { FMG }=1 / 138=0,007=0,8 \%
\end{aligned}
$$

Assim, a existência, no presente estudo, de uma área/UBS com $8,1 \%$ do potencial de demanda global do pronto-socorro (total de 3.000 atendimentos/mês) limita a inclusão de ocorrência com freqüência menor que $0,8 \%$, sem o que ela pode não estar representada nessa menor área/UBS. Alerta-se para o fato de que mesmo trabalhando com o universo de atendimentos mensais algumas ocorrências não atingiriam essa freqüência mínima de $0,8 \%$, o que reforça a idéia de que se deva trabalhar com uma amostra, para facilitar o monitoramento, e com a devida atenção e ponderação na hora de incluir ou não determinada ocorrência.

\subsubsection{Entrevistas com as pessoas atendidas por uma das ocorrências escolhidas:} às pessoas diagnosticadas com uma das ocorrências previamente escolhidas, os médicos socorristas, após o atendimento, solicitaram a participação numa pesquisa e indicaram o local para o caso de concordância. Tal procedimento foi reforçado pela equipe de enfermagem, que colaborou na solicitação da participação na entrevista e na orientação. Em uma sala fixa durante todo o período (duas semanas) e no horário da pesquisa, o pesquisador entrevistou as pessoas atendidas, para lá encaminhadas, que concordaram em participar. Concordaram e participaram da entrevista $18 \%$ das pessoas (amostra não intencional) diagnosticadas com uma das ocorrências escolhidas.

3.3.4 Diretores das unidades básicas de saúde incluídas no estudo: quatro diretores entrevistados pelo pesquisador.

3.3.5 Médicos das unidades básicas de saúde escolhidas: foram entregues formulários para auto-resposta dos médicos das unidades básicas, obtendo-se $50 \%$ de devoluções. 


\subsection{Principais variáveis de estudo e levantamento dos dados}

\subsubsection{Em relação aos médicos socorristas:}

Instrumento (anexo 1): questionário com perguntas abertas para levantamento da opinião dos médicos socorristas sobre:

- quais ocorrências atendidas por eles, no serviço em questão, deveriam estar sendo resolvidas ou acompanhadas em unidades básicas, por não necessitarem de atendimento de urgência ou emergência. Conforme explicação a seguir, no item 5 do capitulo "Método", as indicações foram utilizadas na escolha das ocorrências, possíveis eventos sentinela, do presente estudo;

- o papel dos serviços básicos e dos socorristas, indagando sobre o que determina esse tipo de procura.

\subsubsection{Em relação aos atendimentos realizados no PS Central de Itapecerica:}

Instrumentos (anexo 2): planilha para anotação de todos os atendimentos realizados no pronto-socorro e ocorridos no período de observação. Houve necessidade de acertos com as gerências do serviço, pois alguns dos dados necessários, como área/UBS de procedência ou hipótese diagnóstica, não são rotineiramente colhidos e sistematizados pelo serviço. Muitas vezes as folhas de atendimento não apresentavam com clareza a hipótese diagnóstica e nunca dispunham do código da Classificação Internacional de Doenças - CID. Assim, foi necessário rever todos os registros dos atendimentos a fim de estabelecer a codificação e, algumas vezes, aclarar a hipótese diagnóstica, antes da digitação do material. Todo esse trabalho foi realizado por uma equipe fixa, com a participação do pesquisador e de mais dois médicos colaboradores.

\subsubsection{Em relação às pessoas diagnosticadas com uma das ocorrências de interesse do estudo:}

Instrumento (anexo 3): formulário com perguntas abertas e fechadas para entrevistar as pessoas atendidas e explorar as circunstâncias pregressas das ocorrências escolhidas de interesse. As respostas às questões abertas foram anotadas pelo pesquisador, que foi o único entrevistador. O questionário levantou informações sobre: 
- variáveis de identificação e caracterização das pessoas atendidas e dos acompanhantes, no caso de crianças;

- variáveis sobre o tipo de uso rotineiro de unidade básica;

- variáveis sobre a ocorrência em questão (queixa e tempo de queixa);

- variáveis sobre o problema atual e a procura ou não de atendimento anterior até a decisão de procurar o pronto-socorro;

- opinião em relação ao atendimento ocorrido na unidade básica pelo problema atual antes de procurar o pronto-socorro ou por que não procurou a unidade básica pelo problema atual.

\subsubsection{Em relação às unidades básicas de saúde e seus diretores:}

Instrumento (anexo 4): formulário com perguntas abertas e fechadas para observar a unidade básica de saúde e entrevistar o seu diretor. A observação-entrevista foi realizada unicamente pelo pesquisador:

- informações relativas à disponibilidade de recursos da unidade básica, em especial no período da ocorrência dos eventos identificados na unidade socorrista;

- situação da organização e humanização do serviço e dos processos de trabalho, em especial quanto ao primeiro atendimento, isto é, o processo de trabalho que garante acesso e continuidade do cuidado;

- situação da participação da população e do controle social.

Além de questionário de entrevista do diretor e observação direta, a pesquisa utilizou-se, também, de dados secundários produzidos pela Secretaria Municipal de Saúde, especialmente os relatórios de supervisão das unidades sobre o processo de mudanças em curso na organização da recepção técnica acolhedora, na implementação da atividade assistencial do enfermeiro e na integração dos médicos na perspectiva de ações cuidadoras integrais. 


\subsection{Em relação aos médicos das unidades básicas de saúde:}

Instrumento (anexo 5): questionário com duas perguntas abertas para os médicos das UBSs opinarem sobre o papel da UBS em algumas situações características da procura de assistência por parte da população:

- situações freqüentes de procura da UBS, pela população, quando o prontosocorro deveria ter sido procurado diretamente;

- tipo de serviço que mais se recomenda à população que procure nos casos de febre, pródromos de infecções de vias aéreas superiores, broncoespasmo, sintomas de descontrole de hipertensão ou diabetes. Solicitou-se opinião e explicação.

\section{A escolha das ocorrências para estudo}

Uma etapa preliminar do trabalho de pesquisa foi dedicada a reunir referências óricas e dados que possibilitaram a escolha e a delimitação daquelas ocorrências endidas em pronto-socorro, que foram analisadas, no desenvolvimento da pesquisa, tanto à potencialidade de serem utilizadas como eventos sentinela para apoiar o onitoramento da atenção básica. A preocupação não foi incluir um grande número de orrências, mas reunir um conjunto que pudesse refletir um maior espectro de situações e odalidades assistenciais realizadas fora e dentro da unidade básica de saúde. Foram ilizados como critérios para um juízo de valor na escolha das ocorrências incluídas no tudo:

a) indicação dos médicos socorristas: respostas aos formulários;

b) freqüência da ocorrência observada em levantamento piloto: retiraram-se aquelas ocorrências que, mesmo indicadas pelos médicos socorristas e consideradas como características do papel da atenção básica, não se apresentavam numa freqüência razoável para o estudo, isto é, quando foram menores que $0,8 \%$ do total dos atendimentos considerados, conforme fundamentado na discussão de população e amostra;

c) sensibilidade para o cuidado contimuado, vinculo com o serviço: procurou-se ponderar com esse critério a necessidade de inclusão de ocorrências que 
refletissem a organização dos serviços para estabelecer os necessários cuidados contínuos de doenças sob controle periódico, particularmente aquelas para as quais a atenção básica já conta com uma programação geral ou com protocolos já estabelecidos;

d) especificidade para diferenciar estágios da dinâmica resolutiva da atenção básica: procurou-se com esse critério garantir a presença de ocorrências que refletissem a história de evolução da atenção básica de ação programática materno-infantil para ação programática múltipla e, desta, para ação programática humanizada, isto é, capaz de abrir o acesso para a demanda do dia, para os agravos e problemas aos quais só a existência prefixada e rígida de uma "oferta programática organizada" é incapaz de dar a devida resposta;

e) opinião de expertos: a listagem e seus objetivos foram apresentados a profissionais com experiência em atendimento na atenção básica para uma avaliação e sugestões.

Nas respostas aos questionários os médicos socorristas indicaram as doenças/ocorrências que na prática de atendimento no PS Central de Itapecerica da Serra são freqüentes, mas as quais eles julgam que podem ser resolvidas ou acompanhadas mais adequadamente em UBSs, por não necessitarem de atendimento ou de recursos de unidades de urgência/emergência, isto é, aqueles casos freqüentes avaliados como ambulatoriais, mais característicos do papel assistencial da rede básica.

O questionário foi entregue a todos os médicos dos plantões diurnos de segunda a sexta-feira, conforme foco definido para o estudo. Do total de 16 médicos plantonistas, obtiveram-se 12 respostas aos questionários com as respectivas indicações das ocorrências.

As ocorrências indicadas foram ordenadas nas três áreas básicas de atuação das UBSs, segundo ciclos de vida - clínica pediátrica, clínica do adulto e clínica da mulher -, e, também, destacadas aquelas mais freqüentes, dentre as diversas citadas (quadro 1). 
Quadro 1 - Ocorrências em pronto-socorro, indicadas pelos médicos socorristas como casos a serem mais adequadamente atendidos na rede básica. Itapecerica da Serra, 2004.

\begin{tabular}{|c|c|}
\hline Área & Ocorrências* \\
\hline Clínica pediátrica & $\begin{array}{l}\text { Anorexia/inapetência, erro alimentar, obesidade } \\
\text { Asma brônquica } \\
\text { Dermatite amoniacal, dermatite atópica } \\
\text { Dermatológicas } \\
\text { Dificuldade escolar e distúrbio de comportamento } \\
\text { Distúrbio de refração e estrabismo } \\
\text { Dor recorrente crônica } \\
\text { Ectoparasitoses (escabiose, pediculose) } \\
\text { IVAS (resfriado comum, otite média, amigdalite, sinusite) } \\
\text { Puericultura (antropometria, check-up, amamentação, hábitos } \\
\text { fisiológicos, cólica do RN, obstrução nasal do lactente) } \\
\text { Rinite alérgica } \\
\text { Verminose }\end{array}$ \\
\hline Clínica do adulto & $\begin{array}{l}\text { Asma brônquica } \\
\text { Diabetes (controle de dextro) } \\
\text { Dispépticas } \\
\text { Guias/exames e troca de receitas } \\
\text { HAS } \\
\text { IVAS (resfriado comum, otite média, amigdalite, sinusite) } \\
\text { Ortopédicas } \\
\text { Piodermite, verruga vulgar, impetigo }\end{array}$ \\
\hline Clínica da mulher & $\begin{array}{l}\text { Distúrbios e irregularidade da menstruação } \\
\text { Vulvovaginites } \\
\text { Pré-natal }\end{array}$ \\
\hline
\end{tabular}

Com a realização de coleta piloto de dados do atendimento do PSC de Itapecerica da Serra observou-se, em linhas gerais, a freqüência das ocorrências indicadas e, também, se a qualidade do preenchimento da folha de atendimento pelo médico socorrista permitia o discernimento e a discriminação da hipótese diagnóstica para uma correta classificação. Com base na intensidade da freqüência das ocorrências indicadas ou na qualidade do 
preenchimento da folha de atendimento e na clareza na formulação das hipóteses diagnósticas pelo médico, optou-se por retirar da lista geral de indicações:

- Pré-natal: os casos de supervisão de gravidez normal $\mathrm{CID}_{10}=\mathrm{Z34}$ não apresentaram uma freqüência alta o suficiente para servirem de sentinela no caso da situação do município de Itapecerica da Serra. A cobertura de mulheres grávidas matriculadas na rotina dos cuidados de pré-natal na rede básica tem sido alta nos últimos dez anos, sempre ao redor de $100 \%$ de cobertura. Destaque-se, ainda, que anexo ao PSC, base do estudo, funciona a maternidade municipal para a qual as grávidas são orientadas a procurar atendimento quando há suspeita de trabalho de parto ou outras intercorrências. Assim, no município em questão, não houve ocorrências com características de supervisão de gravidez normal, e portanto esse tipo de ocorrência não ajuda no monitoramento e na diferenciação da situação das unidades da rede básica.

- Piodermites, verminoses, ectoparasitoses, distúrbios de refração, estrabismo, dificuldade escolar, anorexia, obesidade: não foram consideradas na análise devido à freqüência geral baixa, muito inferior ao mínimo estabelecido de $0,8 \%$.

- Ortopédicas, dorsalgias, dor recorrente na criança, sintomas dispépticos, rinites alérgicas e dermatológicas: foram tiradas da lista geral de indicações por se apresentarem como hipóteses diagnósticas muito genéricas, por vezes confusas, ou por ser pouco definido o papel da UBS e do PS. Lembre-se que só há aparelhos de Raios X no PS, portanto a população tende a procurá-lo, quando há suspeita de trauma ou problema semelhante.

- Guias de exame e troca de receitas: foram desconsideradas pela baixa freqüência, pela dificuldade de separação dessas ocorrências com retornos para a continuidade no atendimento do próprio PS e devido à instabilidade das motivações determinantes dessa ocorrência e sua ligação com questões administrativas.

Após esse ajuste, procurou-se garantir que o rol das ocorrências escolhidas espelhasse distintas situações de organização do atendimento e de cuidados conforme os 
ciclos de vida. Assim, foi definido um conjunto de ocorrências (quadro 2), obviamente sem nenhuma pretensão de ser o único possível e alertando-se, ainda, para a plasticidade do processo de escolha, intencionalmente relacionado à situação da realidade local a ser estudada. Com a preocupação de espelhar diferentes situações e estágios de organização da atenção básica, duas ocorrências com freqüência menor que $0,8 \%$ foram mantidas no rol das escolhidas. Tais exceções foram as hipóteses diagnósticas de vulvovaginites e diabetes. No caso das vulvovaginites, decidiu-se por deixá-las tendo em vista que a retirada diminuiria a presença e a análise dos agravos especificos da assistência à mulher. Considerou-se, ainda, que essa reduzida mas não ausente freqüência (caso do pré-natal) pode ser um instrumento de monitoramento no futuro imediato e ainda permite o acompanhamento de unidades maiores. No caso do diabetes, optou-se por mantê-lo, dado as circunstâncias de sua presença em co-morbidade com HAS, havendo uma interação tal que torna, muitas vezes, difícil identificar o diagnóstico primeiro do atendimento.

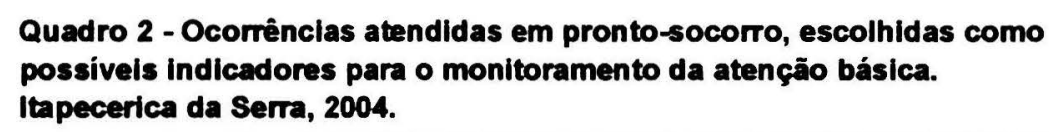

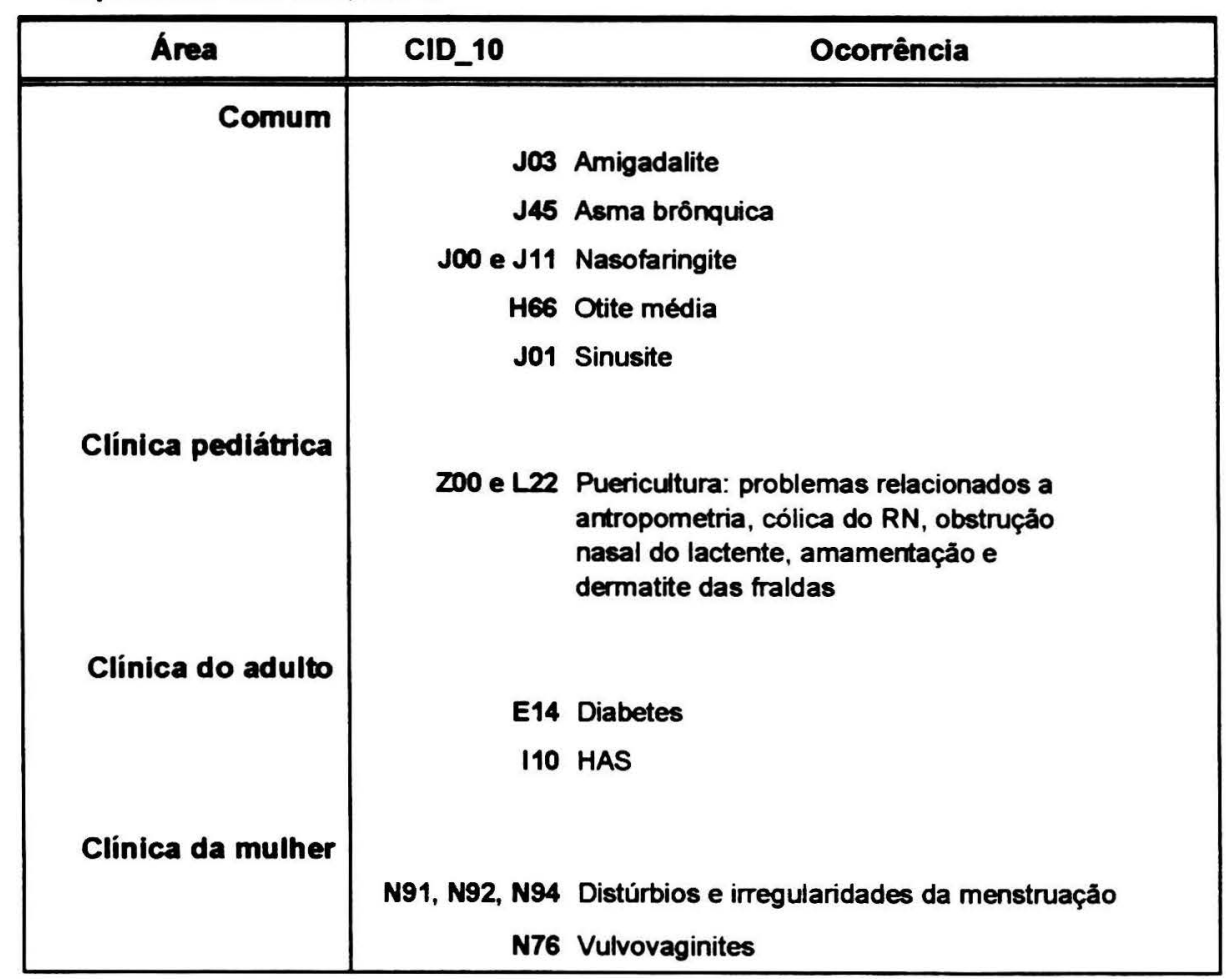

No anexo 6, as ocorrências escolhidas para estudo são delimitadas do ponto de vista da conceituação nosológica e da prática de codificação adotada. Definem-se, também, os critérios utilizados na padronização da codificação e da inclusão ou não dos atendimentos no estudo, enquanto ocorrências em verificação. 


\subsection{Análise de dados}

Avaliar ou monitorar serviços de saúde não é um processo exclusivamente técnico, um método pelo qual, dispondo-se de um conjunto de procedimentos, medidas e indicadores, se possa então deduzir, quase que algebricamente, a efetividade de determinado serviço ou programa. O sucesso ou não de determinado serviço está implicado com valores, ideologias, posições de classe, crenças dos usuários e dos profissionais. Dessa forma, avaliar é também decodificar os interesses em disputa, visando a um entendimento contextualizado da cultura institucional e da prática dos agentes que o serviço ou programa envolve (DESLANDES 1997).

Para a decodificação do conflito apresentado no presente estudo, isto é, a incapacidade da atenção básica gerando ocorrências desnecessárias no pronto-socorro, é preciso encontrar os caminhos de análise dos dados que respondam de forma objetiva e contextualizada às perguntas: Como determinadas ocorrências em unidades socorristas podem ser relacionadas a possíveis falhas na atenção básica e, assim, converter-se em eventos sentinela, instrumentos que colaborem com o monitoramento da rede básica de serviços, visando à concretização dos rumos gerais pretendidos pela reforma sanitária brasileira? Como é que determinada ocorrência passa de potencial evento sentinela a indicador de monitoramento? Quais são as precondições, os critérios para tal transmutação dos dados?

Para sair do dado situado no campo do saber não sistematizado das evidências práticas cotidianas e chegar aos campos epistêmico e teórico de realização da pesquisa, BRUYNE et al. (1977) realçam a importância de que problemáticas gerais dêem lugar a hipóteses de pesquisa. Por sua vez, estas precisam ser traduzidas operacionalmente na coleta de dados de determinadas variáveis, convertendo os dados em informações úteis para responder às questões colocadas pela pesquisa. $\mathrm{O}$ dado, propõe o autor, transforma-se em informação pelas operações, orientadas pelos referenciais teóricos, que os selecionam e especificam, e pelo comprometimento com o esclarecimento das hipóteses de trabalho da pesquisa.

Para converter o dado genérico da freqüência de ocorrências escolhidas do estudo em informações úteis para a problemática da pesquisa, é preciso, portanto, além do referencial teórico desenvolvido, estabelecer hipóteses de trabalho. No presente estudo, a 
pótese geral desenvolvida no capítulo "Introdução" pode ser decomposta como o ıcadeamento de três hipóteses de trabalho:

a. a freqüência das ocorrências escolhidas para estudo é influenciada pelo funcionamento da atenção básica em cada uma das áreas/UBSs de procedência dos usuários do $\mathrm{PS}$, e isso pode ser estatisticamente demonstrado;

b. é possível contextualizar tais diferenças procurando construir explicações nas quais, além de valores freqüenciais, incluem-se as visões dos envolvidos, em particular, dado o tipo de desenho do estudo, dos médicos socorristas, dos médicos de UBS e dos usuários dos serviços;

c. é possível, com essa triangulação de informações, contextualizar e associar as diferenças nas taxas de freqüência das ocorrências escolhidas com a estrutura, a organização e o funcionamento das UBSs.

Demonstrada uma associação, uma determinada ocorrência escolhida assumiria a sndição de evento sentinela, isto é, de indicador capaz de colaborar com o monitoramento $\mathfrak{i}$ atenção básica de uma localidade. Sintetizando, busca-se com os dados a serem Jhidos informações que relacionem adequadamente a freqüência de determinadas sorrências (hipóteses diagnósticas) em pronto-socorro com a organização e o Incionamento das UBSs e que essa relação seja evidenciada e discutida no âmbito mais nplo das políticas públicas e da ação concreta e das motivações das pessoas envolvidas.

tapas de organização e análise dos dados:

3.6.1 Organizar e realizar tratamento exploratório dos dados para verificar qualidade e consistências e esquematizar as possibilidades de ordenação e relacionamento do conjunto dos dados levantados. Todos os dados foram organizados em bancos de dados utilizando-se o programa Excell 2000 para Windows.

3.6.2 Caracterizar o perfil da amostra das pessoas atendidas no pronto-socorro, verificando a distribuição das ocorrências, segundo hipótese diagnóstica, sexo, faixa etária, ciclo de vida e área/UBS de procedência. 
3.6.3 Verificar a diferença entre as freqüências de HDEs de cada área/UBS de procedência. Para tanto foi utilizada, como índice comparativo, a razão entre as HDEs e as HDs demais originadas em cada área/UBS em estudo. $\mathrm{O}$ uso desse índice (HDE/HD demais) evita o erro de comparar diretamente os valores absolutos de cada ocorrência, obviamente enviesados pelo diferente tamanho da população de cada área/UBS, e evita, também, utilizar a razão entre HDE e população de cada área/UBS. Esta última estratégia comparativa tem um pressuposto difícil de ser garantido, isto é, que cada uma das populações utilizariam o PSC na mesma proporção, que haveria um mesmo risco de utilização da unidade socorrista em estudo, por ser igualmente procurado pelas populações de cada área/UBS quando da necessidade de atendimento, por qualquer uma das ocorrências escolhidas. Esse pressuposto trabalha, portanto, com o índice da razão entre o número de casos favoráveis (as ocorrências escolhidas) e o número de casos possíveis (população da área com risco de vir-a-ser caso), o que pressupõe uma hipótese de condição de risco para a qual não se controlam as variáveis populacionais de confundimento. Quando se adota a comparação da razão entre HDEs e HDs demais de cada área, abandona-se a idéia de risco em prol da concepção de chance, isto é, trabalha-se com a razão entre o número de casos favoráveis (HDEs) e o número de casos desfavoráveis (HDs demais). Assim, evitam-se erros potenciais, o que torna a análise estatística mais simples, robusta e confiável, requisitos importantes para a seleção de indicadores.

3.6.4 Analisar a significância estatística das diferenças entre os índices resultantes das razões de HDE e HDs demais de cada uma das áreas/UBSs. Utilizou-se o teste do qui-quadrado $\left(\mathrm{X}^{2}\right)$ quando a análise considerava o grupo das quatro áreas/UBSs, e, nos casos de comparação entre as áreas/UBSs tomadas duas a duas, utilizou-se também o cálculo do odds ratio. $\mathrm{Na}$ avaliação de cada uma das ocorrências, levou-se em consideração o fato de serem pequenas as freqüências de cada ocorrência escolhida, dada a condição de amostragem assumida como pressuposto do estudo, determinado pelas condições operacionais da gestão dos serviços. Nessa condição de baixas freqüências, o poder estatístico para detectar e 
interpretar diferenças de freqüência, ainda que relevantes, é sempre limitado.

Assim, adotou-se a técnica de análise estatística da metanálise, não usualmente utilizada em circunstâncias semelhantes de pesquisa, mas aqui apropriada com o mesmo sentido e preocupações de suas aplicações mais comuns, isto é, como uma técnica estatística que visa responder à necessidade de combinar ocorrências homogêneas independentes, agregando vários estudos, cada um com um número reduzido de casos, e, assim, aumentar a probabilidade de detectar variações. Note-se, e este é um aspecto fundamental, que com a metanálise não se busca apenas produzir uma medida síntese do somatório de casos de cada um dos estudos, mas, também, facilitar a comparação entre os resultados de cada estudo, visando descrever e detectar concordâncias e discordâncias entre eles. A metanálise realiza uma análise ilustrada graficamente e comparativa entre os resultados de diversos estudos, o que possibilita amplificar as inconsistências entre os achados, colaborando com a construção de teorias e modelos explicativos. Isso significa dizer que o uso da metanálise não é útil apenas para o cálculo de uma medida-sumário que agregue e resuma os resultados de vários estudos, mas para explorar os estudos incluídos e seus resultados particulares. Os estudos constituem as unidades primárias de análise em que se buscam padrões consistentes e fontes de discordância entre seus achados (DAWSON 2003; COUTINHO 2004).

$\mathrm{Na}$ presente pesquisa, aquilo que na metanálise é comumente chamado de estudo será representado pelas dez ocorrências escolhidas. Assim, o número de casos HDE propiciado pela ocorrência das amigdalites, por exemplo, foi comparado simultaneamente, por meio da técnica da metanálise, com o número de casos $\mathrm{HDE}$ propiciado pelas outras nove ocorrências em estudo. Realizou-se esse procedimento para cada um dos pares possíveis das quatro áreas/UBSs incluídas na pesquisa. Comparou-se, portanto, HDE com HDs demais como se cada ocorrência escolhida fosse um dos estudos agregados numa metanálise. Cada ocorrência escolhida (usualmente chamada de estudo, na metanálise) propicia um número de HDE e de HDs demais, segundo cada uma das quatro áreas/UBSs, que são comparadas duas a duas 
como se fossem o grupo tratado e grupo controle num estudo do tipo ensaio clínico. Uma das áreas/UBSs, nesse arranjo, assume o papel de um grupo controle para verificar o comportamento e as diferenças em relação a outra área/UBS. Calculou-se, assim um odds ratio sumário, ponderado pelo peso individual de cada ocorrência, utilizando-se o método de Mantel-Haenszel. Essa medida é mais consistente do que o cálculo de odds ratio resultante do simples somatório de HDEs e HDs demais propiciados por cada uma das dez ocorrências. Isso porque a metanálise, ao permitir trabalhar e combinar freqüências muito pequenas ao lado de outras não tão pequenas, realiza uma ponderação para cada estudo agregado, segundo a variabilidade de cada estudo, que depende, no caso em questão, da frequeência de cada HDE e do tamanho da amostra levantada nos dez dias.

A base de dados e as análises descritivas foram elaboradas com o apoio do programa Excell 2000 para Windows, os testes de estatística analítica realizados com o programa SPSS 10.0, e para a metanálise foi utilizado o software RevMan (Review Manager) 4.2, desenvolvido pela "The Cochrane Collaboration". Em toda a análise, o nível de confiança utilizado foi de $95 \%$ $(\alpha=0,05)$.

3.6.5 Conhecer os discursos das pessoas atendidas no pronto-socorro sobre o uso ou não dos serviços básicos e as razões e motivações que resultaram na procura do pronto-socorro pelo problema atual. Os depoimentos foram analisados com o recurso da técnica de análise categórica de discurso. A escolha dessa técnica para a análise dos discursos fundamentou-se nas condições limitadas dos depoimentos colhidos, expressos em declarações sintéticas sobre as motivações e a vivência concreta do uso ou não da atenção básica, antes da procura de atendimento no pronto-socorro, por uma das ocorrências escolhidas para estudo.

A análise de conteúdo, utilizando categorias temáticas, é a técnica de análise de conteúdo, que realiza operações de desmembramento do texto em unidades de significado segundo categorias pré-estabelecidas. Segundo BARDIN (2000), embora limitada, essa é uma técnica rápida e eficaz, que pode ser aplicada a discursos diretos e simples. Consiste em identificar 
núcleos de sentido presentes na enunciação, descrevê-los quanto ao significado temático e à freqüência, tendo como pressuposto que esses núcleos podem significar aspectos esclarecedores para o objetivo do estudo.

No processo de análise, as unidades de significação foram sendo gradativamente definidas com a exploração das particularidades do material empírico coletado, segundo a orientação geral propiciada pelos aspectos e pelos princípios discutidos nos referenciais teóricos. Assim, a definição das categorias temáticas foi sendo estabelecida com o apoio das categorias gerais desenvolvidas nos referenciais teóricos - acesso, integralidade com humanização dos serviços, conceito ampliado de saúde e participação da população. As categorias gerais foram traduzidas em algumas questões operacionais, isto é, em alguns possíveis problemas, identificados por muitos autores e corriqueiros na experiência prática de gestão. Essa listagem de problemas operacionais, que também foi utilizada como orientadora para a elaboração dos formulários de entrevistas com os usuários e os médicos e no roteiro de levantamento das informações de cada uma das UBSs, identificou questões tais como: demora na obtenção de um atendimento agendado; tempo de espera para ser atendido; dificuldade nas relações interpessoais, incapacidade de escutar, rigidez burocrática e normas disciplinares que dificultam o acesso aos cuidados; forma de organizar o acesso com balcão que dispensa, sem acolhimento do usuário; equipe simplificada, mínima, com baixa resolubilidade; trabalho centrado só no médico, falta de trabalho em equipe; falta de recurso; desarticulação com outros serviços; fragilidade das ações de promoção e de interação com a comunidade, desejo do usuário pela tecnologia e por ser atendido pelo profissional médico, considerado o único resolutivo. As categorias temáticas foram definidas com a aproximação entre o sentido principal do material empírico e as questões operacionais listadas.

As categorias temáticas resultantes desse procedimento metodológico são explicadas no capítulo "Resultados" e apresentadas com a adição de segmentos dos discursos das pessoas entrevistadas, de modo a delimitar a expressividade presente na idéia da categoria. Por fim, são também 
apresentadas as freqüências das categorias temáticas, segundo as áreas/UBSs de procedência dos entrevistados.

3.6.6 Caracterizar a estrutura das unidades básicas, recursos disponíveis, processo de trabalho, em especial durante o periodo mais proximamente relacionado com as ocorrências em estudo.

3.6.7 Conhecer a opinião dos médicos socorristas e das UBSs sobre o papel assistencial da UBS e do pronto-socorro, com ênfase na opinião sobre as circunstâncias e situações em que consideram desnecessário o uso do atendimento de urgência/emergência e sobre as razões desse uso desnecessário. Utilizou-se, também nestes casos, a técnica de análise categórica de discurso.

$\mathrm{Na}$ discussão dos dados procurou-se analisar as diferenças da razão HDE/HDs demais entre as áreas/UBSs segundo características da atenção básica. Procurou-se ambém contextualizar os achados quantitativos com a opinião e os valores manifestos ’elas pessoas envolvidas, verificando uma possível associação entre maiores ou menores valores dessa razão com os hiatos da prática da rede básica que poderiam ser mais elevantes na determinação das ocorrências indesejáveis e desnecessárias. Para o lesenvolvimento do capítulo "Discussão" utilizou-se a figura metodológica de um nterlocutor fictício (DONATO 2000), que assume a função de questionar os achados, ımpliar a crítica de forma a integrar os diversos tipos de dados coletados. Esse foi o 'ecurso utilizado na condução da discussão e no encaminhamento das conclusões, também levido à inexistência de estudos semelhantes que permitissem uma confrontação entre os ıchados e as explicações.

\subsection{Considerações éticas}

Elaborou-se termo de consentimento para os médicos socorristas e das UBSs ntrevistados, esclarecendo-os sobre o questionário aplicado (anexo 7), e outro para as ,essoas participantes da pesquisa atendidas no PS que foram entrevistadas (anexo 8). As :tapas da pesquisa e os materiais foram analisados e aprovados pelo Comitê de Ética em 'esquisa da Faculdade de Saúde Pública - USP e, também, os objetivos da pesquisa liscutidos com o gestor local, o qual autorizou a realização do trabalho (anexo 9). 


\section{Resultados}

\subsection{Os atendimentos no Pronto-Socorro Central}

Durante duas semanas, de segunda a sexta-feira, foram levantados dados de todo o atendimento realizado no Pronto-Socorro Central de Itapecerica da Serra e entrevistadas pessoas lá atendidas que tiveram como hipótese diagnóstica uma das ocorrências escolhidas, conforme definido. Nas 24 horas desses dez dias foram atendidas 4.038 pessoas, ficando 69 atendimentos sem definição diagnóstica, resultando em 3.969 observações válidas (tabela 3). As 1.295 pessoas para as quais detectaram-se hipóteses diagnósticas escolhidas como possíveis eventos sentinela (HDEs) representaram $32,6 \%$ dos casos válidos. Não houve associação estatística significante entre dia da semana e hipótese diagnóstica categorizada em HDE e HDs demais $\left(X^{2}=6,127 p=0,19\right)$.

Tabela 3 - Freqüéncia dos atendimentos, segundo dia da semana e hipótese dlagnóstica. PS Central, Itapecerica da Serra, 2004

\begin{tabular}{|c|c|c|c|c|c|c|}
\hline \multirow{2}{*}{ Dia da semana } & \multicolumn{2}{|l|}{ HoEs } & \multicolumn{2}{|c|}{ HDs Demais } & \multicolumn{2}{|l|}{ Total } \\
\hline & $\mathbf{n}$ & $\%$ & $\mathbf{n}$ & $\%$ & $\mathbf{n}$ & $\%$ \\
\hline segunda-feira & 261 & 20,2 & 586 & 21,9 & 847 & 21,3 \\
\hline lerça-feira & 238 & 18,4 & 551 & 20,6 & 789 & 19,9 \\
\hline quarta-feira & 260 & 20,1 & 525 & 19,6 & 785 & 19,8 \\
\hline quinta-feira & 291 & 22,5 & 532 & 19,9 & 823 & 20,7 \\
\hline searta-feira & 245 & 18,9 & 480 & 18,0 & 725 & 18,3 \\
\hline Total & 1.295 & 100,0 & 2.674 & 100,0 & 3.969 & 100,0 \\
\hline
\end{tabular}

$H D=$ hipótese diagnóstica e HDE $=$ HD escol hida

Porcentagem calculada com exclus so das ignoradas

$H D$ ignorada $=69$ obsenvaçes $(1,7 \%$ do total $)$

No horário-UBS (das $7 \mathrm{~h}$ às $16 \mathrm{~h}$ ) definido para o estudo das ocorrências, durante os mesmos dez dias, ocorreram 60,2\% do total dos 3.969 casos. Dos 1.295 casos com HDEs, $65,4 \%$ (847) ocorreram no horário-UBS (tabela 4). O horário-UBS aumentou em 1,4 vez a chance de $\operatorname{HDE}\left(\mathrm{X}^{2}=21,6-\mathrm{p}<0,001\right)$

Tabela 4 - Freqüéncia das HDs escolhidas e demais, segundo horário de atendimento. PS Central, ltapecerica da Serra, 2004.

\begin{tabular}{|c|c|c|c|c|c|c|}
\hline \multirow{2}{*}{ Horário de atendimento } & \multicolumn{2}{|l|}{ HDEs } & \multicolumn{2}{|c|}{ HDs Demais } & \multicolumn{2}{|c|}{ Total } \\
\hline & $\mathbf{n}$ & $\%$ & $\mathbf{n}$ & $\%$ & $\mathbf{n}$ & $\%$ \\
\hline $7 h-16 h$ & 847 & 65,4 & 1.543 & 57,7 & 2.390 & 60,2 \\
\hline $16 h-7 h$ & 448 & 34,6 & 1.131 & 42,3 & 1.579 & 39,8 \\
\hline Nas 24 horas & 1.295 & 100,0 & 2.674 & 100,0 & 3.969 & 100,0 \\
\hline
\end{tabular}

HD = hipótese diagnóstica e HDE $=$ HD secolhida 
A tabela 5 apresenta a distribuição dos 2.390 atendimentos no horário-UBS, segundo a área/UBS de procedência do usuário. As áreas/UBSs escolhidas para o estudo foram responsáveis por $70,6 \%$ de todos os atendimentos e por $73,8 \%$ das HDEs, no horário-UBS considerado.

Tabela 5 - Frequiência das HDEs e HDs demais, no horário-UBS, segundo áreas/UBSs de procedência dos usuários. PS Central, Itapecerica da Serra, 2004.

\begin{tabular}{|c|c|c|c|c|c|c|}
\hline \multirow{2}{*}{ Área/UBS } & \multicolumn{2}{|c|}{ HDES } & \multicolumn{2}{|c|}{ HDs demais } & \multicolumn{2}{|l|}{ Total } \\
\hline & $\mathbf{n}$ & $\%$ & $\mathbf{n}$ & $\%$ & $\mathbf{n}$ & $\%$ \\
\hline \multicolumn{7}{|l|}{ Áreas/UBSs escolhidas } \\
\hline Salvador Leone & 308 & 36,4 & 489 & 31,7 & 797 & 33,3 \\
\hline Parque Paraiso & 169 & 20,0 & 286 & 18,5 & 455 & 19,0 \\
\hline Valo Velho & 89 & 10,5 & 208 & 13,5 & 297 & 12,4 \\
\hline Branca Flor & 59 & 7,0 & 79 & 5,1 & 138 & 5,8 \\
\hline Total - UBSs escolhidas & 625 & 73,8 & 1.062 & 68,8 & 1.687 & 70,6 \\
\hline Outras UBSs do município & 169 & 20,0 & 326 & 21,1 & 495 & 20,7 \\
\hline Outrros municipios & 53 & 6,3 & 145 & 9,4 & 198 & 8,3 \\
\hline lgnorado & & - & 10 & 0,6 & 10 & 0,4 \\
\hline Total & 847 & 100,0 & 1.543 & 100,0 & 2.390 & 100,0 \\
\hline
\end{tabular}

HD = hipótese diagnóstica e HDE = HD escolhida

A figura 3 apresenta um quadro-resumo da freqüência dos atendimentos, segundo sucessivas restrições de categorias populacionais e critérios para a seleção da amostra.

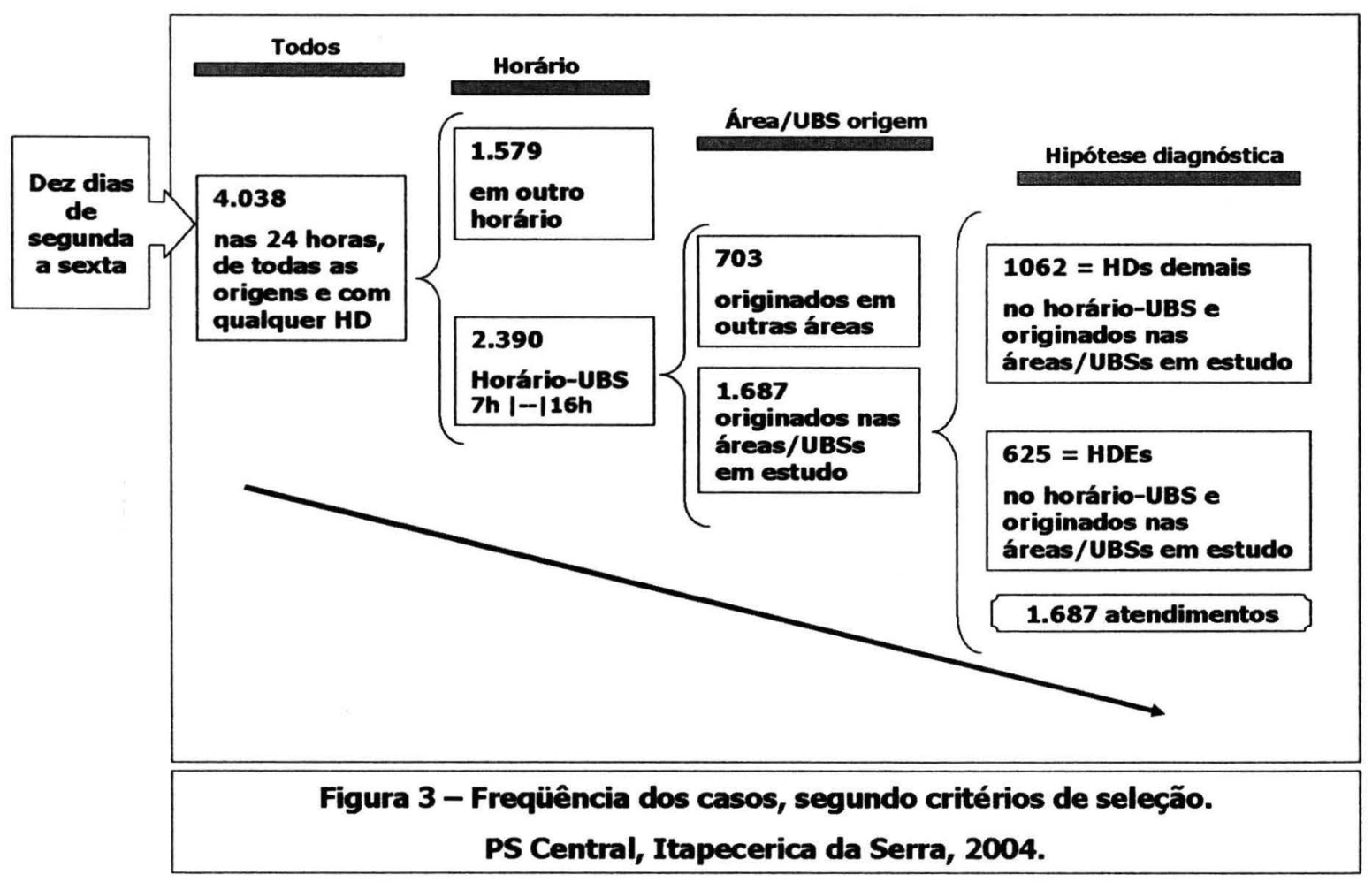


Considerando-se os 1.687 atendimentos da amostra da população em estudo com ipóteses diagnósticas estabelecidas, ordenaram-se as 25 primeiras hipóteses diagnósticas, tilizando-se a classificação de três dígitos da CID-10. Elas corresponderam, quanto à eqüência relativa acumulada, a $76,5 \%$ do total dos 1.687 atendimentos. Das dez corrências incluídas nas HDEs, oito apareceram dentre essas 25 primeiras (tabela 6) 「asofaringite, amigdalite e HAS são respectivamente a primeira, a terceira e a quarta ipóteses diagnósticas mais freqüentes, considerando-se todas as ocorrências.

\section{Tabela 6 - Frequiência das 25 primeiras HDs dos atendimentos realizados no horário-UBS e originados nas áreas/UBSs escolhidas. PS Central, Itapecerica da Serra, 2004.}

\begin{tabular}{|c|c|c|c|c|}
\hline HD* & CID & $\mathbf{n}$ & $\%$ & $\begin{array}{r}\% \\
\text { acum. } \\
\end{array}$ \\
\hline Nasofaringite & J00 & 266 & 15,8 & 15,8 \\
\hline Trauma único não especificado & T14 & 141 & 8,4 & 24,1 \\
\hline Amigdalite & J03 & 111 & 6,6 & 30,7 \\
\hline HAS & 110 & 88 & 5,2 & 35,9 \\
\hline Exame de seguimento & $\mathrm{ZO9}$ & 73 & 4,3 & 40,2 \\
\hline Dorsalgia & M54 & 57 & 3,4 & 43,6 \\
\hline Asma & $\mathbf{J 4 5}$ & 52 & 3,1 & 46,7 \\
\hline Outros transtornos dos tecidos moles & M79 & 50 & 3,0 & 49,7 \\
\hline Outros transtornos urinários (ITU) & N39 & 49 & 2,9 & 52,6 \\
\hline Broncopneumonia\Pneumonia & J15 & 44 & 2,6 & 55,2 \\
\hline Sinusite & J01 & 39 & 2,3 & 57,5 \\
\hline Dispepsia & K30 & 34 & 2,0 & 59,5 \\
\hline Dor de garganta e no peito & R07 & 34 & 2,0 & 61,5 \\
\hline Dor abdominal & R10 & 30 & 1,8 & 63,3 \\
\hline Diarréia e gastroenterite & A09 & 28 & 1,7 & 65,0 \\
\hline Outros transtornos articulares & M25 & 25 & 1,5 & 66,4 \\
\hline Dermatite atópica & $\mathrm{L} 20$ & 24 & 1,4 & 67,9 \\
\hline Otite média & H66 & 22 & 1,3 & 69,2 \\
\hline Cefaléia & R51 & 20 & 1,2 & 70,4 \\
\hline Não respondeu & NR & 20 & 1,2 & 71,5 \\
\hline Conjuntivite & $\mathrm{H} 10$ & 20 & 1,2 & 72,7 \\
\hline Dor e outras do ciclo menstrual & N94 & 17 & 1,0 & 73,7 \\
\hline Urticária & L50 & 16 & 0,9 & 74,7 \\
\hline Puericultura & $\mathbf{Z} 00$ & 16 & 0,9 & 75,6 \\
\hline Falso trabalho de parto & 047 & 15 & 0,9 & 76,5 \\
\hline Demais & & 396 & 23,5 & 100,0 \\
\hline Total & & 1.687 & 100,0 & \\
\hline
\end{tabular}

* Em negrito hipóteses diagnósticas escolhidas 
Utilizando-se o agrupamento dos capítulos da CID, o capítulo X (doenças do aparelho respiratório) é o principal grupo de HDs dos atendimentos, com 31,2\% do total, certamente muito influenciado pelas infecções de vias aéreas superiores (tabela 7). As lesões externas características de unidades de urgência/emergência seguem em segundo lugar, com $10,6 \%$ dos atendimentos.

\section{Tabela 7 - Distribuição de todas as HDs dos atendimentos realizados no horário e nas áreas de procedência em estudo, segundo capítulos da CID/10. PS Central, Itapecerica da Serra, 2004.}

\begin{tabular}{|c|c|c|c|}
\hline Capítulo e descrição CID & $\mathbf{n}$ & $\%$ & acum. \\
\hline X. Doenças do aparelho respiratório (J00-J99) & 526 & 31,2 & 31,2 \\
\hline XIX. Lesōes, envenenamento e outras causas externas (S00-T98) & 178 & 10,6 & 41,7 \\
\hline $\begin{array}{l}\text { XVIII. Sintomas, sinais e achados anormais de exames, não classificados em outra } \\
\text { parte (R00-R99) }\end{array}$ & 169 & 10,0 & 51,7 \\
\hline XIII. Doenças do sistema osteomuscular e do tecido conjuntivo (M00-M99) & 152 & 9,0 & 60,8 \\
\hline $\begin{array}{l}\text { XXI. Fatores que influenciam o estado de saúde e o contato com os serviços de } \\
\text { saúde (Z00-Z99) }\end{array}$ & 110 & 6,5 & 67,3 \\
\hline XIV. Doenças do aparelho geniturinário (N00-N99) & 92 & 5,5 & 72,7 \\
\hline IX. Doenças do aparelho circulatório (100-199) & 98 & 5,8 & 78,5 \\
\hline XI. Doenças do aparelho digestivo (KOO-K93) & 52 & 3,1 & 81,6 \\
\hline XII. Doenças da pele e do tecido subcutâneo (L00-L99) & 75 & 4,4 & 86,1 \\
\hline XV. Gravidez, parto e puerpério (000-099) & 37 & 2,2 & 88,3 \\
\hline I. Algumas doenças infecciosas e parasitárias (A00-B99) & 35 & 2,1 & 90,3 \\
\hline VIII. Doenças do ouvido e da apófise mastóide (H60-H95) & 36 & 2,1 & 92,5 \\
\hline XX. Causas externas de morbidade e de mortalidade (V01-Y98) & 17 & 1,0 & 93,5 \\
\hline II. Neoplasias [tumores] (COO-D48) & 32 & 1,9 & 95,4 \\
\hline V. Transtornos mentais e comportamentais (F00-F99) & 12 & 0,7 & 96,1 \\
\hline Não respondeu à chamada & 20 & 1,2 & 97,3 \\
\hline VII. Doenças do olho e anexos (H0O-H59) & 23 & 1,4 & 98,6 \\
\hline VI. Doenças do sistema nervoso (G00-G99) & 13 & 0,8 & 99,4 \\
\hline IV. Doenças endócrinas, nutricionais e metabólicas (E00-E90) & 8 & 0,5 & 99,9 \\
\hline $\begin{array}{l}\text { III. Doenças do sangue e dos órgãos hematopoéticos e alguns transtornos } \\
\text { imunitários (D50-D89) }\end{array}$ & 1 & 0,1 & 99,9 \\
\hline XVI. Algumas afeçcōes originadas no periodo perinatal (P00-P96) & 1 & 0,1 & 100,0 \\
\hline Total & 1.687 & 100,0 & \\
\hline
\end{tabular}

CID = Classificação Internacional das Doenças

Porcentagem calculada com exclusão dos ignorados - 24 ignorados $(1,4 \%)$ 
Considerando-se os 1.687 atendimentos, verificou-se a distribuição segundo sexo e faixa etária. O sexo feminino foi mais freqüente no total de atendimentos, com $56,6 \%$, e no total das HDEs, com 57,1\% (tabela 8). A ocorrência de HDEs não foi influenciada de forma estatisticamente significante pela variável sexo $\left(X^{2}=0,105-p=0,745\right)$.

Tabela 8 - Frequéncia das HDs escolhidas e demais, no horário-UBS e originados nas áreas/UBSs escolhidas, segundo sexo. PS Central, Itapecerica da Serra, 2004.

\begin{tabular}{|c|c|c|c|c|c|c|}
\hline \multirow{2}{*}{ Sexo } & \multicolumn{2}{|c|}{ HDEs } & \multicolumn{2}{|c|}{ HDs Demais } & \multicolumn{2}{|c|}{ Total } \\
\hline & $\mathbf{n}$ & $\%$ & $\mathbf{n}$ & $\%$ & $\mathbf{n}$ & $\%$ \\
\hline Feminino & 357 & 57,1 & 598 & 56,3 & 955 & 56,6 \\
\hline Masculino & 268 & 42,9 & 464 & 43,7 & 732 & 43,4 \\
\hline Total & 625 & 100,0 & 1.062 & 100,0 & 1.687 & 100,0 \\
\hline
\end{tabular}

$H D=$ hipótese diagnóstica e HDE $=$ HD escolhida

Porcentagem calculada com exclusáo dos ignorados. Ignorados $=24$ (1,4\% do total)

$$
X^{2}=0,105-p=0,745
$$

As HDEs predominaram no sexo masculino até os 14 anos de idade, e a partir dos 15 anos a predominância é feminina. Até a faixa etária $1-4$ anos as HDEs superam as HDs demais, mas o maior contingente de HDE provém da faixa 15 - 49 (tabela 9). A variável idade em faixas etárias não apresentou associação significativa com horário de atendimento, mas apresentou associação com a ocorrência de HDEs. Isto é, conforme a faixa etária, a chance de ser uma HDE é maior ou menor. A faixa etária $<1$ ano é a mais fortemente associada positivamente com a ocorrência de HDEs. Comparando-se a faixa $<1$ ano com a de 15 - 49, a chance de um caso atendido na faixa $<1$ ano ser $\mathrm{HDE}$ é 5,8 vezes maior $\left(O R_{<1 \times 15-49}=5,8\right.$ com IC $\left.95 \%=3,5-9,5\right)$.

Tabela 9 - Frequếncia das HDEs e HDs demais, no horário-UBS e áreas/UBSs de procedência em estudo, segundo faixas etárias. PS Central, Itapecerica da Serra, 2004.

\begin{tabular}{|c|c|c|c|c|c|c|}
\hline \multirow{2}{*}{ Faixa etária } & \multicolumn{2}{|c|}{ HDES } & \multicolumn{2}{|c|}{ HDs Demais } & \multicolumn{2}{|c|}{ Total } \\
\hline & $\mathbf{n}$ & $\%$ & $\mathbf{n}$ & $\%$ & $\mathbf{n}$ & $\%$ \\
\hline$<1$ & 62 & 9,9 & 28 & 2,6 & 90 & 5,3 \\
\hline $1-4$ & 140 & 22,4 & 83 & 7,8 & 223 & 13,2 \\
\hline $5-9$ & 84 & 13,4 & 85 & 8,0 & 169 & 10,0 \\
\hline $10-14$ & 23 & 3,7 & 52 & 4,9 & 75 & 4,4 \\
\hline $15-49$ & 234 & 37,4 & 610 & 57,5 & 844 & 50,1 \\
\hline $50-64$ & 55 & 8,8 & 127 & 12,0 & 182 & 10,8 \\
\hline 65 ou + & 27 & 4,3 & 76 & 7,2 & 103 & 6,1 \\
\hline Total & 625 & 100,0 & 1.061 & 100,0 & 1.686 & 100,0 \\
\hline
\end{tabular}

$H D=$ hipótese diagnóstica e HDE $=$ HD escolhida $X^{2}=155,59-p<0,001$ 
Categorizando a variável idade segundo três grupos - crianças (0 --|14) jovens (15 $|-| 20$ ) e adultos (21 ou mais) -, constata-se que a chance de o atendimento ser uma HDE foi maior no grupo criança (tabelas 10 e 11). No total de $625 \mathrm{HDEs}$, o grupo etário criança contém 309 HDEs, o jovem 42 e o adulto 274.

Tabela 10 - Frequéência das HDEs e HDs demais, no horário-UBS e áreas/UBSs de procedência em estudo, segundo grupos etários. PS Central, Itapecerica da Serra, 2004.

\begin{tabular}{|c|c|c|c|c|c|c|}
\hline \multirow{2}{*}{ Grupo de idade } & \multicolumn{2}{|c|}{ HDEs } & \multicolumn{2}{|c|}{ HDs demais } & \multicolumn{2}{|l|}{ Total } \\
\hline & $\mathbf{n}$ & $\%$ & $\mathbf{n}$ & $\%$ & $\mathbf{n}$ & $\%$ \\
\hline Criança $(0-15)$ & 309 & 49,4 & 248 & 23,4 & 557 & 33,0 \\
\hline Jovem (15 - -21$)$ & 42 & 6,7 & 114 & 10,7 & 156 & 9,2 \\
\hline \multirow[t]{2}{*}{ Adulto $(21 \mid-)$} & 274 & 43,8 & 700 & 65,9 & 974 & 57,7 \\
\hline & 625 & 100,0 & 1.062 & 100,0 & 1.687 & 100,0 \\
\hline $\begin{array}{l}\text { HD = hipótese diagnóstic } \\
\text { Porcentagem calculada } \\
\text { lgnorados = } 24 \text { obseravé }\end{array}$ & & & & & $16-p$ & 0,001 \\
\hline
\end{tabular}

Tabela 11 - Valores de odds ratio entre grupos de idade e HDEs no horário e nas áreas de procedência em estudo. PS Central, Itapecerica da Serra, 2004.

\begin{tabular}{l|cc}
\hline Grupos comparados & OR & IC95\% \\
\hline \hline Criança X Jovem & 3,38 & $2,29-5,00$ \\
Criança X Adulto & 3,18 & $2,56-3,96$ \\
Jovem X Adulto & 0,94 & $0,94-1,38$ \\
\hline
\end{tabular}

$\mathrm{HD}=$ hipótese diagnóstica e HDE $=\mathrm{HD}$ escolhida

Criança (0 - 15); Jovem (15 |- 21); Adulto (21 |-) 
Portanto, na verificação de possiveis influências das variáveis dias da semana, sexo e idade (categorizada em grupos etários) na ocorrência de HDEs, apenas a variável idade mostrou-se significativamente associada (tabela 12).

Tabela 12 - Freqüência de algumas variáveis e verificação da respectiva influência na ocorrência das HDEs dos atendimentos realizados no horário e nas áreas de procedência em estudo. PS Central, Itapecerica da Serra, 2004.

\begin{tabular}{|c|c|c|c|c|c|c|c|c|}
\hline Variável & \multicolumn{2}{|c|}{ HDEs } & \multicolumn{2}{|c|}{ HDs demais } & \multicolumn{2}{|l|}{ Total } & $\begin{array}{r}\text { Qui- } \\
\text { quadrado }\end{array}$ & $\begin{array}{r}\text { Valor } \\
\text { dep }\end{array}$ \\
\hline \multicolumn{9}{|l|}{ Dia da semana } \\
\hline segunda-feira & 138 & 36,3 & 242 & 63,7 & 380 & 100,0 & & \\
\hline terça-feira & 126 & 37,7 & 208 & 62,3 & 334 & 100,0 & & \\
\hline quarta-feira & 109 & 35,2 & 201 & 64,8 & 310 & 100,0 & & \\
\hline quinta-feira & 140 & 39,9 & 211 & 60,1 & 351 & 100,0 & & \\
\hline sexta-feira & 112 & 35,9 & 200 & 64,1 & 312 & 100,0 & & \\
\hline Total dia da semana & 625 & 37,0 & 1062 & 63.0 & 1687 & 100,0 & 2,02 & 0,73 \\
\hline Sexo & & & & & & & & \\
\hline Feminino & 357 & 37,4 & 598 & 62,6 & 955 & 100,0 & & \\
\hline Masculino & 268 & 36,6 & 464 & 63,4 & 732 & 100,0 & & \\
\hline Total sexo & 625 & 37,0 & 1062 & 63,0 & 1687 & 100,0 & 0,11 & 0,75 \\
\hline \multicolumn{9}{|l|}{ Grupo de idade } \\
\hline Criança & 308 & 55,3 & 248 & 44,5 & 557 & 100,0 & & \\
\hline Jovem & 42 & 26,9 & 114 & 73,1 & 156 & 100,0 & & \\
\hline Adulto & 274 & 28,1 & 700 & 71,9 & 974 & 100,0 & & \\
\hline Total grupo de idade & 624 & 37,0 & 1062 & 63,0 & 1687 & 100,0 & 121,16 & $<0,01$ \\
\hline
\end{tabular}

$\mathrm{HD}=$ hipótese diagnóstica e HDE = HD escolhida

Porcentagem calculada com exclusăo dos ignorados

24 ignorados $(1,4 \%)$

A seguir, inclusive pelo fato de a variável idade estar associada com a maior ou menor ocorrência de HDEs, a preocupação foi verificar se as variáveis dia da semana, sexo e, sobretudo, idade (categorizada em grupos etários), por distribuição significativamente diferente entre as áreas/UBSs, por obra do acaso, estariam produzindo uma tendenciosidade nos dados, isto é, se as diferenças na freqüência entre as áreas/UBSs das HDEs ocorrem não por diferenças entre as áreas, mas pela diferente distribuição dessas variáveis. A tabela 13 apresenta os resultados dos testes dessa verificação, que demonstram a inexistência de associação estatística significante entre essas variáveis e as áreas/UBSs de procedência das HDEs. 
Tabela 13 - Verificação da influência de algumas variáveis na ocorrência das HDEs, segundo horário e área de procedência em estudo. PS Central, Itapecerica da Serra, 2004.

\begin{tabular}{|c|c|c|c|c|c|c|c|}
\hline Variável & B. Flor & P. Paraíso & S. Leone & V. Velho & Total & $\begin{array}{l}\text { Qui- } \\
\text { quadrado }\end{array}$ & $\begin{array}{l}\text { Valor } \\
\text { de p }\end{array}$ \\
\hline \multicolumn{8}{|l|}{ Dia da semana } \\
\hline segunda-feira & 14 & 39 & 68 & 17 & 138 & & \\
\hline terça-feira & 8 & 30 & 66 & 22 & 126 & & \\
\hline quarta-feira & 8 & 28 & 58 & 15 & 109 & & \\
\hline quinta-feira & 13 & 43 & 64 & 20 & 140 & & \\
\hline sexta-feira & 16 & 29 & 52 & 15 & 112 & & \\
\hline Total dia da semana & 59 & 169 & 308 & 89 & 625 & 8,52 & 0,74 \\
\hline \multicolumn{8}{|l|}{ Sexo } \\
\hline Feminino & 35 & 89 & 174 & 59 & 357 & & \\
\hline Masculino & 24 & 80 & 134 & 30 & 268 & & \\
\hline Total sexo & 59 & 169 & 308 & 89 & 625 & 4,59 & 0,20 \\
\hline \multicolumn{8}{|l|}{ Grupo de idade } \\
\hline Criança & 28 & 87 & 148 & 46 & 309 & & \\
\hline Jovem & 4 & 12 & 23 & 3 & 42 & & \\
\hline Adulto & 27 & 70 & 137 & 40 & 274 & & \\
\hline Total grupo de idade & 59 & 169 & 308 & 89 & 625 & 2,51 & 0,87 \\
\hline
\end{tabular}

$\mathrm{HD}=$ hipótese diagnóstica e $\mathrm{HDE}=\mathrm{HD}$ escolhida 24 ignorados $(1,4 \%)$

Controlado o efeito dessas variáveis (dia da semana, sexo e grupo etário), procurouse analisar a área de procedência das pessoas atendidas como fator associado com maior ou menor ocorrência de HDEs. Mas, como já discutido no capítulo "Método", as populações das áreas/UBSs são diferentes em tamanho e, provavelmente, em relação ao uso do PS, e portanto comparar as freqüências absolutas de HDEs de cada uma das áreas é inútil, pois não permite encontrar diferenças entre as áreas quanto à utilização/resolução da atenção básica.

Em razão dessa situação, procedeu-se à comparação da freqüência das HDEs com a das HDs demais de cada uma das áreas, evitando-se o fator tamanho de cada população e, também, as diferenças de uso do PS Central. Para proceder a essa verificação os grupos HDEs e HDs demais procedentes de cada área/UBS foram comparados com os mesmos grupos originados em outra área/UBS. O objetivo foi verificar se uma determinada área/UBS produz relativamente mais HDEs do que HDs demais, quando comparada com outra área/UBS. Ou seja, foi verificar se a área/UBS influi na ocorrência de HDEs.

Em outros termos, procurou-se verificar, estatisticamente, se a ocorrência de HDEs pode ser usada para monitorar diferenças entre as áreas/UBSs de procedência dos usuários do pronto-socorro. 
A tabela 14 apresenta a análise do conjunto das quatro áreas/UBSs e a ocorrência de HDEs e HDs demais. A maior freqüência relativa de HDEs ocorreu na área/UBS Branca Flor $(42,8 \%)$, e a menor na área/UBS do Valo Velho $(30,0 \%)$. No conjunto, as áreas/UBSs apresentaram diferença significativa quanto à ocorrência de HDEs $\left(X^{2}=9,19 \mathrm{e}\right.$ p-valor $=0,027$ ).

Tabela 14 - Frequiéncia das HDEs e HDs demais, no horário-UBS, segundo áreas/UBS em estudo. PS Central, Itapecerica da Serra, 2004.

\begin{tabular}{|c|c|c|c|c|c|c|}
\hline \multirow{2}{*}{ Área/UBS } & \multicolumn{2}{|c|}{ HDES } & \multicolumn{2}{|c|}{ HDs demais } & \multicolumn{2}{|c|}{ Total } \\
\hline & $\mathbf{n}$ & $\%$ & $\mathbf{n}$ & $\%$ & $\mathbf{n}$ & $\%$ \\
\hline Salvador Leone & 308 & 38,6 & 489 & 61,4 & 797 & 100,0 \\
\hline Parque Paraiso & 169 & 37,1 & 286 & 62,9 & 455 & 100,0 \\
\hline Valo Velho & 89 & 30,0 & 208 & 70,0 & 297 & 100,0 \\
\hline Branca Flor & 59 & 42,8 & 79 & 57,2 & 138 & 100,0 \\
\hline Total & 625 & 37,0 & 1.062 & 63,0 & 1.687 & 100,0 \\
\hline
\end{tabular}

A tabela 15 apresenta a análise das áreas/UBSs, duas a duas, com os respectivos valores de qui-quadrado, com seu p-valor, e de odds ratio e seu intervalo de confiança. Todas as áreas/UBSs apresentaram diferenças significativas quando comparadas com a área/UBS do Valo Velho. Segundo os valores de odds ratio, a chance de HDE é 1,75 vez maior na área/UBS Branca Flor quando comparada com a do Valo Velho.

Tabela 15 - Verificação da diferença entre pares de áreas/UBSs de origem dos atendimentos na frequiéncia das HDEs. PS Central, Itapecerica da Serra, 2004.

\begin{tabular}{|c|c|c|c|c|}
\hline \multirow{2}{*}{ HDE } & \multicolumn{3}{|c|}{ HDE * HDs demais } & \multirow[b]{2}{*}{ IC95\% } \\
\hline & Qui-quadrado & Valor de $p$ & OR & \\
\hline B. Flor * V. Vetho & 6,86 & $<0,01$ & $1,75^{*}$ & $1,15-2,65$ \\
\hline S. Leone " V. Velho & 7,05 & $<0,01$ & $1,47^{*}$ & $1,11-1,96$ \\
\hline P. Paraiso * V. Velho & 4,11 & 0,04 & $1,38^{*}$ & $1,01-1,53$ \\
\hline B. Flor " S. Leone & 0,83 & 0,36 & 1,19 & $0,82-1,71$ \\
\hline B. Flor * P. Paraiso & 1,41 & 0,24 & 1,26 & $0,86-1,86$ \\
\hline S. Leone * P. Paraiso & 0,28 & 0,60 & 1,07 & $0,83-1,36$ \\
\hline
\end{tabular}


Controladas as variáveis dia da semana, sexo e idade e identificada uma possível associação entre as HDEs no seu conjunto e as áreas/UBSs de procedência dos usuários atendidos no Pronto-Socorro Central, passou-se para a análise de cada uma das dez ocorrências incluídas no grupo das HDEs.

Explorando cada uma das HDEs em relação à variável idade, categorizada em grupos etários, amigdalite, asma, otite média e sinusite distribuíram-se com semelhança entre o grupo criança e adulto. A nasofaringite, embora seja mais freqüente no grupo criança, não tem pequena ocorrência no grupo adulto, correspondendo a $23,7 \%$ do total de casos (tabela 16).

Tabela 16 - Frequencia das HDEs e HDs demais no horário e nas áreas de procedéncia em estudo, segundo grupos

\begin{tabular}{|c|c|c|c|c|c|c|c|c|}
\hline \multirow{2}{*}{ HD } & \multicolumn{2}{|c|}{ Crianga } & \multicolumn{2}{|c|}{ Jovem } & \multicolumn{2}{|c|}{ Adulto } & \multicolumn{2}{|c|}{ Total } \\
\hline & $\mathbf{n}$ & \% & $\mathbf{n}$ & $\mathbf{x}$ & $\mathbf{n}$ & $\mathbf{x}$ & $\mathbf{n}$ & \% \\
\hline \multicolumn{9}{|l|}{ HDE } \\
\hline Nasofaringite & 192 & 72,2 & 11 & 4,1 & 63 & 23,7 & 266 & 100,0 \\
\hline Amigdalite & 45 & 40,5 & 18 & 16,2 & 48 & 43,2 & 111 & 100,0 \\
\hline HAS & - & - & 1 & 1,1 & 87 & $\mathbf{9 8 , 9}$ & 88 & 100,0 \\
\hline Acma & 23 & 44,2 & 3 & 5,8 & 26 & 50,0 & 52 & 100,0 \\
\hline Sinusile & 20 & 51,3 & 3 & 7,7 & 16 & 41,0 & 39 & 100,0 \\
\hline Ocite média & 12 & 54,5 & 1 & 4,5 & 9 & 40,9 & 22 & 100,0 \\
\hline Dor e outras do ciclo menetrual & - & - & 5 & 29,4 & 12 & 70,6 & 17 & 100,0 \\
\hline Puericultura & 16 & 100,0 & - & - & - & - & 16 & 100,0 \\
\hline Diabetes & - & - & - & - & 8 & 100,0 & 8 & 100,0 \\
\hline Vutrovaginiles & 1 & 16,7 & - & - & 5 & 83,3 & 6 & 100,0 \\
\hline Todas a HDEs & 300 & 49,4 & 42 & 6,7 & 274 & 43,8 & 625 & 100,0 \\
\hline Todas as HDs demaic & 248 & 23,4 & 114 & 10,7 & 700 & 65,9 & 1.062 & 100,0 \\
\hline Total & 557 & 33,0 & 156 & 9,2 & 974 & 57,7 & 1.687 & 100,0 \\
\hline
\end{tabular}

$H D=$ hipdtece dienondica e $H D E=H D$ escolhida

Crienga (0-15); Jovem (15 - 21); Adrto (21 -$)$

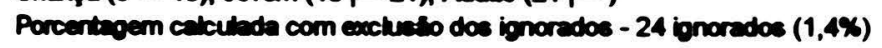

Em relação ao sexo, as HDEs, exceto aquelas diretamente ligadas ao sexo, distribuíram-se de maneira próxima, com leve tendência para maiores freqüências no sexo feminino (tabela 17). 
Tabela 17 - Freqüência de cada uma das HDEs e HDs demais no horário e nas áreas de procedência em estudo, segundo sexo.

PS Central, Itapecerica da Serra, 2004

\begin{tabular}{|c|c|c|c|c|c|c|}
\hline \multirow{2}{*}{ HD } & \multirow{2}{*}{$\begin{array}{c}\text { Masculino } \\
\mathbf{n} \\
\end{array}$} & \multirow[b]{2}{*}{$\%$} & \multirow{2}{*}{$\begin{array}{c}\text { Feminino } \\
\mathbf{n} \\
\end{array}$} & \multirow[b]{2}{*}{$\%$} & \multirow{2}{*}{$\begin{array}{c}\text { Total } \\
\mathbf{n} \\
\end{array}$} & \multirow[b]{2}{*}{$\%$} \\
\hline & & & & & & \\
\hline \multicolumn{7}{|l|}{ HDE } \\
\hline Nasofaringite & 127 & 47,7 & 139 & 52,3 & 266 & 100,0 \\
\hline Amigdalite & 52 & 46,8 & 59 & 53,2 & 111 & 100,0 \\
\hline HAS & 37 & 42,0 & 51 & 58,0 & 88 & 100,0 \\
\hline Asma & 23 & 44,2 & 29 & 55,8 & 52 & 100,0 \\
\hline Sinusite & 12 & 30,8 & 27 & 69,2 & 39 & 100,0 \\
\hline Otite media & 5 & 22,7 & 17 & 77,3 & 22 & 100,0 \\
\hline Dor e outras do ciclo menstrual & & - & 17 & 100,0 & 17 & 100,0 \\
\hline Puericultura & 10 & 62,5 & 6 & 37,5 & 16 & 100,0 \\
\hline Diabetes & 2 & 25,0 & 6 & 75,0 & 8 & 100,0 \\
\hline Vulvovaginites & & - & 6 & 100,0 & 6 & 100,0 \\
\hline Todas as HDEs & 268 & 42,9 & 357 & 57,1 & 625 & 100,0 \\
\hline Todas as HDs demais & 464 & 43,7 & 598 & 56,3 & 1.062 & 100,0 \\
\hline Total & 732 & 43,4 & 955 & 56,6 & 1.687 & 100,0 \\
\hline
\end{tabular}

HD = hipotese diagnostica e HDE = HD escolhida

Porcentagem calculada com exclusăo dos ignorados - 24 ignorados $(1,4 \%)$

A tabela 18 apresenta a freqüência das ocorrências escolhidas segundo cada área/UBS e no total. A maior freqüência foi de nasofaringite, com 15,8\% do total. Diabetes e vulvovaginites foram as duas ocorrências com menor freqüência, apresentando zero casos na menor área/UBS, como era previsível, conforme discussão no capítulo "Método".

Tabela 18 - Freqüência de cada uma das HDEs e HDs demais no horário-UBS, segundo áreas/UBSs em estudo. PS Central, Itapecerica da Serra, 2004.

\begin{tabular}{|c|c|c|c|c|c|c|c|c|c|c|}
\hline \multirow{2}{*}{ HD } & \multicolumn{2}{|c|}{ Branca Flor } & \multicolumn{2}{|c|}{ Parque Paraiso } & \multicolumn{2}{|c|}{ Salvador Leone } & \multicolumn{2}{|c|}{ Valo Velho } & \multicolumn{2}{|r|}{ Total } \\
\hline & $\mathbf{n}$ & $\%$ & $\mathbf{n}$ & $\%$ & $\mathbf{n}$ & $\%$ & $\mathbf{n}$ & $\%$ & $\mathbf{n}$ & $\%$ \\
\hline Nasofaringite & 23 & 1,4 & 70 & 4,1 & 132 & 7,8 & 41 & 2,4 & 266 & 15,8 \\
\hline Amigdalite & 8 & 0,5 & 25 & 1,5 & 60 & 3,6 & 18 & 1,1 & 111 & 6,6 \\
\hline HAS & 12 & 0,7 & 21 & 1,2 & 47 & 2,8 & 8 & 0,5 & 88 & 5,2 \\
\hline Asma & 4 & 0,2 & 15 & 0,9 & 26 & 1,5 & 7 & 0,4 & 52 & 3,1 \\
\hline Sinusite & 6 & 0,4 & 16 & 0,9 & 13 & 0,8 & 4 & 0,2 & 39 & 2,3 \\
\hline Otite média & 3 & 0,2 & 8 & 0,5 & 9 & 0,5 & 2 & 0,1 & 22 & 1,3 \\
\hline Dor e outras do ciclo menstrual & 1 & 0,1 & 3 & 0,2 & 10 & 0,6 & 3 & 0,2 & 17 & 1,0 \\
\hline Puericultura & 2 & 0,1 & 5 & 0,3 & 7 & 0,4 & 2 & 0,1 & 16 & 0,9 \\
\hline Diabetes & 0 & 0,0 & 3 & 0,2 & 2 & 0,1 & 3 & 0,2 & 8 & 0,5 \\
\hline Vulvovaginites & 0 & 0,0 & 3 & 0,2 & 2 & 0,1 & 1 & 0,1 & 6 & 0,4 \\
\hline Todas as HDEs & 59 & 3,5 & 169 & 10,0 & 308 & 18,3 & 89 & 5,3 & 625 & 37,0 \\
\hline Todas as HDs demais & 79 & 4,7 & 286 & 17,0 & 489 & 29,0 & 208 & 12,3 & 1.062 & 63,0 \\
\hline Total & 138 & 8,2 & 455 & 27,0 & 797 & 47,2 & 297 & 17,6 & 1.687 & 100,0 \\
\hline
\end{tabular}

$H D=$ hipótese diagnóstica e $H D E=H D$ escolhida

Porcentagem calculada com exclusâo dos ignorados - 24 ignorados $(1,4 \%)$ 
Hipertensão arterial sistêmica (HAS) e sinusite, isoladamente, foram as ocorrências mais influenciadas pelas áreas/UBSs, quando consideradas em conjunto, isto é, distribuíram-se de forma significativamente diferente, quando comparadas com as HDs demais, conforme a área/UBS de procedência considerada (tabela 19).

\section{Tabela 19 - Valores do qui-quadrado e valores de $p$ da diferença entre as quatro áreas/UBSs de procedência e a frequência de cada uma das HDEs. PS Central, Itapecerica da Serra, 2004}

\begin{tabular}{|c|c|c|c|}
\hline \multirow{2}{*}{ HDE } & \multicolumn{2}{|c|}{ B. Flor - P. Paraíso - S. Leone - Valo Velho } & \\
\hline & Qui-quadrado & Valor de $p$ & \\
\hline Amigadalite & 2,72 & 0,44 & \\
\hline Asma & 1,20 & 0,75 & \\
\hline Diabetes & 2,98 & 0,39 & as áreas/UBSs \\
\hline Dor e outras do ciclo menstrual & 1,22 & 0,75 & diferem com \\
\hline HAS & 9,94 & 0,02 & signimicancia \\
\hline Nasofaringite & 2,99 & 0,39 & quanto à \\
\hline Otite & 3,15 & 0,37 & freqüência de \\
\hline Puericultura & 1,07 & 0,78 & HAS e sinusite \\
\hline Sinusite & 8,84 & 0,03 & \\
\hline Vulvovaginite & 1,86 & 0,60 & \\
\hline
\end{tabular}

$\mathrm{HD}=$ hipótese diagnóstica e HDE $=\mathrm{HD}$ escolhida 24 ignorados $(1,4 \%)$

A seguir, utilizando o instrumental analítico da metanálise, verificou-se a influência e o comportamento de cada uma das ocorrências escolhidas em relação às áreas/UBSs tomadas duas a duas. As figuras 4 a 9 apresentam os relatórios padronizados desse procedimento, contendo a quantidade das HDEs e HDs demais propiciadas por cada uma das ocorrências escolhidas, como se estas fossem, no modelo mais comum de utilização da metanálise, estudos a serem agregados. Pode-se observar que há uma pequena diferença entre o odds ratio calculado com a soma simples dos casos HDEs e HDs demais, conforme tabela 15, e os valores calculados pelo método estatístico da metanálise, este mais confiável, conforme discutido no capítulo "Método". Das seis comparações realizadas, três apresentaram medida-sumário significativa e três não tiveram significância. A tabela 20 , após as figuras, resume os valores de odds ratio de cada ocorrência e o odds ratio como medida-sumário, todos calculados com a técnica da metanálise, segundo pares de áreas/UBSs. 


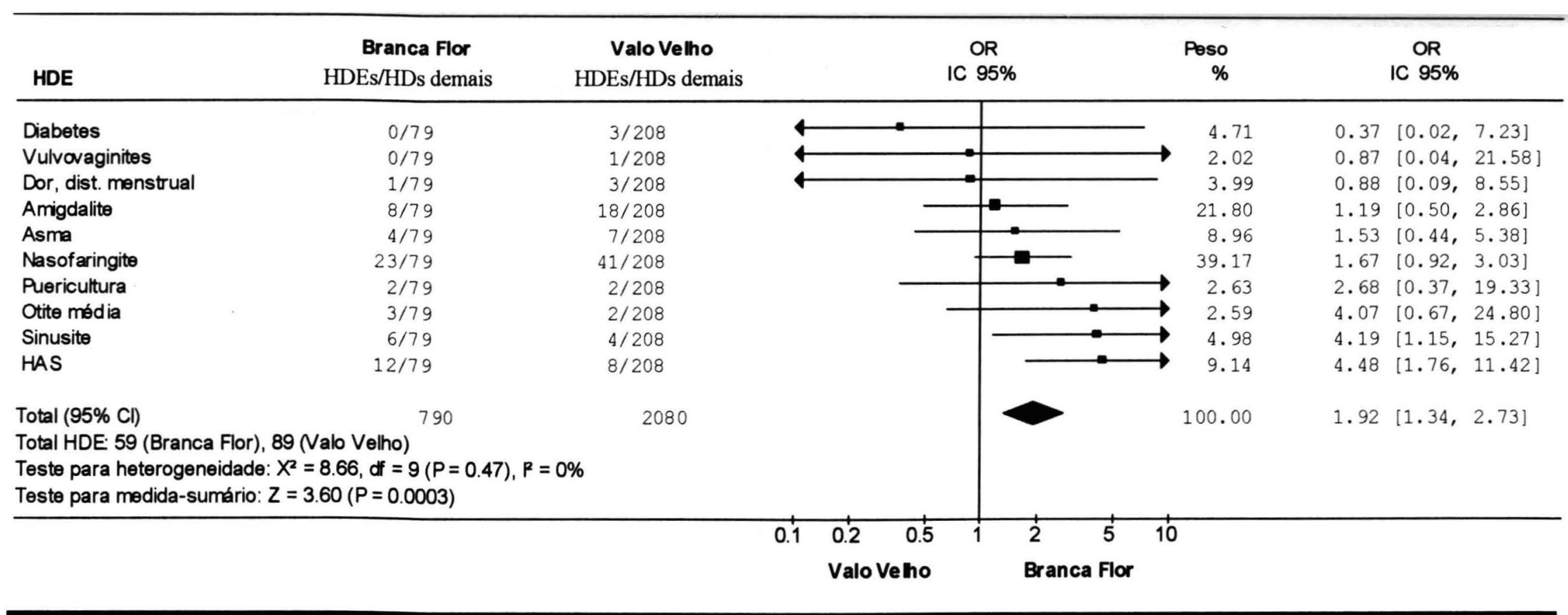

Figura 4 - Metanálise da contribuição de cada uma das HDEs no cálculo da medida-sumário de odds ratio, segundo comparação entre as áreas/UBSs de procedência Branca Flor e Valo Velho. Itapecerica da Serra, 2004.

\section{Legenda:}

HDEs = hipóteses diagnósticas de pessoas atendidas no Pronto-Socorro Central de Itapecerica da Serra, escolhidas para verificação da possibilidade de serem usadas como eventos sentinelas para monitorar as UBSs e procedentes de uma das áreas/UBSs em estudo (obs.: no conceito de chance $=$ numerador $)$.

HDs demais = demais hipóteses diagnósticas ocorridas nas mesmas circunstâncias (obs.: no conceito de chance $=$ denominador) .

$\mathbf{O R}=1,92 \rightarrow$ significa que a chance de ocorrência de HDEs procedente da área/UBS Branca Flor é 1,92 vez maior do que a chance de HDEs procedente da área/UBS Valo Velho. Considerando IC95\%, o valor de OR tem significância estatística. 


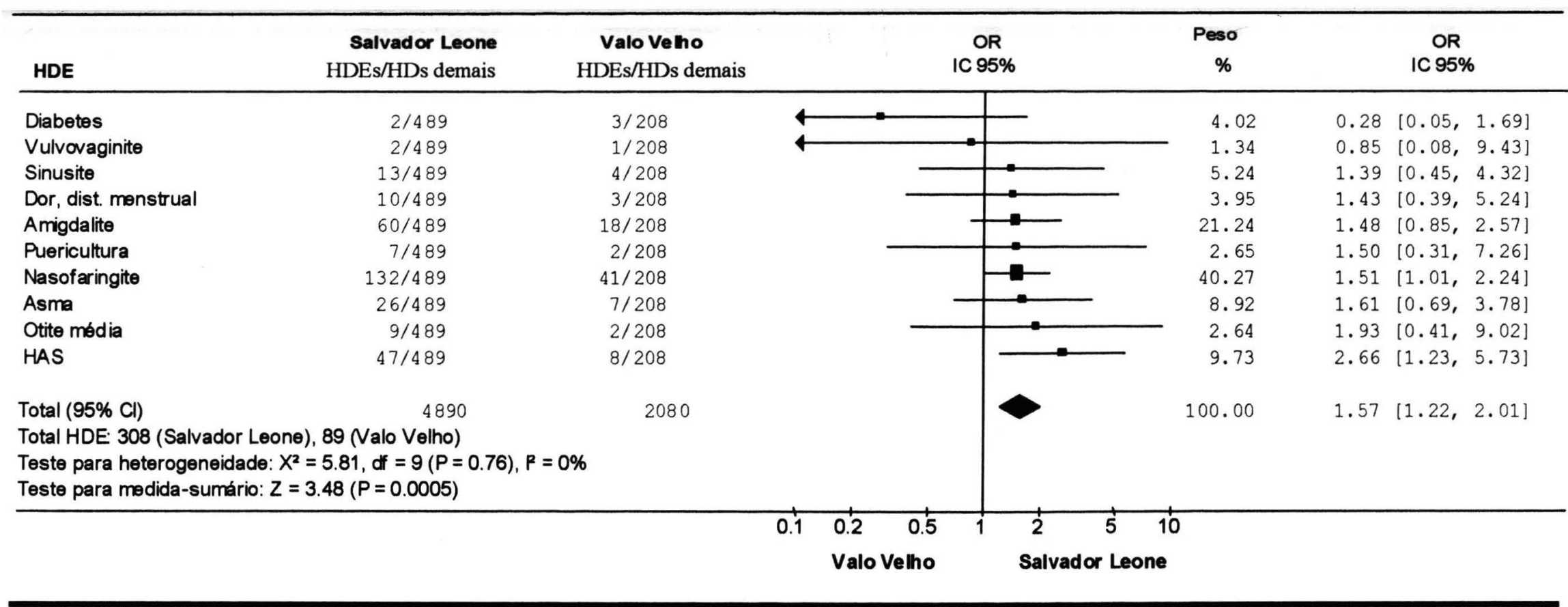

Figura 5 - Metanálise da contribuição de cada uma das HDEs no cálculo da medida-sumário de odds ratio, segundo comparação entre as áreas/UBSs de procedência Salvador Leone e Valo Velho. Itapecerica da Serra, 2004.

\section{Legenda:}

HDEs = hipóteses diagnósticas de pessoas atendidas no Pronto-Socorro Central de Itapecerica da Serra, escolhidas para verificação da possibilidade de serem usadas como eventos sentinelas para monitorar as UBSs e procedentes de uma das áreas/UBSs em estudo (obs. : no conceito de chance $=$ numerador) .

HDs demais = demais hipóteses diagnósticas ocorridas nas mesmas circunstâncias (obs.: no conceito de chance $=$ denominador $)$.

$\mathbf{O R}=1,57 \rightarrow$ significa que a chance de ocorrência de HDE procedente da área/UBS Salvador Leone é 1,57 vez maior do que a chance de HDEs procedente da área/UBS Valo Velho. Considerando IC95\%, o valor de OR tem significância estatística. 


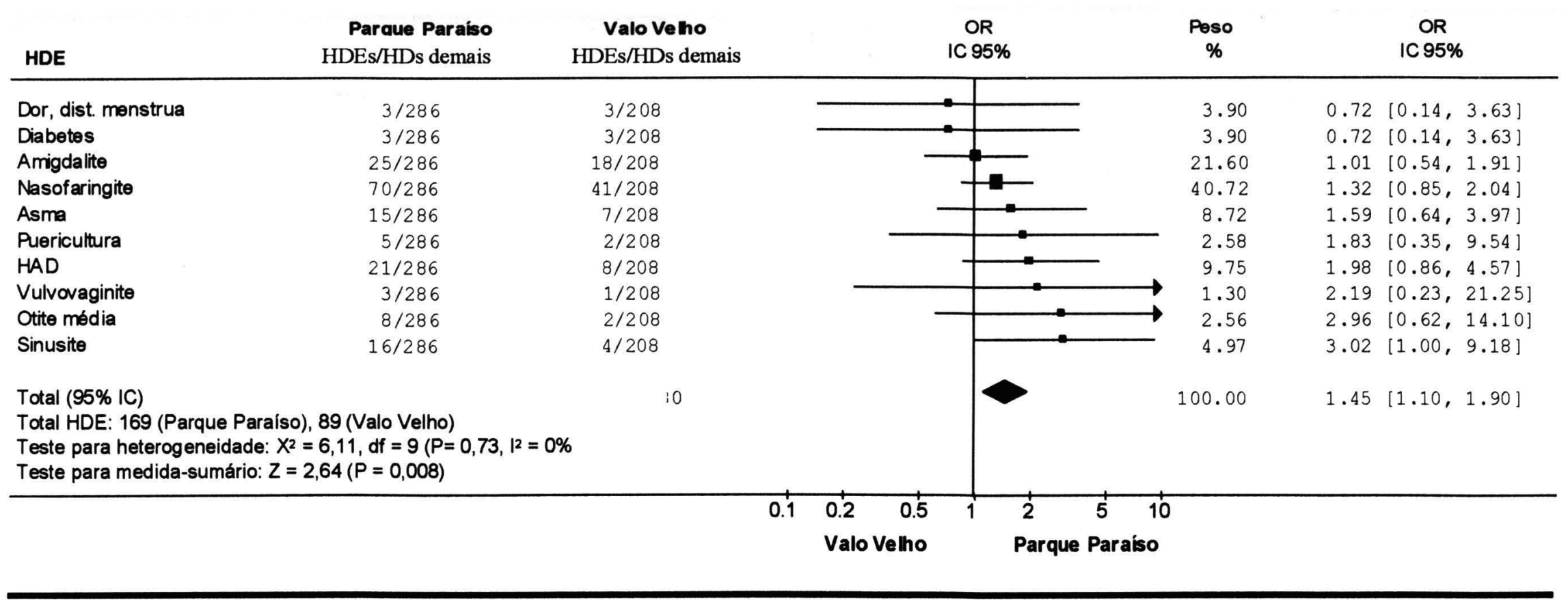

Figura 6 - Metanálise da contribuiçăo de cada uma das HDEs no cálculo da medida-sumário de odds ratio, segundo comparação entre as áreas/UBSs de procedência Parque Paraíso e Valo Velho. Itapecerica da Serra, 2004.

\section{Legenda:}

HDEs = hipóteses diagnósticas de pessoas atendidas no Pronto-Socorro Central de Itapecerica da Serra, escolhidas para verificação da possibilidade de serem usadas como eventos sentinelas para monitorar as UBSs e procedentes de uma das áreas/UBSs em estudo (obs.: no conceito de chance $=$ numerador).

HDs demais = demais hipóteses diagnósticas ocorridas nas mesmas circunstâncias (obs.: no conceito de chance $=$ denominador)

$\mathbf{O R}=1,45 \rightarrow$ significa que a chance de ocorrência de HDEs procedente da área/UBS Parque Paraíso é 1,45 vez maior do que a chance de HDEs procedente da área/UBS Valo Velho. Considerando IC $95 \%$, o valor de OR tem significância estatística. 


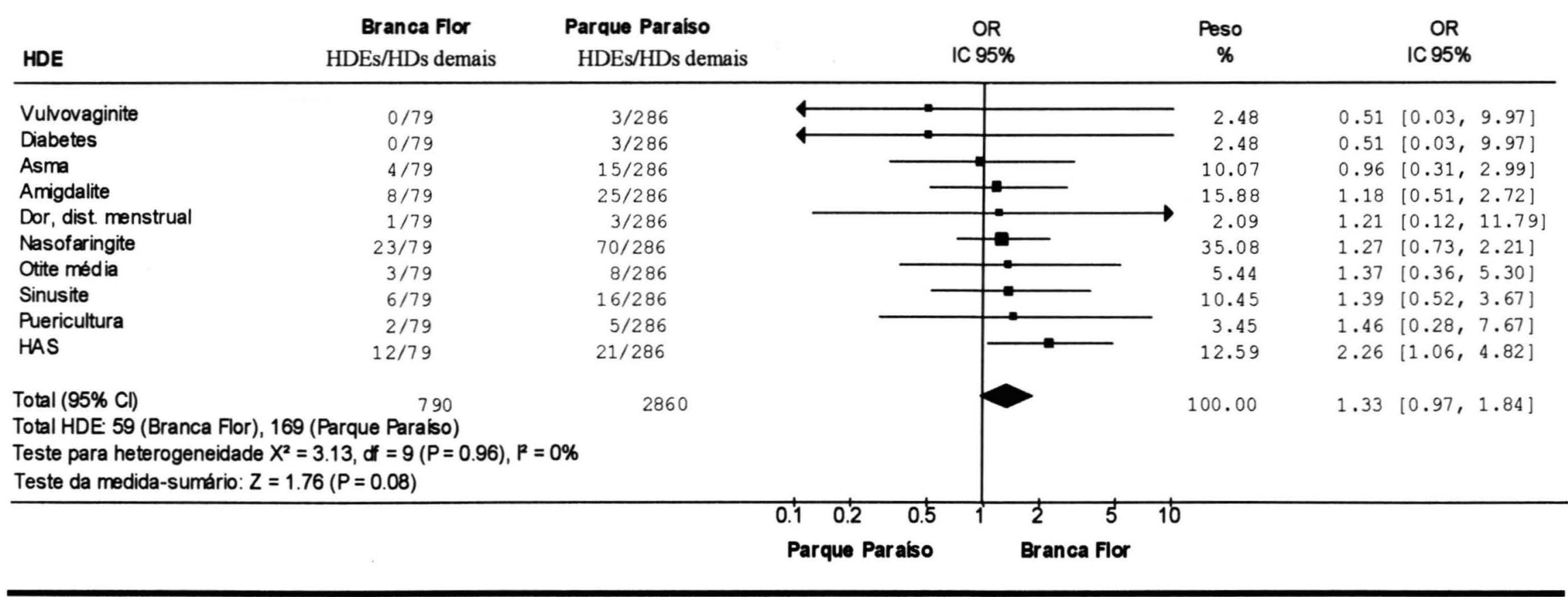

Figura 7 - Metanálise da contribuição de cada uma das HDEs no cálculo da medida-sumário de odds ratio, segundo comparação entre as áreas/UBSs de procedência Branca Flor e Parque Paraíso. Itapecerica da Serra, 2004.

\section{Legenda:}

HDEs = hipóteses diagnósticas de pessoas atendidas no Pronto-Socorro Central de Itapecerica da Serra, escolhidas para verificação da possibilidade de serem usadas como eventos sentinelas para monitorar as UBSs e procedentes de uma das áreas/UBSs em estudo (obs.: no conceito de chance $=$ numerador).

HDs demais = demais hipóteses diagnósticas ocorridas nas mesmas circunstâncias (obs.: no conceito de chance $=$ denominador) .

$\mathbf{O R}=1,33 \rightarrow$ significa que a chance de ocorrência de HDEs procedente da área/UBS Branca Flor é 1,33 vez maior do que a chance de HDEs procedente da área/UBS Parque Paraíso. Considerando IC95\%, o valor de OR não tem significância estatística. 


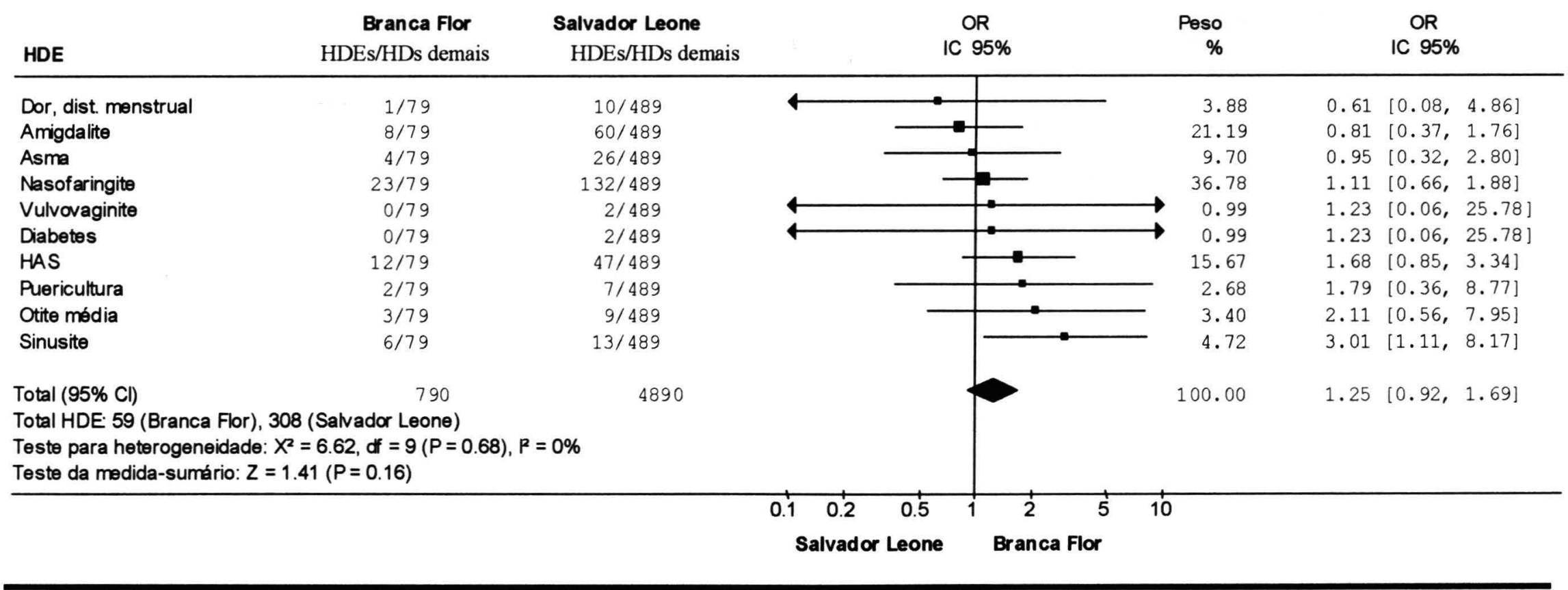

Figura 8 - Metanálise da contribuição de cada uma das HDEs no cálculo da medida-sumário de odds ratio, segundo comparação entre as áreas/UBSs de procedência Branca Flor e Salvador Leone. Itapecerica da Serra, 2004.

\section{Legenda:}

HDEs = hipóteses diagnósticas de pessoas atendidas no Pronto-Socorro Central de Itapecerica da Serra, escolhidas para verificação da possibilidade de serem usadas como eventos sentinelas para monitorar as UBSs e procedentes de uma das áreas/UBSs em estudo (obs.: no conceito de chance $=$ numerador).

HDs demais $=$ demais hipóteses diagnósticas ocorridas nas mesmas circunstâncias (obs.: no conceito de chance $=$ denominador $)$.

$\mathbf{O R}=1,25 \rightarrow$ significa que a chance de ocorrência de HDEs procedente da área/UBS Branca Flor é 1,25 vez maior do que a chance de HDEs procedente da área/UBS Salvador Leone. Considerando IC95\%, o valor de OR não tem significância estatística. 


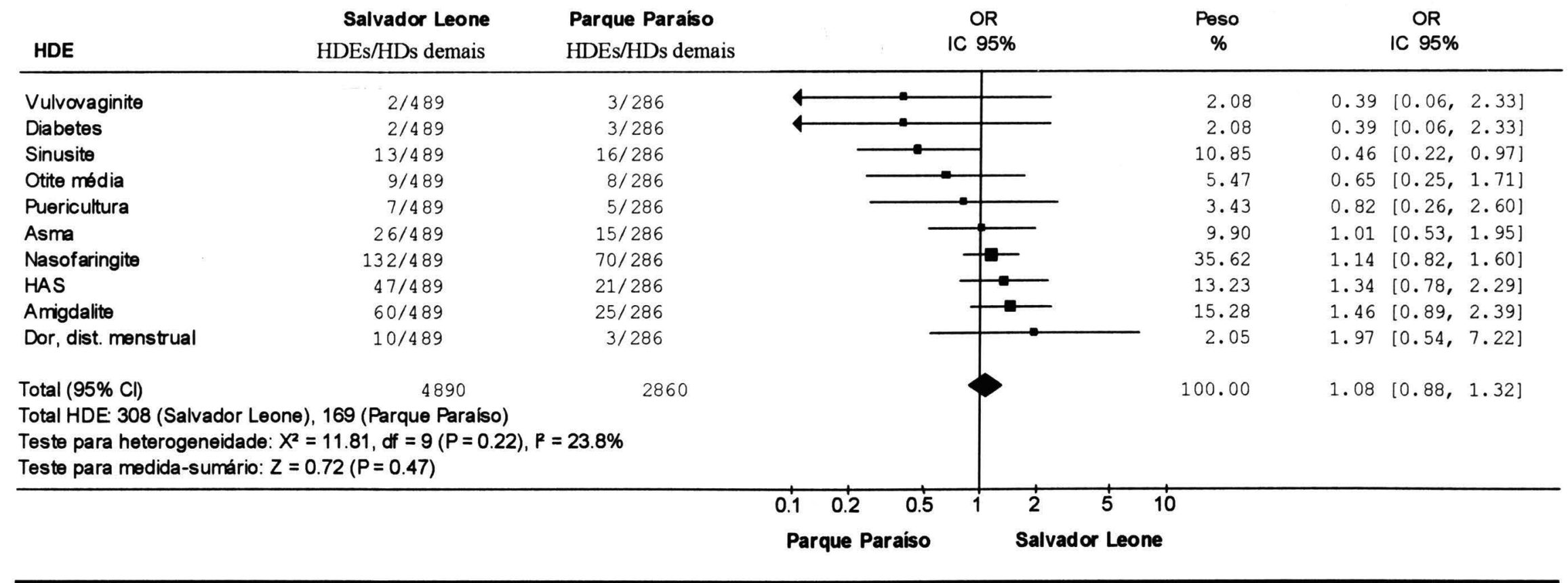

Figura 9 - Metanálise da contribuição de cada uma das HDEs no cálculo da medida-sumário de odds ratio, segundo comparação entre as áreas/UBSs de procedência Salvador Leone e Parque Paraíso. Itapecerica da Serra, 2004.

\section{Legenda:}

HDEs = hipóteses diagnósticas de pessoas atendidas no Pronto-Socorro Central de Itapecerica da Serra, escolhidas para verificação da possibilidade de serem usadas como eventos sentinelas para monitorar as UBSs e procedentes de uma das áreas/UBSs em estudo (obs.: no conceito de chance $=$ numerador).

HDs demais = demais hipóteses diagnósticas ocorridas nas mesmas circunstâncias (obs. : no conceito de chance = denominador).

$\mathbf{O R}=1,08 \rightarrow$ significa que a chance de ocorrência de HDEs procedente da área/UBS Salvador Leone é 1,08 vez maior do que a chance de HDEs procedente da área/UBS Parque Paraíso. Considerando IC95\%, o valor de OR não tem significância estatística. 
Tabela 20 - Resumo dos valores de odds ratio de cada uma das HDEs, segundo áreas/UBSs tomadas duas a duas, e valor da medida-sumário de odds ratio, caloulados oom a téonica da metanálise. PS Contral, Itapecorica da Serra, 2004.

\begin{tabular}{|c|c|c|c|c|c|c|c|c|}
\hline \multirow{2}{*}{ HDE } & \multicolumn{6}{|c|}{ áreas/UBSs tomadas duas a duas"* } & \multirow{2}{*}{$\begin{array}{l}\text { ne de } \\
\text { contradic des }\end{array}$} & \multirow{2}{*}{$\begin{array}{c}n^{0} \text { de } \\
\text { significativos }\end{array}$} \\
\hline & $\begin{array}{l}\text { B. Flor * } \\
\text { V. Velho }\end{array}$ & $\begin{array}{l}\text { S. Leone * } \\
\text { V. Velho }\end{array}$ & $\begin{array}{l}\text { P. Paraiso * } \\
\text { V. Velho }\end{array}$ & $\begin{array}{l}\text { B. Flor * } \\
\text { P. Paraiso }\end{array}$ & $\begin{array}{l}\text { B. Flor * } \\
\text { S. Leone }\end{array}$ & $\begin{array}{l}\text { S. Leone " } \\
\text { P. Paraiso }\end{array}$ & & \\
\hline Amigdalite & 1,19 & 1,48 & 1,01 & 1,18 & (?) 0,81 & 1,46 & 1 & 0 \\
\hline Asma & 1,53 & 1,61 & 1,59 & (8) 0,96 & (?) 0,95 & 1,01 & 2. & 0 \\
\hline Diabetes & (?) 0,37 & (?) 0,28 & (?) 0,72 & (?) 0,51 & 1,23 & (?) 0,39 & 6. & 0 \\
\hline Dor, dist. menstrual & (?) 0,88 & 1,43 & (2) 0,72 & 1,21 & (?) 0,61 & 1,97 & 3. & 0 \\
\hline HAS & 4,48 & 2,66 & 1,98 & 2,26 & 1,68 & 1,34 & 0 & 3 \\
\hline Nasofaringite & 1,67 & 1,51 & 1,32 & 1,27 & 1,11 & 1,14 & 0 & 1 \\
\hline Otite média & 4,07 & 1,93 & 2,96 & 1,37 & 2,11 & (7) 0,65 & 1 & 0 \\
\hline Puericultura & 2,68 & 1,50 & 1,83 & 1,46 & 1,79 & (2) 0,82 & 1. & 0 \\
\hline Sinusite & 4,19 & 1,39 & 3,02 & 1,39 & 3,01 & 0,46 & 1 & 3 \\
\hline Vulvovaginite & (?) 0,87 & (?) 0,85 & 2,19 & (?) 0,51 & 1,23 & (7) 0,39 & 4. & 0 \\
\hline medida-sumário & 1,92 & $\Rightarrow 1,57$ & 1,45 & 1,33 & 1,25 & 1,08 & & 3 \\
\hline
\end{tabular}

$\mathrm{HD}=$ hipótese diagnóstica e HDE $=\mathrm{HD}$ escolhida 24 ignorados $(1,4 \%)$

(3) apontou para o sentido oposto da medida-sumário

valor estatisticamente significante

** Exemplificando com amigdalite e o primeiro par de UBSs: 1,19 significa que a chance da ocorrência de amigdalite é 1,19 vez maior na área/UBS B. Flor quando comparada com a Valo Velho. 


\subsection{As entrevistas com as pessoas diagnosticadas com uma das hipóteses} diagnósticas escolhidas para estudo

Das 625 pessoas com uma das HDEs em estudo, $113(18,1 \%)$ foram entrevistadas. A distribuição dos entrevistados segundo os dias da semana mostrou maior número de entrevistas realizadas na quinta-feira (tabela 21).

Tabela 21 - Frequiência dos atendidos com HDE entrevistados, segundo dia da semana. PS Central, Itapecerica da Serra, 2004.

\begin{tabular}{|c|c|c|c|c|c|c|}
\hline \multirow{3}{*}{ Dia da semana } & \multicolumn{6}{|c|}{ Entrevistados } \\
\hline & \multicolumn{2}{|c|}{ Sim } & \multicolumn{2}{|c|}{ Nāo } & \multicolumn{2}{|l|}{ Total } \\
\hline & $n$ & $\%$ & $n$ & $\%$ & $\mathbf{n}$ & $\%$ \\
\hline segunda-feira & 17 & 12,3 & 121 & 87,7 & 138 & 100,0 \\
\hline terça-feira & 26 & 20,6 & 100 & 79,4 & 126 & 100,0 \\
\hline quarta-feira & 20 & 18,3 & 89 & 81,7 & 109 & 100,0 \\
\hline quinta-feira & 35 & 25.0 & 105 & 75,0 & 140 & 100,0 \\
\hline sexta-feira & 15 & 13,4 & 97 & 86,6 & 112 & 100,0 \\
\hline Total & 113 & 18,1 & 512 & 81,9 & 625 & 100,0 \\
\hline
\end{tabular}

Entretanto, em relação às áreas/UBSs de procedência das pessoas atendidas, não foi constatada diferença estatística significante (tabela 22).

Tabela 22 - Freqüência dos atendidos com HDE entrevistados, segundo área/UBS de procedência. PS Central, Itapecerica da Serra, 2004.

\begin{tabular}{|c|c|c|c|c|c|c|}
\hline \multirow{3}{*}{ Área/UBS } & \multicolumn{6}{|c|}{ Entrevistados } \\
\hline & \multicolumn{2}{|c|}{ Sim } & \multicolumn{2}{|c|}{ Não } & \multicolumn{2}{|l|}{ Total } \\
\hline & $n$ & $\%$ & $\mathbf{n}$ & $\%$ & $n$ & $\%$ \\
\hline Branca Flor & 11 & 18,6 & 48 & 81,4 & 59 & 100,0 \\
\hline Parque Paraiso & 25 & 14,8 & 144 & 85,2 & 169 & 100,0 \\
\hline Salvador Leone & $\mathfrak{6}$ & 20,5 & 245 & 79,5 & 308 & 100,0 \\
\hline Valo Velho & 14 & 15,7 & 75 & 84,3 & 89 & 100,0 \\
\hline Total & 113 & 18,1 & 512 & 81,9 & 625 & 100,0 \\
\hline
\end{tabular}


Em relação às ocorrências em estudo, há maior número de entrevistados com a hipótese diagnóstica de nasofaringite, e puericultura foi relativamente a mais entrevistada (tabela 23).

Tabela 23 - Frequiéncia dos atendidos com HDE entrevistados, segundo cada uma das HDEs escolhidas para estudo. PS Central, Itapecerica da Serra, 2004.

\begin{tabular}{|c|c|c|c|c|c|c|}
\hline \multirow{3}{*}{ Áreanus } & \multicolumn{6}{|c|}{ Entrevistados } \\
\hline & \multicolumn{2}{|c|}{ Sim } & \multicolumn{2}{|c|}{ Não } & \multicolumn{2}{|l|}{ Total } \\
\hline & $\mathbf{n}$ & $\%$ & $\mathbf{n}$ & $\%$ & $\mathbf{n}$ & $\%$ \\
\hline Amigdalite & 11 & 9,9 & 100 & 90,1 & 111 & 100,0 \\
\hline Asma & 9 & 17,3 & 43 & 82,7 & 52 & 100,0 \\
\hline Diabetes & 1 & 12,5 & 7 & 87,5 & 8 & 100,0 \\
\hline Dor e outras do ciclo menstrual & - & - & 17 & 100,0 & 17 & 100,0 \\
\hline HAS & 12 & 13,6 & 76 & 86,4 & 88 & 100,0 \\
\hline Nasofaringite & 71 & 26,7 & 195 & 73,3 & 266 & 100,0 \\
\hline Otite média & 2 & 9,1 & 20 & 90,9 & 22 & 100.0 \\
\hline Puericultura & 5 & 31,3 & 11 & 68,8 & 16 & 100,0 \\
\hline Sinusite & 1 & 2,6 & 38 & 97,4 & 39 & 100,0 \\
\hline Vulvovaginites & 1 & 16,7 & 5 & 83,3 & 6 & 100,0 \\
\hline Total & 113 & 18,1 & 512 & 81,9 & 625 & 100,0 \\
\hline
\end{tabular}

A tabela 24 compara a distribuição da variável sexo entre o total das pessoas atendidas com uma das HDEs e as 113 pessoas entrevistadas. Observa-se que o grupo de entrevistados não se distribui com diferença significativa em relação à variável sexo.

Tabela 24 - Distribuição dos entrevistados e do total de atendidos com HDE, segundo sexo. PS Central, Itapecerica da Serra, 2004.

\begin{tabular}{cc|cccccccc}
\hline \multirow{2}{*}{ Sexo } & Branca Flor & $\begin{array}{c}\text { Parque } \\
\text { Paraiso }\end{array}$ & $\begin{array}{c}\text { Salvador } \\
\text { Leone }\end{array}$ & \multicolumn{2}{c}{$\begin{array}{c}\text { Valo } \\
\text { Velho }\end{array}$} & \multicolumn{2}{c}{ Total de } & \multicolumn{2}{c}{ Total de HDE } \\
& & $\%$ & $\%$ & $\%$ & $\%$ & $n$ & $\%$ & $n$ & $\%$ \\
\hline \hline Feminino & 63,6 & 44,0 & 49,2 & 71,4 & 59 & 52,2 & 357 & 57,1 \\
Masculino & & 36,4 & 56,0 & 50,8 & 28,6 & 54 & 47,8 & 268 & 42,9 \\
\hline & Total & 100,0 & 100,0 & 100,0 & 100,0 & 113 & 100,0 & 625 & 100,0 \\
\hline
\end{tabular}

$X^{2}$ para diferença de sexo entre o grupo dos entrevistados e $\circ$ grupo HDE total $=0,94$ e valor de $p=0,33$ 
A tabela 25 compara, da mesma forma que a anterior, a variável idade categorizada em três grupos etários. A maior parte dos entrevistados foi composta pelos acompanhantes dos menores na faixa $0-15$ anos atendidos.

Tabela 25 - Distribuição dos entrevistados e do total de atendidos com HDE, segundo grupo etário. PS Central, Itapecerica da Serra, 2004.

\begin{tabular}{r|ccccccccc}
\hline \multirow{2}{*}{ Grupo etário } & Branca Flor & $\begin{array}{c}\text { Parque } \\
\text { Paraiso }\end{array}$ & $\begin{array}{c}\text { Salvador } \\
\text { Loone }\end{array}$ & \multicolumn{2}{c}{$\begin{array}{c}\text { Valo } \\
\text { Velho }\end{array}$} & \multicolumn{2}{c}{ Total de } & \multicolumn{2}{c}{ Total de HDE } \\
& $\%$ & $\%$ & $\%$ & $\%$ & $\mathbf{n}$ & $\%$ & $\mathbf{n}$ & $\boldsymbol{\%}$ \\
\hline Criança $(0-15)$ & 72,7 & 80,0 & 77,8 & 57,1 & 85 & 75,2 & 309 & 49,4 \\
Jovem $(15 \mid-21)$ & - & 4,0 & 3,2 & - & 3 & 2,7 & 42 & 6,7 \\
Adulto $(21-)$ & 27,3 & 16,0 & 19,0 & 42,9 & 25 & 22,1 & 274 & 43,8 \\
\hline Total & 100,0 & 100,0 & 100,0 & 100,0 & 113 & 100,0 & 625 & 100,0 \\
\hline
\end{tabular}

$X^{2}$ para diferença de grupo etário entre o grupo dos entrevistados e o grupo HDE total $=25,65$ e valor de $p<0,001$

A tabela 26 apresenta a distribuição das características ocupação, anos de estudo e de residência atual. No caso dessas características, foram considerados os dados dos acompanhantes quando a pessoa atendida era criança ou adolescente menor de 15 anos. Em relação a todas essas características, as quatro áreas/UBSs apresentam uma similaridade acentuada. Destacam-se as diferenças dos anos de residência das pessoas com procedência da área do Branca Flor e a freqüência da ocupação "Do lar" entre os procedentes da área/UBS Salvador Leone.

Tabela 26 - Distribuição das principais ocupaçōes, média de anos de estudo e média de anos na residência atual dos entrevistados, segundo área/UBS de procedência. PS Central, Itapecerica da Serra, 2004.

\begin{tabular}{|c|c|c|c|c|c|c|}
\hline \multirow[t]{2}{*}{ Característica } & \multirow{2}{*}{$\begin{array}{c}\text { Branca Flor } \\
\qquad\end{array}$} & \multirow{2}{*}{$\begin{array}{c}\text { Parque } \\
\text { Paraiso } \\
\%\end{array}$} & \multirow{2}{*}{$\begin{array}{r}\begin{array}{r}\text { Salvador } \\
\text { Leone }\end{array} \\
\%\end{array}$} & \multirow{2}{*}{$\begin{array}{l}\text { Valo } \\
\text { Velho } \\
\%\end{array}$} & \multicolumn{2}{|c|}{$\begin{array}{r}\text { Total de } \\
\text { entrevistados }\end{array}$} \\
\hline & & & & & $\mathbf{n}$ & $\%$ \\
\hline \multicolumn{7}{|l|}{ Ocupaçäo } \\
\hline Do lar & 30,0 & 29,2 & 45,2 & 35,7 & 43 & 38,1 \\
\hline Desempregado & 30,0 & 33,3 & 24,2 & 28,6 & 30 & 26,5 \\
\hline Doméstica e caseiro & 20,0 & - & 6,5 & 7,1 & 7 & 6,2 \\
\hline Aposentado & - & 8,3 & 4,8 & - & 5 & 4,4 \\
\hline Demais & 20,0 & 29,2 & 19,4 & 28,6 & 28 & 24,8 \\
\hline Total & 100,0 & 100,0 & 100,0 & 100,0 & 113 & 100,0 \\
\hline Média de anos de estudo & 7 & 7 & 7 & 8 & & 7 \\
\hline $\begin{array}{l}\text { Média de anos na } \\
\text { residência atual }\end{array}$ & 15 & 9 & 11 & 9 & & 11 \\
\hline
\end{tabular}


A tabela 27 resume algumas características de uso dos serviços básicos e de prontosocorro por parte das pessoas entrevistadas. Destaca-se que $88 \%$ dos entrevistados costumam procurar atendimento nas UBSs e que dois terços deles estiveram durante o último ano ao menos uma vez em consulta médica. Ressalte-se ainda que $75 \%$ dos entrevistados eram acompanhantes de crianças e adolescentes menores de 15 anos atendidas, fato que pode induzir tendenciosidade nesses resultados. De qualquer forma, a alta freqüência relativa dessa faixa etária no atendimento geral do pronto-socorro é parte de um padrão de expressiva utilização dos serviços assistenciais por essas populações. Entretanto, é muito interessante verificar que apenas $22 \%$ procuraram a UBS pelo problema atual antes de procurar atendimento no pronto-socorro.

Tabela 27 - Freqüência de algumas caraterísticas de uso dos serviços de saúde por parte dos entrevistados, segundo áreas/UBSs escolhidas. PS Central, Itapecerica da Serra, 2004.

\begin{tabular}{|c|c|c|c|c|c|c|}
\hline Tipo de uso dos serviços de saúde & $\begin{array}{c}\text { Branca Flor } \\
\% \\
\end{array}$ & $\begin{array}{c}\text { Parque } \\
\text { Paraiso } \\
\%\end{array}$ & $\begin{array}{c}\text { Salvador } \\
\text { Leone } \\
\%\end{array}$ & $\begin{array}{l}\text { Valo } \\
\text { Velho } \\
\% \\
\end{array}$ & $\begin{array}{l}\text { Total } \\
\mathbf{n} \\
\end{array}$ & $\%$ \\
\hline Costuma procurar atendimento na UBS & 90,9 & 88,0 & 87,3 & 92,9 & 100 & 88,5 \\
\hline Usa a UBS mais próxima de casa & 100,0 & 96,0 & 93,7 & 92,9 & 107 & 94,7 \\
\hline Tem matricula na UBS & 100,0 & 92,0 & 87,3 & 92,9 & 102 & 90,3 \\
\hline Esteve na UBS este ano para consulta médica & 100,0 & 76,0 & 55,6 & 78,6 & 76 & 67,3 \\
\hline Há quantos meses foi à UBS & 3,0 & 3,0 & 2,0 & 2,0 & & \\
\hline Procurou a UBS pelo problema atual & 18,2 & 36,0 & 15,9 & 28,6 & 25 & 22,1 \\
\hline \multirow[t]{2}{*}{ tempos médios } & Branca Flor & $\begin{array}{l}\text { Parque } \\
\text { Paraiso }\end{array}$ & $\begin{array}{r}\text { Salvador } \\
\text { Leone }\end{array}$ & $\begin{array}{r}\text { Valo } \\
\text { Velho }\end{array}$ & Total & \\
\hline & média & média & média & média & média & \\
\hline $\begin{array}{r}\text { Média de meses desde a última consulta médica na UBS } \\
\text { daqueles que foram no ano }\end{array}$ & 2,7 & 3,2 & 2,1 & 1,8 & 2,5 & \\
\hline Média de dias desde o inicio da queixa & 16,8 & 4,3 & 8,9 & 3,2 & 8,0 & \\
\hline $\begin{array}{r}\text { Média de outros comparecimentos no PSC, } \\
\text { nos últimos } 3 \text { meses }\end{array}$ & 2,3 & 1,0 & 1,5 & 1,3 & 1,4 & \\
\hline
\end{tabular}

Os entrevistados foram indagados, para uma resposta aberta, sobre uma de três perguntas alternativas, mas que visavam todas conhecer a motivação da utilização do PS. Foi solicitado às pessoas que falassem sobre as razões de terem ido à UBS e depois ao PS, ou de terem ido ao PS sem tentar a UBS, ou ainda de não usarem os serviços da UBS. As respostas foram organizadas em seis categorias, conforme o sentido fundamental da motivação enunciada. 


\section{Desconfiança em relação ao atendimento recebido na UBS, anseio por} exames ou medicações. Reuniram-se nessa categoria os discursos em que a motivação para procurar atendimento no PS era obter resposta a dúvidas, ou desconfiança em relação ao atendimento oferecido/recebido na unidade básica, ou insatisfação pela não-realização de exames ou pela não-administração de medicações na UBS. Essa primeira categoria de motivação pode ser exemplificada com alguns dos discursos:

- Passei na consulta no posto e depois vim para cá. Achei que não resolveu nada...

- A enfermeira que avaliou falou que não tinha nada...

- Aqui no PS dão medicamento na hora, qualquer coisa faz exame.

- Porque aqui no PS eu já tomo inalação. Passei mais para tirar uma chapa da cabeça...

- Cansei de ir no posto. Vou lá, tomo injeção, a dor passa mais depois volta.

- No posto não ia dar injeção assim logo.

- Aqui tem medicação, RX na hora, eu prefiro trazer aqui mesmo.

- Acompanho a pressão lá no Posto, mas hoje deu vontade de vir no PS, tirar a dúvida.

- Fui lá, a médica atendeu, mas como o peito encheu e começou a tossir mais, resolvi vir aqui. Lá no posto se fosse eles não iam passar nada.

- Passei no pediatra que examinou e falou que era gripe. Mas fiquei meio desconfiada, ai resolvi trazer aqui.

2. Busca do PS não alternativa ao uso da UBS. Nesta categoria estão as pessoas que não usam regularmente a UBS por terem médico particular/convênio, os "peregrinos" de serviços de saúde que não conseguem perder a oportunidade ao estar passando por perto e as pessoas premidas por sensação de temor das possíveis conseqüências dos seus sintomas. É bom lembrar que os discursos originam-se apenas de usuários diagnosticados com um dos eventos em estudo. Exemplos:

- Começou com febre muito alta ai resolvi vir aqui.

- Ela foi operada do coração, fiquei preocupada com a febre e trouxe ela aqui.

- Vim trazer minha irmã que quebrou o dedo e aproveitei para passar o menino.

- Tinha que vir no banco ai aproveitei para dar uma passada. 
- Passei no médico do trabalho que identificou pressão alta e encaminhou para cá.

- Não uso porque uso o médico particular.

- Fui atendida no posto da Samcil, tomei remédio, mas não estava melhorando então resolvi vir aqui.

3. Falta de médico na UBS. Nesta categoria foram incluídas as pessoas que mencionaram a inexistência de médico na UBS no momento necessário. A afirmação foi checada com a grade de horários dos médicos das UBSs, e verificou-se que as informações dos usuários revelaram um bom conhecimento dos dias, períodos e especialidades médicas não disponíveis. Exemplos:

- Passei lá, mas a médica não ia hoje. Aí vim direto ao PS...

- Estive lá, passei no acolhimento, mas não tinha pediatra hoje...

- Passei lá, mas hoje não tinha pediatra. Só tem às $2^{a s}$., $4^{a s}$. e $6^{\text {as. }}$., ai mandaram vir ao PS.

- Passei lá no posto, e ai a moça falou que só tem médico de manhã, à tarde não tem.

- Ontem lá nem médico tinha..

- Não fui na UBS porque hoje não tem pediatra de manhã.

4. Dificuldade de obtenção de vaga no dia. Esta categoria engloba as respostas que evidenciam um conjunto de dificuldades ou obstáculos que, associados ou não à falta objetiva de vagas no dia, interpõe-se entre o usuário e o início do cuidado na UBS. Exemplos:

- No posto também eu gosto, mas aqui passa rápido. No posto não passa rápido.

- Cheguei cedo. A balconista falou que não tinha mais vaga.

- Cheguei às 6 horas. Esperei para ser atendida. No balcão mandaram esperar e depois falaram que não tinha mais vaga.

- Não tinha vaga, as médicas estavam lotadas.

- Cheguei antes do posto abrir. A moça da ficha falou que não tinha encaixe. Deixei marcado para daqui um mês.

- Trabalho e não posso ir lá tentar a vaga do dia.

- Não dava mais para tentar vaga do dia, por que lá tem que chegar muito cedo. 
- No posto não consegue passar no médico.Nunca tentei. A vizinha falou que tem que esperar sobrar uma vaga.

- Não tem consulta na hora, mesmo acompanhando a pressão alta não consigo sem agendar.

- Agora com aquele negócio de acolhimento a gente tem que passar primeiro lá e só depois no médico. É muito raro a gente conseguir passar no médico no mesmo dia.

- Fica o dia inteiro aguardando vaga de bobeira e acaba não sendo atendido.

- Não passei lá porque lá só atende com consulta marcada, ou então tem que chegar às 6 horas da manhã para tentar uma vaga.

- No posto demora, aqui é melhor. Se tivesse ido no posto estaria lá até o meiodia.

- Aqui é mais rápido, no posto tinha que ir de madrugada, sair na friagem com ela.

- A gente chega lá fica e fica esperando. Venho direto para cá quando as crises (asma) são muito fortes.

- Lá é ruim para passar, tem que ir muito cedo, é muito frio para levar o bebê.

- Lá com um tal de acolhimento só passa se tem febre, se não tem, não passa.

5. Dificuldade para agendar consulta. Nesta categoria o discurso era de crítica às sistemáticas operacionais e organizacionais das UBSs, que na visão do usuário criam dificuldades para o agendamento. Exemplos:

- O acolhimento mandou marcar, ai no balcão falaram que agendamento só no dia 1 ou 23 do próximo mês.

- Fui agendar e eles falaram que só para janeiro (2 a 3 meses).

- Criança com 8 anos não marca mais no posto.

- Passei lá a última vez quando ele completou 1 ano, depois não tem mais acompanhamento.

- Como completou 1 ano é dificil passar no posto.

- Falaram que não tinha agenda aberta para pediatria e para ir passando até abrir a agenda. Tá muito dificil...

- Fui lá hoje de manhã e falaram que não está aberto para marcar consulta e que tem que tentar uma vaga às 6 horas da manhã.

- Dificil para conseguir. Quando marca é para 3 meses. Estou trabalhando e eles falam que tem que ficar esperando encaixe...

- Chego lá, dizem que a agenda abriu e já lotou, ai mandam vir outro dia. 
6. Orientações restritivas. Grupo que mencionou o fato de se disseminarem aos usuários, de maneira formal ou informal, orientações muitas vezes contraditórias, que vão estabelecendo um padrão restritivo de uso dos serviços. Essas orientações são alvo de críticas por distanciarem-se das expectativas dos usuários. Exemplos:

- Não consegui transferir a matricula para o posto (mudou de Embu). Passei lá, eles não deixam a gente falar, não dão orientação nenhuma.

- Outro dia passei lá com febre, atenderam, mas falaram que quando acontecer isso outra vez, problema de febre, é para ir direto ao PS. Falaram que lá só cuida de rotina e que quando ficar grave é para ir ao PS.

- A médica falou que quando é problema assim (IVAS) é para ir direto no PS. Acho que quando chega criança ruim no posto eles podiam ver! Agora trago direto aqui.

- Falam que aqui é o local para trazer criança com crise de asma. Que lá não é e não tem médico para isso.

- Lá no posto eles não atendem quando está com dor de garganta. Falam que em caso de febre, cólica, dor de cabeça tem que vir ao PS.

- Eles falam que quando não é rotina é para vir ao PS.

- Quando é febre, no posto eles falam para procurar o PS mais próximo.

- O pediatra acha ruim, fala que emergência é no PS.

- Quando a gente vai no Posto com uma queixa mais grave eles mandam vir aqui. Então para não gastar dinheiro a gente vem direto.

- Já tentei outra vez e não tinha vaga. Falam que só é para ir se estiver passando muito mal.

- Tem que estar muito grave para passar no médico lá.

- Só com gripe lá não passa, só em caso de muita urgência.

A tabela 28 apresenta a distribuição das seis categorias discursivas, segundo duas situações, não excludentes, vividas pelos entrevistados: comparecimento a pelo menos uma consulta na UBS no último ano e procura da UBS pelo problema atual. As quatro últimas categorias discursivas, como se referem especificamente a facetas complementares de problemas na organização e no acesso aos serviços da UBS, foram agrupadas e apresentadas, também, em subtotal.

Observa-se que, dentre aqueles que procuraram atendimento na UBS pelo problema atual antes de procurar o pronto-socorro, as freqüências das categorias "falta de médico" e "vaga no dia" são as maiores e semelhantes, sendo que para os que não foram à UBS a 
maior justificativa é a "vaga no dia". Para os que foram à UBS no último ano, portanto têm experiência anterior de uso, a maior motivação para procurar o PS foi, também, o acesso no dia.

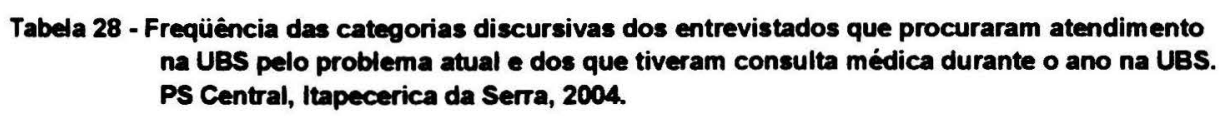
na UBS pelo problema atual e dos que tiveram consulta médica durante o ano na UBS. PS Central, Itapecerica da Serra, 2004.

\begin{tabular}{|c|c|c|c|c|c|c|}
\hline \multirow{2}{*}{ Categoria discursiva } & \multicolumn{3}{|c|}{$\begin{array}{l}\text { Consulta médica no ano } \\
\text { na UBS }\end{array}$} & \multicolumn{3}{|c|}{$\begin{array}{r}\text { Procurou atendimento na UBS } \\
\text { pelo problema atual }\end{array}$} \\
\hline & $\begin{array}{r}\text { Sim } \\
\end{array}$ & $\begin{array}{r}\text { Não } \\
\% \\
\end{array}$ & $\begin{array}{r}\text { Total } \\
\% \\
\end{array}$ & $\begin{array}{r}\operatorname{sim} \\
\%\end{array}$ & $\begin{array}{r}\text { Não } \\
\%\end{array}$ & $\begin{array}{r}\text { Total } \\
\%\end{array}$ \\
\hline Desconfiança, anseios & 11,7 & 8,6 & 10,7 & 20,0 & 8,0 & 10,6 \\
\hline Usa comvenio, peregrino/premencia & 11,7 & 20,0 & 14,4 & 4,0 & 17,0 & 14,2 \\
\hline Subtotal & 23,4 & 28,6 & 25,1 & 24,0 & 25,0 & 24,8 \\
\hline Falta de médico & 15,6 & 2,9 & 11,6 & 28,0 & 6,8 & 11,5 \\
\hline Vaga no dia & 51,9 & 37,1 & 47,3 & 28,0 & 53,4 & 47,8 \\
\hline Agendamento & 3,9 & 14,3 & 7,1 & 8,0 & 6,8 & 7,1 \\
\hline Orientaçăo restritiva & 5,2 & 17,1 & 8,9 & 12,0 & 8,0 & 8,8 \\
\hline Organizaçấ, acesso -- subtotal & 76,6 & 71,4 & 74,9 & 76,0 & 75,0 & 75,2 \\
\hline Todas & 100,0 & 100,0 & 100,0 & 100,0 & 100,0 & 100,0 \\
\hline
\end{tabular}

Total dos entrevistados $=113$

Ignorados = 1 na questấo consulta no ano

Encerrando a apresentação dos resultados das entrevistas, a tabela 29 ilustra as freqüências relativas das categorias discursivas, segundo as áreas/UBSs de procedência. No geral, a busca por uma vaga no dia representou $47,8 \%$ das motivações, que somadas às demais categorias relacionadas mais diretamente com a organização do processo de trabalho e do acesso aos serviços perfazem $75,2 \%$.

Tabela 29 - Frequéncia das categorias discursivas dos entrevistados, segundo área/UBS de procedência. PS Central, Itapecerica da Serra, 2004.

\begin{tabular}{|c|c|c|c|c|c|}
\hline Categoria discurssiva & $\begin{array}{r}\text { Branca } \\
\text { Flor }\end{array}$ & $\begin{array}{l}\text { Parque } \\
\text { Paralso }\end{array}$ & $\begin{array}{r}\text { Salvador } \\
\text { Leone }\end{array}$ & $\begin{array}{r}\text { Valo } \\
\text { Velho }\end{array}$ & Total \\
\hline & $\%$ & $\%$ & $\%$ & $\%$ & $\%$ \\
\hline Desconfiança, anseios & 9,1 & 8,0 & 9,5 & 21,4 & 10,6 \\
\hline Usa convênio, peregrino/premência & 18,2 & 12,0 & 11,1 & 28,6 & 14,2 \\
\hline Subtotal & 27,3 & 20,0 & 20,6 & 50,0 & 24,8 \\
\hline Falta de médico & 9,1 & 20,0 & 9,5 & 7,1 & 11,5 \\
\hline Vaga no dia & 54,5 & 44,0 & 49,2 & 42,9 & 47,8 \\
\hline Agendamento & 9,1 & 4,0 & 9,5 & 0,0 & 7,1 \\
\hline Orientaçāo restritiva & 0,0 & 12,0 & 11,1 & 0,0 & 8,8 \\
\hline Organizaçăo, acesso - subtotal & 72,7 & 80,0 & 79,4 & 50,0 & 75,2 \\
\hline Todas & 100,0 & 100,0 & 100,0 & 100,0 & 100,0 \\
\hline
\end{tabular}

Total dos entrevistados $=113$ 
A categoria "vaga no dia" é a mais indicada em todas as quatro áreas/UBSs de procedência. Mas, para comparações da distribuição de cada uma das categorias discursivas entre as áreas/UBSs de procedência das pessoas atendidas, a tabela 29 não ajuda, uma vez que cada área/UBS tem um total de casos. Assim, de uma comparação direta dos dados colhidos resultaria que a área/UBS com maior população, obviamente, sempre apresentaria as maiores freqüências das categorias discursivas. Para comparar, por exemplo, o peso do motivo "vaga no dia" entre áreas/UBSs, não basta o número absoluto de casos: é preciso levar em conta o peso que esse motivo teve no total de categorias de cada UBS e, segundo o seu número total de casos. Para tanto, foi preciso considerar a força da ocorrência de cada motivo em cada UBS, padronizando o número de casos. Trata-se de um procedimento semelhante, por exemplo, ao utilizado na padronização de coeficientes, como o geral de mortalidade, para possibilitar comparações entre países com estruturas populacionais diferentes, em que cada faixa etária tem uma força distinta na ocorrência da mortalidade. Em razão do exposto, a tabela 30 apresenta resultados padronizados, calculados com os seguintes procedimentos:

- definiu-se uma população hipotética, padrão de casos/categorias de 1.000;

- para cada área/UBS, de acordo com a força de ocorrência de cada motivo, calculou-se o número de casos, multiplicando-se $1.000 \mathrm{x}$ freqüência relativa do motivo na área/UBS considerada;

- somou-se o novo número de casos, calculados na base-padrão 1.000 , de todas as áreas/UBSs, de cada um dos motivos;

- calculou-se quanto percentualmente cada área/UBS contribuiu no total de casos de cada um dos motivos.

Tabela 30 - Distribuição percentual do número de casos padronizados das categorias discursivas, segundo as áreas/UBSs de procedéncia. PS Central, Itapecerica da Serra, 2004.

\begin{tabular}{|c|c|c|c|c|c|}
\hline Categoria discursiva & $\begin{array}{r}\text { Branca } \\
\text { Flor } \\
\% \\
\end{array}$ & $\begin{array}{r}\text { Parque } \\
\text { Paraiso } \\
\% \\
\end{array}$ & $\begin{array}{r}\text { Salvador } \\
\text { Leone } \\
\% \\
\end{array}$ & $\begin{array}{r}\text { Valo } \\
\text { Velho } \\
\% \\
\end{array}$ & $\begin{array}{r}\text { Total } \\
\% \\
\end{array}$ \\
\hline Desconfiança, anseios & 18,9 & 16,7 & 19,8 & 44,6 & 100,0 \\
\hline Usa convênio, peregrino/premência & 26,0 & 17,2 & 15,9 & 40,9 & 100,0 \\
\hline Subtotal & 23,1 & 17,0 & 17,5 & 42,4 & 100,0 \\
\hline Falta de médico & 19,9 & 43,7 & 20,8 & 15,6 & 100,0 \\
\hline Vaga no dia & 28,6 & 23,1 & 25,8 & 22,5 & 100,0 \\
\hline Agendamento & 40,2 & 17,7 & 42,1 & 0,0 & 100,0 \\
\hline Orientação restritiva & 0,0 & 51,9 & 48,1 & 0,0 & 100,0 \\
\hline Organizaçāo, acesso - subtotal & 25,8 & 28,4 & 28,1 & 17,7 & 100,0 \\
\hline
\end{tabular}




\subsection{Algumas características das unidades básicas escolhidas para estudo}

A tabela 31 apresenta informações sobre as UBS referentes ao mesmo periodo em que foram levantadas as informações sobre as pessoas atendidas no pronto-socorro. Com base na população estimada de cada área/UBS, calcularam-se valores de horas profissionais disponiveis por 1.000 habitantes. Esses índices de horas profissionais, segundo população da área, são maiores na área/UBS Branca Flor para médicos, enfermeiros, auxiliares e técnicos de enfermagem e agentes comunitários de saúde. A área/UBS Valo Velho tem a menor relação de horas médicas disponíveis por habitante. A UBS Parque Paraiso, por perdas anteriores de médicos, tem o maior número de períodos do dia sem médico.

Tabela 31 - Algumas caracteristicas das UBSs escolhidas para o estudo. Itapecerica da Serra, 2004.

\begin{tabular}{|c|c|c|c|c|c|}
\hline Características da área/UBS & $\begin{array}{c}\text { Branca } \\
\text { Flor }\end{array}$ & $\begin{array}{l}\text { Parque } \\
\text { Paraiso }\end{array}$ & $\begin{array}{l}\text { Salvador } \\
\text { Leone }\end{array}$ & $\begin{array}{l}\text { Valo } \\
\text { Velho }\end{array}$ & Total \\
\hline Populaçăo (2004) & 7.000 & 24.500 & 36.500 & 18.500 & 86.500 \\
\hline Horas de funcionamento diário & 10 & 10 & 12 & 10 & - \\
\hline Total de horas médicas semanais & 75 & 135 & 178 & 104 & 492 \\
\hline \multicolumn{6}{|l|}{ Horas semanais/1.000 hab. } \\
\hline Médico pediatra & 2,86 & 1,59 & 1,40 & 1,78 & 1,65 \\
\hline Médico gineco-obstetra & 3,57 & 1,22 & 1,56 & 1,89 & 1,70 \\
\hline Médico clínico geral & 4,29 & 2,69 & 1,92 & 1,95 & 2,34 \\
\hline Todos & 10,71 & 5,51 & 4,88 & 5,62 & 5,69 \\
\hline Enfermeiro & 10,00 & 2,86 & 2,47 & 5,41 & 3,82 \\
\hline Auxiliarfécnico de enfermagem & 22,86 & 9,80 & 16,16 & 12,97 & 14,22 \\
\hline Agente comunitario de saúde & 51,43 & 11,43 & 10,96 & 6,49 & 13,41 \\
\hline \multicolumn{6}{|l|}{$\begin{array}{l}\text { w. de periodos do dia sem } \\
\text { profissional, na semana }\end{array}$} \\
\hline Médico pediatra & 6,0 & 9,0 & 4,0 & 4,0 & 23,0 \\
\hline Médico gineco-obstetra & 4,0 & 7,0 & 2,0 & 4,0 & 17,0 \\
\hline Médico clínico geral & 3,0 & 5,0 & 1,0 & 4,0 & 13,0 \\
\hline Todos & 13,0 & 21,0 & 7,0 & 12,0 & 53,0 \\
\hline Enfermeiro & 3,0 & - & - & - & 3,0 \\
\hline
\end{tabular}

A UBS Parque Paraiso, por exemplo, na época de realização do levantamento, chegou a ter nove períodos na semana sem pediatra e seis sem clínico, de dez períodos 
semanais possíveis, devido a dificuldades criadas por demissão de médicos, má distribuição das horas existentes e problemas decorrentes de férias ou licenças. Verificando-se as coincidências de períodos sem médico, observou-se que em três períodos da semana a unidade ficou sem nenhum médico presente. Em relação à realização de consultas médicas básicas por habitante/ano, as UBSs Parque Paraíso e Valo Velho são as que apresentaram os menores índices (tabela 32).

Tabela 32 - Produçăo e índice por 1.000 habitantes de consultas médicas (CM), segundo UBSs em estudo e Pronto-Socorro Central. Itapecerica da Serra, 2004.

\begin{tabular}{|c|c|c|c|c|c|c|c|}
\hline Produção e índice & $\begin{array}{l}\text { Branca } \\
\text { Flor }\end{array}$ & $\begin{array}{l}\text { Parque } \\
\text { Paraiso }\end{array}$ & $\begin{array}{l}\text { Salvador } \\
\text { Leone* }\end{array}$ & $\begin{array}{l}\text { Valo } \\
\text { Velho }\end{array}$ & $\begin{array}{r}\text { Todas as } \\
\text { UBSs }\end{array}$ & PSC* & Total \\
\hline CM média mês - 2004 & 841 & 1.581 & 4.496 & 1.147 & 8.065 & 8.336 & 16.401 \\
\hline CM/ano - 2004 & 10.090 & 18.977 & 53.956 & 13.763 & 96.785 & 100.029 & 196.814 \\
\hline CM habitante/ano & 1,44 & 0,77 & 1,48 & 0,74 & 1,12 & 1,16 & 2,28 \\
\hline população & 7.000 & 24.500 & 36.500 & 18.500 & 86.500 & & 86.500 \\
\hline
\end{tabular}

* Estimativa de consultas de pronto-socorro para usuários originados na área/UBS.

Parte das consultas da UBS Salvador Leone foi rateada em cotas para as outras, como atendimento referenciado.

Em relação aos recursos materiais, em nenhuma unidade houve retardo ou cancelamento de atendimento motivado por falta de materiais de consumo e medicamentos nem por mau funcionamento ou falta de manutenção de equipamentos. Há registro de faltas pontuais de alguns medicamentos básicos (problema esse levantado somente na UBS Branca Flor): cefalexina, furosemida, metildopa e AAS infantil. Em relação à organização dos serviços e dos processos de trabalho, são dois os destaques diferenciais:

- algumas unidades estabelecem - às vezes deixando a data "no ar" -, o dia em que irão abrir agenda, enquanto outras trabalham com agenda sempre aberta, procurando agendar no momento do comparecimento do usuário no serviço;

- o estágio de funcionamento da recepção técnica acolhedora, com a necessária integração da equipe de enfermagem e médica a essa atividade, é muito desigual. Algumas unidades trabalham de forma parcial ou inconstante com a recepção técnica acolhedora, com maior dificuldade em fixar a mudança na maneira tradicional de funcionamento via balcão/recepção. A equipe de enfermagem foi, em algumas unidades, mais resistente em participar ativamente da nova recepção técnica, estando por vezes mais vulnerável à ação de intimidação desencadeada por órgãos 
corporativos dos enfermeiros, que com visitas fiscalizadoras e posterior convocação do pessoal de enfermagem para oitivas no conselho profissional, ameaçavam formalmente os que participassem das mudanças em curso. Também o movimento do "ato médico", desencadeado unilateralmente por órgãos representativos da profissão, contribuiu para dificultar as mudanças e a melhora na articulação de funções e responsabilidades da equipe de saúde, obstaculizando avanços que valorizam, de fato, o profissional médico.

Ainda em relação à organização de atividades, todas as UBSs possuem pelo menos grupos de cuidados para hipertensos, diabéticos, mulheres em pré-natal, odontológico de lactentes e para atividades físicas. Promovem visitas domiciliares quando necessário e contam com o trabalho de campo de agentes comunitários de saúde. As quatro UBSs vivem dificuldades semelhantes em relação ao encaminhamento de pessoas para algumas especialidades e procedimento médicos e ao tempo de retorno de exames que, atualmente, quando não se solicita urgência, demora em torno de 15 dias para urina e bioquímica, 40 dias para papanicolaou e hormônios e 30 dias para os demais. Todas as UBSs têm conselho gestor de saúde, com participação direta da população e reuniões regulares com eleição bienal. $\mathrm{O}$ quadro 3 apresenta uma síntese de aspectos da organização das quatro unidades, baseada em observações de campo e relatórios de supervisão da Secretaria Municipal de Saúde.

Quadro 3 - Observação de aspectos negativos na organização das UBSs em estudo, segundo situação de cada UBS diante da superação do problema. Itapecerica da Serra, 2004.

\begin{tabular}{|c|c|c|c|c|}
\hline \multirow[b]{2}{*}{ Aspectos negativos } & \multicolumn{4}{|c|}{ UBS e a superação do negativo } \\
\hline & $\begin{array}{l}\text { Branca } \\
\text { Flor }\end{array}$ & $\begin{array}{l}\text { Parque } \\
\text { Paraiso }\end{array}$ & $\begin{array}{l}\text { Salvador } \\
\text { Leone }\end{array}$ & $\begin{array}{l}\text { Valo } \\
\text { Velho }\end{array}$ \\
\hline $\begin{array}{l}\text { Dispensar uma pessoa que procura atendimento na UBS, com base numa } \\
\text { comunicação administrativa de capacidade esgotada de atendimento, que é } \\
\text { anunciada na porta, na fila ou no balcão/recepção da unidade, seja pela } \\
\text { dificuldade operacional em manter funcionando a recepção técnica } \\
\text { acolhedora durante o dia, seja pela limitação da mudança no processo de } \\
\text { trabalho }\end{array}$ & parcial & parcial & parcial & $\operatorname{sim}$ \\
\hline $\begin{array}{l}\text { Atribuir à recepção/balcão o papel de controlar e decidir sobre o agendamento } \\
\text { das consultas médicas }\end{array}$ & parcial & parcial & parcial & parcial \\
\hline Enfermeiro sem papel direto e sistemático na assistência & sim & $\operatorname{sim}$ & $\operatorname{sim}$ & $\operatorname{sim}$ \\
\hline $\begin{array}{l}\text { Equipe de enfermagem com papel cuidador reduzido e sem participação } \\
\text { efetiva na recepção técnica acolhedora. Ação da recepção técnica mais } \\
\text { entendida como um novo balcão para agendamento }\end{array}$ & parcial & parcial & parcial & $\operatorname{sim}$ \\
\hline $\begin{array}{l}\text { Agendamento estabelecido de forma a obrigar os usuários a voltarem, com } \\
\text { ou sem data estabelecida, para poder marcar uma consulta }\end{array}$ & năo & parcial & não & $\operatorname{sim}$ \\
\hline
\end{tabular}


4.4 Opinião dos médicos socorristas e dos médicos das unidades básicas de saúde

4.4.1 Médicos do pronto-socorro entrevistados: além de terem sido solicitados a ndicar as ocorrências/doenças mais freqüentes no atendimento do PS que poderiam ter ido atendidas nas UBSs - havendo suas respostas ajudado a compor o rol de ocorrências sscolhidas para o estudo -, esses médicos foram também perguntados sobre o porquê desse Iso inadequado do pronto-socorro.

As respostas a essa questão podem ser apresentadas em quatro categorias undamentais:

Problemas na disponibilidade de oferta de atendimento na rede básica:

- os postos de saúde não funcionam

- a rede básica não funciona, faltam profissionais

- faltam médicos na rede básica, resultando em muito demora na marcação de consultas

- a demanda é maior do que as UBSs podem absorver

\section{Características negativas do funcionamento da UBS}

- a consulta e os exames demoram, e a pessoa acaba procurando um prontosocorro

- os médicos da UBS resolvem pouco e encaminham demais

- não há pronto-atendimento para os casos que procuram a UBS

\section{Características atrativas do funcionamento do PS}

- facilidade e rapidez do atendimento no PS

- o PS acaba funcionando como pronto-atendimento: como só o médico pode descaracterizar a urgência, ninguém é dispensado sem a consulta, e o PS fica lotado

- as pessoas não querem aguardar vagas para consulta na UBS, e no PS o atendimento é imediato 
Falta informação e há conflito de expectativas entre usuários e serviços de saúde:

- muitas vezes há falta de esclarecimento da mãe: a explicação que o médico da UBS dá à mãe não é a esperada, e ela acaba recorrendo ao PS

- as pessoas não compreendem o funcionamento do sistema e acham que tudo pode ser resolvido no PS

\subsubsection{Médicos das UBSs - foram solicitadas respostas a duas questões:}

- Entre as ocorrências/doenças que chegam às unidades básicas de saúde, quais poderiam ser mais bem resolvidas se as pessoas procurassem diretamente os prontos-socorros?

- Considerando a necessidade de melhor delimitar as funções das unidades básicas de saúde e dos prontos-socorros, nos casos de febre, pródromos de IVAS, broncoespasmo, sintomas de descontrole de hipertensão ou diabetes, em qual desses dois serviços as pessoas, em geral, deveriam ser orientadas a procurar atendimento? Comente um pouco sua indicação.

Nas quatro unidades básicas incluídas no estudo existiam cerca de 24 médicos, atendendo nas áreas básicas - pediatria, clínica do adulto e gineco-obstetrícia. Com o objetivo de conhecer a opinião e a visão desses profissionais sobre o papel da atenção básica e do pronto-socorro, 11 deles foram entrevistados, sendo seis clínicos gerais, três gineco-obstetras e dois pediatras. Optou-se por entrevistar os médicos de duas das quatro unidades - UBS Valo Velho e Salvador de Leone -, por se considerar esse conjunto de informações suficientes para o objetivo do trabalho.

Em relação à primeira questão - ocorrências freqüentes nas UBSs em que as pessoas deveriam ter procurado diretamente os PSs -, as respostas foram organizadas em três grupos:

Causas externas: foram, no conjunto, as mais indicadas. Incluiram-se nesse grupo os acidentes de forma geral, traumatismo, ferimento cortante, corpo estranho, afogamento e estupro. 
Ocorrências agudas: convulsão, cólica nefrética, cólica biliar, meningite, desidratação graus II e III, diarréia aguda, abscesso, lipotimia, epistaxe, metrorragias, abortamento em curso, início de trabalho de parto, infarto, quadros febris, infecção urinária, surto psicótico e alcoolismo.

Doenças de controle: crise HAS, crise asmática e diabetes descompensado.

Observa-se que várias das ocorrências incluídas como características da atenção básica estão relacionadas, pelo menos por um médico das UBSs, como doenças que poderiam ser mais bem resolvidas procurando-se diretamente os PSs. Em relação às crises asmática e hipertensiva, metade dos entrevistados indicou-as como ocorrências em que as pessoas deveriam procurar diretamente o PS. Mas como eles justificam essa posição?

A segunda pergunta contribui para aclarar o que pensam os entrevistados a respeito do papel de cada tipo de serviço no sistema local de saúde. Indagou-se especificamente sobre essas situações pela relação entre elas e as hipóteses diagnósticas escolhidas para o estudo. Essas situações dão origem às hipóteses diagnósticas que foram analisadas como possíveis indicadores de monitoramento da atenção básica, com base no pressuposto de que poderiam ser plenamente atendidas e acompanhadas nas UBSs. O entendimento dos médicos das UBSs entrevistados a respeito do tipo de serviço que seria o mais adequado para atender a essas situações não foi consensual, e houve muitas contradições. Por exemplo, alguns apontam que:

"Nos casos de febre, pródromos de IVAS e broncoespasmo, entendo que no PS há melhor condição para atendimento (apesar da demanda); já nos sintomas de descompensação de diabetes e hipertensão, acho mais prudente a avaliação na UBS com posterior encaminhamento para o PS se os casos forem graves."

Outros afirmam que:

"Nos pródromos de IVAS e até broncoespasmo leves e moderados que não caracterizem insuficiência respiratória, a UBS comporta o atendimento, bem como diabetes não descompensado, podendo inclusive ter acompanhamento ambulatorial e é a isto que o ambulatório se propõe." 
Pode-se dividir a argumentação dos médicos entrevistados, para uma melhor compreensão de suas opiniões, em duas linhas de discurso:

A primeira avalia que não caberia à $U$ UBS atender esses casos por não dispor de complexidade tecnológica suficiente, levando à conclusão de que no PS há melhor condição para o atendimento. Assim, a resposta a essas situações não seria papel da UBS, que já tem como responsabilidade o atendimento às pessoas agendadas, e, nessas situações adicionais perguntadas, é necessário, muitas vezes, atendimento imediato.

"Nos casos de febre, pródromos de IVAS e broncoespasmo, entendo que no PS há melhor condição para atendimento."

“A UBS não possui condição de ter exames de forma rápida, local apropriado para soroterapia, não tem em mãos equipamentos e medicamentos."

"No PS seriam mais bem atendidas. No ambulatório as agendas são lotadas, às vezes são casos que necessitam atendimento imediato."

A segunda avalia que esses atendimentos cabem à $U B S$, desde que se satisfaçam determinadas precondições. Com base nesses condicionamentos foram criadas subcategorias, visando à compreensão mais detalhada dos discursos. Assim, o atendimento dessas ocorrências na UBS, na visão dos entrevistados, dependeria:

- da gravidade do caso: em geral se considera que atender ocorrências graves é atribuição do PS, mas não fica claro o que seja um caso grave, nem como é possível definir gravidade antes de a pessoa ser atendida por um profissional na UBS. Na dúvida, ou diante da dificuldade operacional para definir o que realmente seja um caso de maior gravidade, flerta-se com a adoção de uma orientação geral de que "casos de crise", ou febre, ou broncoespasmo sejam de fato objeto do PS, tal como exposto na primeira tendência de argumentação.

"Caberia à UBS o atendimento desses casos, encaminhando ao PS casos não controlados." 
“Em relação à hipertensão, vejo mais casos que não estão compensados, mas que não são em geral crises hipertensivas, e um acompanhamento ambulatorial pode resolver esses casos."

"Creio que a maioria desses casos, desde que sejam de menor gravidade, poderia ser atendida nas UBSs [...] Os mais graves: broncoespasmo com cianose, com desconforto respiratório importante, crise hipertensiva com sintomas/sinais neurológicos ou angina ou ambos, diabetes descompensado são mesmo para o PS."

"Febre, pródromos de IVAS, broncoespasmo leve atender na UBS. Broncoespasmo moderado a grave no PS."

- da existência de médicos em todos os períodos: a preocupação é que, para assumir o atendimento das situações de crise dessas morbidades crônicas em acompanhamento ou de ocorrências agudas mesmo que corriqueiras, é necessário tempo de observação até o momento adequado de dispensar a pessoa atendida do serviço para casa. Isso inviabilizaria o atendimento na UBS, caso ela não ofereça possibilidade de acompanhamento médico à pessoa durante todo o dia, até a alta, como é garantido no PS.

“Em relação aos quadros de broncoespasmo, penso que é melhor o atendimento no PS, visto ser necessário um período maior de observação do paciente até alívio do mesmo [...] Em relação ao diabetes descompensado, penso que o paciente deveria ser atendido no PS pela mesma razão citada acima e, claro, pelo risco maior a que está exposto."

"Muitas vezes o broncoespasmo não melhora somente com inalações; muitas vezes precisa ficar em observação ou internar.”

"Em relação aos broncoespasmos recorrentes, também podem ser atendidos em UBSs que possuam clínicos em todos os períodos, pois na maioria dos casos há necessidade de avaliação médica." 
- da existência de um pronto-atendimento na UBS: a preocupação é, sobretudo, com a capacidade de atendimento para responder à demanda do dia. Essa condição articula-se com a idéia de que o médico da UBS tem pessoas agendadas para atender, e é impossível ficar a todo o momento interrompendo sua missão para uma consulta, seja para um curativo, seja para uma sutura de ferimento, seja para outra ocorrência, que inevitavelmente toma tempo e "embola" o atendimento das pessoas já agendadas. Então, é enfatizado que, para atender à demanda do dia, há necessidade de outra forma organizativa da assistência, que se adicione à exclusiva oferta de consultas agendadas. Como alternativa à visão do pronto-atendimento médico também são propostas iniciativas como a combinação de recepção técnica acolhedora com retaguarda médica e de enfermeiro, trabalho com grupos (hipertensão e diabetes), trabalho em equipe multiprofissional, com a ênfase especial na retomada do papel assistencial do enfermeiro.

"[...] poderiam ser atendidos na UBS por um médico que atendesse no PA."

"As UBSs poderiam atender e acolher esses casos com a retaguarda médica da unidade para que, dependendo da análise do caso pelo médico, este verifique a necessidade de referenciar para um PS."

" $[\ldots]$ a menos que contratem mais profissionais para fazer prontoatendimento e sejam adequadas as UBSs para atendimento desses tipos." 


\section{Discussão}

O desenvolvimento da discussão partiu da condição de inexistência na literatura de trabalhos semelhantes. Há estudos sobre demanda ambulatorial ou de pronto-socorro, mas nenhum deles tratou de evento sentinela em pronto-socorro com vistas à sua utilização como um indicador de monitoramento da atenção básica, de modo que se possa estabelecer uma confrontação de achados e discussões. Porém, reconhecendo a necessidade de o conjunto diverso de dados coletados ser questionado no entrecruzamento de informações, utilizou-se, para o desenvolvimento da discussão, o recurso metodológico de um questionador fictício (DONATO 2000). Fazendo as vezes de um crítico oculto, esse recurso cumpre o papel de instigar, problematizar e provocar reflexões, com o objetivo de ampliar a interpretação, a identificação das limitações das possíveis conclusões e, sobretudo, estimular a estratégia de triangulação das informações coletadas. Procura-se, assim, reduzir o risco de parcelamento da discussão, segundo cada um dos tipos e momentos dos dados levantados, quebrando a necessária totalidade do processo crítico.

Serão três as questões fundamentais em debate: A freqüência das ocorrências escolhidas é influenciada pela área de procedência das pessoas? É possível atribuir essa possível influência detectada à situação da atenção básica de cada área? É operacionalmente viável a utilização dessas ocorrências no monitoramento da atenção básica?

\section{- A freqüência relativa das HDEs apresentou variação conforme a área/UBS de procedência das pessoas atendidas?}

A tabela 14 apresenta valores que variam de $30 \%$ até $42,8 \%$ da proporção das HDEs no total de atendimento de cada uma das quatro áreas/UBSs de procedência. Essa

diferença mostrou-se estatisticamente significante $\left(\mathrm{X}^{2}=9,19\right.$ e $\mathrm{p}$-valor $\left.=2,7 \%\right)$. Isso significa dizer que, aceitando um erro de $2,7 \%$, há uma ou mais diferenças na distribuição das HDEs entre as quatro áreas/UBSs. 
- Essa diferença pode ter ocorrido devido à presença de uma variável de confundimento, que, estando distribuída de forma diferente entre as amostras das pessoas atendidas de cada área, causaria um viés, produzindo uma diferença entre as áreas/UBSs?

Foi por causa dessa indagação que se procurou, na análise dos dados, controlar algumas variáveis com maior potencial de confundimento. As situações de atendimento em fins de semana ou em horário que a UBS não funciona foram controladas com o uso de restrições de categorias na definição da população de estudo. $\mathrm{Na}$ análise dos dados, formulou-se a hipótese, a controlar, de que a distribuição diferente de HDEs entre as áreas poderia dever-se a uma distribuição tendenciosa das variáveis sexo, idade ou dia da semana de coleta dos dados, o que poderia resultar em confundimento. Por exemplo, se a variável idade, pelo acaso, associar-se com a maior ocorrência de HDE e se sua distribuição não for semelhante entre as áreas/UBSs, estar-se-á diante da possibilidade de um confundimento.

Essa situação, no caso da característica idade, de fato foi uma preocupação, em razão de as faixas etárias menores associarem-se positivamente com a ocorrência de HDEs.

Após a análise estatística apresentada na tabela 13, foi evidenciado que, embora a característica idade tenha se associado à maior ocorrência de HDEs, ela não se associou a nenhuma das áreas/UBSs, isto é, não se distribuiu de forma diferente entre as áreas de modo a enviesar os dados. Tampouco, sexo e dia da semana se associaram às áreas/UBSs de procedência (tabela 33).

Tabela 33 - Valores do qui-quadrado entre grupos de idade, dias da semana e sexo e as ocorrências de HDEs nas áreas/UBSs em estudo. PS Central, Itapecerica da Serra, 2004.

\begin{tabular}{l|cc}
\hline Variáveis de estudo & \multicolumn{2}{|c}{ B. Flor - P. Paraíso - S. Leone - Valo Velho } \\
\cline { 2 - 3 } & Qui-quadrado & Valor de $\mathrm{p}$ \\
\hline \hline Dia da semana & 8,52 & 0,74 \\
Sexo & 4,59 & 0,20 \\
Grupo de idade & 2,51 & 0,87 \\
\hline
\end{tabular}

HDE = hipótese diagnóstica escolhida

24 ignorados $(1,4 \%)$

Criança $(0-15)$; Jovem $(15 \mid-21)$; Adulto $(21 \mid-)$ 
- Houve preocupação em controlar outras variáveis de confundimento, como, por exemplo, o tamanho da população de cada área, o tipo de uso que cada uma faz do PS, a proximidade maior ou menor de cada área/UBS com a unidade socorrista?

Sim. Essas questões levaram a não fixar a avaliação na diferença entre as freqüências absolutas das HDEs de cada área, mas a comparar o índice resultante da razão - HDEs/HDs demais - de cada área. Esse índice expressa a chance de ocorrência de HDE em cada área/UBS, que em termos probabilísticos independe do tamanho da população de cada área ou de ela procurar mais ou menos esse PS por estar mais próxima ou mais distante dele.

Entretanto, neste último caso a afirmação depende da aceitação do pressuposto de que uma possível tendência de maior ou menor uso do PS por uma das áreas/UBSs se manifestaria tanto nas HDEs como nas HDs demais da mesma área. Esse pressuposto é razoável, uma vez que as diferenças de uso pelas populações estão relacionadas à acessibilidade da área, independentemente de tratar-se de HDEs ou das HDs demais. É fato que as populações das vizinhanças do PS tendem a utilizá-lo mais, mas essa influência se faria exercer nos dois grupos diagnósticos. Se não for assim, por que outra razão uma população usaria mais o PS para HDEs e menos para HDs demais ou vice-versa? A questão seria, então, exatamente aquela da natureza do estudo, que busca verificar se diferenças existentes na atenção básica de cada área/UBS provocam uso diferenciado do PS, para determinadas queixas/doenças características do poder resolutivo da atenção básica. Isto é, a hipótese de trabalho é que a motivação da população de determinada área/UBS em usar mais ou menos o PS nos casos das HDEs estaria relacionada à situação da atenção básica e ao seu reconhecimento por essa população.

- Mas é possivel excluir estatisticamente a possibilidade de que outros fatores, não controlados, produzam uma interferência unilateral para maior ou menor de uso do PS nas HDs demais, alterando uma relação esperada como função da situação da atenção básica de cada área?

É impossível estatisticamente, considerando o desenho do estudo adotado, excluir por completo essa possibilidade de erro. Embora seja uma ocorrência pouco provável, ela é possível e, se não bem delimitada, pode representar uma limitação do indicador em discussão. 
Qualquer tentativa de comprovar completa independência entre as HDs demais e a atenção básica ou de supor uma ocorrência de HDs demais relativamente constante nas diversas populações iria esbarrar em novos problemas metodológicos. Por exemplo, falar que as HDs demais ocorrem na mesma proporção em qualquer área/UBS de procedência, apenas dependendo do tamanho da população, não levaria em conta a maior ou menor proximidade da população, ou a sua possibilidade de utilizar outro serviço. Ou, ainda, achar que as HDs demais são totalmente independentes da situação da atenção básica também é exagerar a situação e não reconhecer que entre as HDs demais estão as dispepsias, dorsalgias e outras ocorrências ao alcance da atuação da atenção básica, ainda que em grau mais reduzido nos dias de hoje.

$\mathrm{O}$ índice HDEs/HDs demais pode, portanto, carregar erros de subestimação quando apenas as HDs demais são influenciadas para maior ou de superestimação quando apenas as HDs demais são influenciadas para menor. Essas são possibilidades cuja incerteza procura-se reduzir com a ampliação dos horizontes no levantamento de dados para análise.

Entretanto, estatisticamente também é possível controlar essa possibilidade de erro. Usando como base de comparação uma estimativa local da população adscrita de cada área/UBS (tabela 2), pode-se demonstrar que, enquanto a razão de prevalência HDs demais/população, com uma exceção, não apresenta variação estatisticamente significativa entre as áreas, a razão de prevalência de $\mathrm{HDE}$ /população varia significativamente entre as áreas/UBSs.

A figura 10 apresenta a comparação das razões de prevalência das HDs demais entre as áreas/UBSs tomadas duas a duas, utilizando-se a técnica da metanálise, e a figura 11 as razões de prevalência de HDE. Pode-se observar, na figura 10, uma tendência da área/UBS Salvador Leone, geograficamente próxima do pronto-socorro, de apresentar valores maiores de HDs demais/população, quando comparada com as demais. Essa ocorrência tenderia, na análise anteriormente realizada, a subestimar a chance de HDEs/HDs demais na UBS Salvador Leone, aproximando-a artificialmente, na comparação, da UBS Valo Velho, por exemplo, que foi aquela que apresentou menor chance de HDEs/HDs demais. Mas, apesar disso, a diferença entre as chances das duas unidades foram significativas (figura 5). 
Figura - 10

Razão de Prevalência (RP) de HDs demais entre pares de áreas/UBSs. Itapecerica da Serra, 2004.

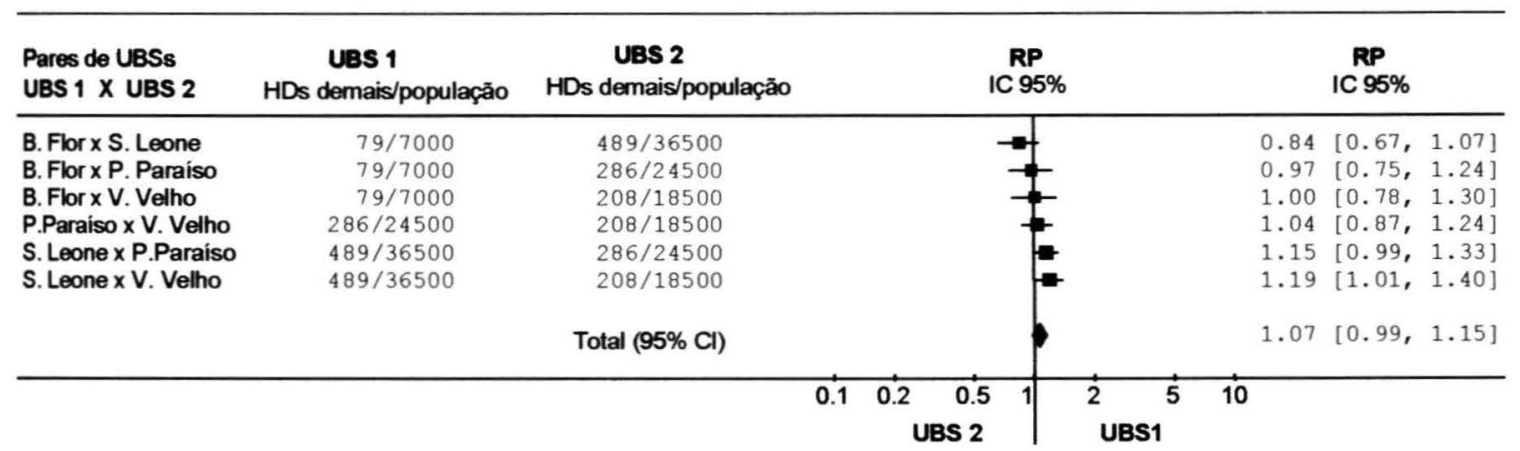

Figura - 11

Razão de Prevalência (RP) de HDEs entre pares de áreas/UBSs. Itapecerica da Serra, 2004.

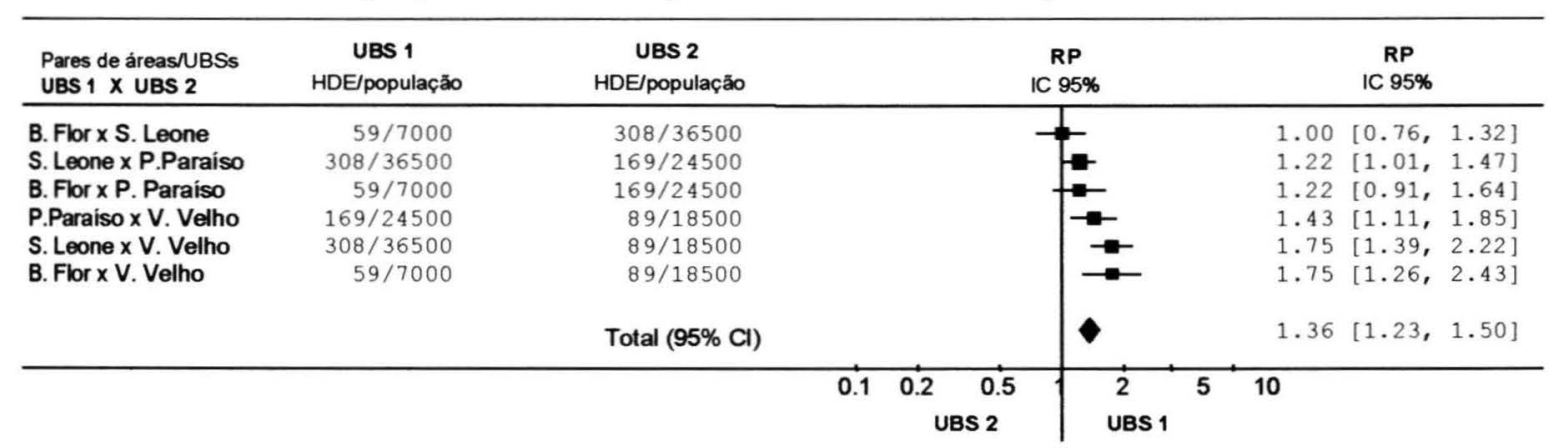

Comparando-se os resultados de ocorrência de casos de HDE e de HD demais de procedência da UBS Salvador Leone com os procedentes da UBS Valo Velho, com base na população estimada de cada área, a UBS Salvador Leone tem 1,19 vez mais casos atendidos de HDs demais no PS do que a UBS Valo Velho e 1,71 vez mais casos de HDE. Esses valores recolocam em cena a busca de uma explicação. $O$ que explicaria essa maior diferença de HDEs entre as áreas, comparada com a pequena diferença das HDs demais? Que fatos poderiam ajudar a determinar tal ocorrência nessas áreas/UBSs? A diferença existe, mas como explicá-la? A hipótese da pesquisa não poderia ser um elo explicativo? Comparando-se as áreas/UBSs no seu conjunto, por meio da medida-sumário, essa mesma tendência de semelhança entre as HDs demais e diferenças entre as HDEs, conforme a procedência, se mantém: 1,07 para as HDs demais, sem significância estatística, para 1,35 das HDEs, com significância estatística.

Essa verificação não prova relação causal entre ocorrência das HDEs com atenção básica, mas reforça a suposição de que as HDs demais ocorrem de forma proporcionalmente semelhante em cada área/UBSs, na dependência do tamanho de sua população. Isso ratifica a possibilidade de o efeito tamanho, uso, distância da população de cada área não ter enviesado significativamente, de forma unilateral, a ocorrência de HDs demais e, assim, atribui consistência maior à análise utilizada das diferenças de chance. 
- A razões de chance HDE/HDs demais não se mostraram diferentes em todas as comparações entre os pares de unidades. Isso não sugere que esse índice terá maiores dificuldades ainda para diferenciar a mesma unidade, em medidas sucessivas ao longo do tempo? Ou seja, o índice proposto terá poder discriminatório para a tarefa a que se propõe?

Como se pode observar nas figuras 4 a 9, a chance de HDE foi significativamente diferente apenas nas comparações da UBS Valo Velho com as outras, embora todas as comparações mostrem uma tendência de variação consistente. A preocupação fundamental do presente estudo foi verificar a hipótese de que ocorrências escolhidas em PS tendem a variar conforme a área/UBS de procedência. Não há para tal propósito a necessidade de que todas as áreas/UBSs se mostrem estaticamente diferentes. Mas, para ser utilizado na prática de monitoramento, o indicador proposto tem que demonstrar amplo poder discriminatório.

$\mathrm{O}$ rigor do método utilizado para o objetivo da pesquisa, uma vez já constatada a existência de associação, pode ser abrandado no cotidiano de sua utilização para o monitoramento de uma UBS, quer ao longo do tempo, quer em comparação com outras.

No processo de monitoramento, algumas adaptações podem ser feitas. Não há necessidade de trabalhar com intervalo de confiança de $95 \%$, como o utilizado. Nas questões de avaliação ou monitoramento de serviços, $80 \%$ a $90 \%$ de nível de confiança é usualmente adotado, considerando-se inclusive que os dados serão articulados numa série histórica. $\mathrm{O}$ tamanho da amostra pode ser aumentado, evitando diferenças muito pequenas, pode-se adotar, com base em uma amostra, uma estimativa de casos por bimestre ou trimestre, podem-se incluir outras ocorrências que se considerem adequadas, podem-se excluir algumas sem repercussão, sempre com o objetivo de viabilizar maior poder discriminatório ao indicador proposto.

Com o objetivo de uma verificação mais concreta, realizou-se uma comparação da UBS Valo Velho, em duas situações hipotéticas, como se fossem dois momentos de uma série histórica, utilizando uma variação pré-fixada de $10 \%$ de diferença entre as duas mensurações. 
Figura - 12

Verificação da significância da diferença de $10 \%$ de ocorrência de HDEs em diferentes tamanhos de amostras, em dois periodos hipotéticos da UBS Valo Velho. Itapecerica da Serra, 2004.

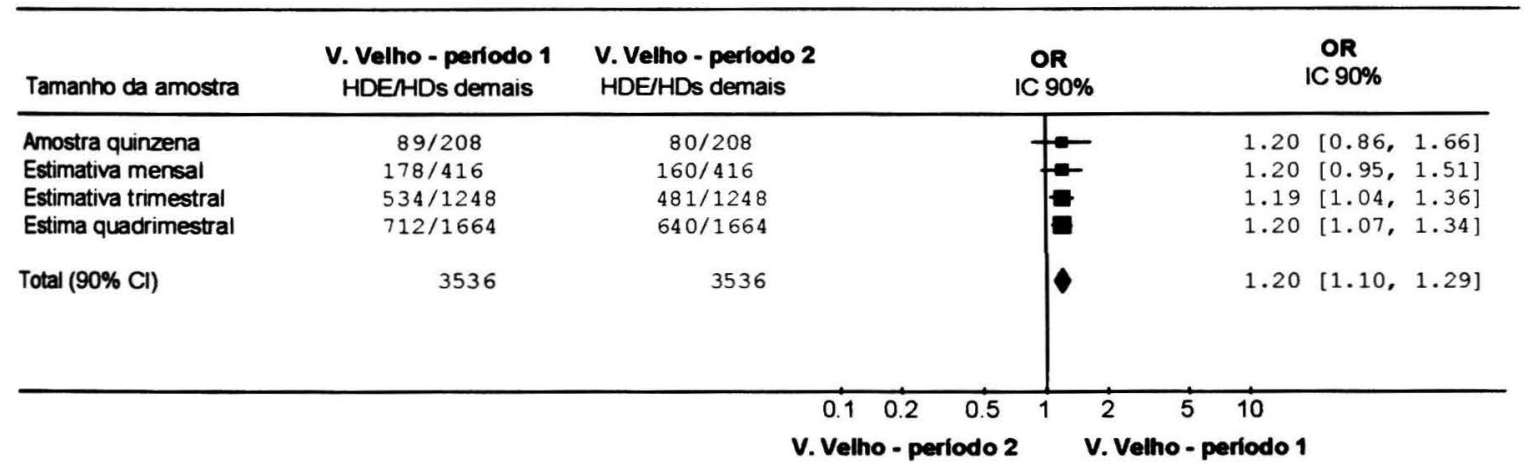

Observe-se que conforme aumenta o tamanho da amostra, extrapolando-se seus valores quinzenais para mês, trimestre, quadrimestre, as diferenças vão ganhando maior significância estatística. Esse é um procedimento razoável, uma vez que para a prática do monitoramento o mais importante é o reconhecimento de uma tendência viável de ser acompanhada com esse instrumental adaptado da metanálise, possibilitando comparações repetidas entre períodos sucessivos do ano, sempre capaz de renovação pela flexibilidade na construção do indicador.

$\mathrm{O}$ poder discriminatório de qualquer indicador é historicamente datado. $\mathrm{O}$ processo é sempre muito dinâmico, com tendência a retirar seu poder discriminatório, particularmente se este está voltado para apoiar o processo de renovação da gestão. Muitos indicadores de saúde sofrem, também, essa perda de poder discriminatório ao longo do tempo. A Razão de Mortalidade Proporcional (indicador de Swaroop-Uemura), que utiliza uma relação de óbitos de pessoas maiores de 50 anos sobre o total de óbitos, vem cada vez mais perdendo seu poder discriminatório em comparações entre países, dado a maior longevidade geral. Como alternativa para sua atualização, tem-se proposto uma mudança no seu cálculo, passando-se a considerar no numerador apenas os óbitos das pessoas acima dos 75 anos (RMP 75). Também o Coeficiente de Mortalidade Infantil, em função de ações focais tem perdido sua capacidade de expressar condições gerais de vida e saúde de uma população (ROUQUAYROL 1999; PEREIRA 2002).

Essa compreensão reforça a necessidade de permanentes adaptações no indicador proposto ou em qualquer outro que se adote. Em especial, seria interessante incluir duas esferas de ocorrências: as de saúde bucal e as de saúde mental. No estudo elas não foram incluídas, pois o objetivo era mais metodológico, mas na prática do monitoramento essas ocorrências não deveriam estar ausentes. $\mathrm{O}$ município em estudo não possui atendimento 
para urgência odontológica, o que dificultou a inclusão dessas ocorrências no presente trabalho. No PS estudado identificou-se a ocorrência de várias queixas de problemas em cavidade oral, mas em quantidade muito reduzida para compor o rol de HDEs. Mas se poderia pensar em outros aspectos a serem incluídos e agrupados, como, por exemplo, ámero de crianças com cáries ativas que freqüentam escolas escolhidas para participar do monitoramento. É importante ressaltar que, na decisão de incluir alguma ocorrência sentinela como um novo componente do indicador, deve-se levar em conta o seu significado como problema de saúde, mas, sobretudo, é preciso que haja facilidade na obtenção do dado e uma atuação palpável da atenção básica para a sua modificação, segundo o estágio local de desenvolvimento, sem o que essa nova ocorrência será um peso morto na composição final do poder discriminatório do indicador.

- Ficou demonstrada uma associação entre HDE e área/UBS, mas como é possível afirmar estatisticamente que a causalidade da diferença está ligada à situação da atenção básica em cada área? Por exemplo, o fato de a UBS Valo Velho ter menor índice quando comparada com as demais (tabela 15) tem explicação na situação da atenção básica ou poderia ser fruto de problemas metodológicos não controlados?

Essa não é uma conclusão pertinente para a análise estatística, e o desenho transversal do estudo permite constatar uma associação, mas não causalidade. Há a necessidade de ampliar o horizonte de análise. A UBS Valo Velho, quando comparada com todas as outras, apresentou menor chance de HDE (menor índice HDEs/HDs demais), e esse fato pode ter duas explicações polares: ou a atenção básica desenvolvida nessa unidade tem um maior efeito na redução da procura do PS, ou que essa diferença foi apenas devida a um erro metodológico de subestimação do índice dessa UBS.

Com a incorporação de informações, além da expressão quantitativa dessas ocorrências, buscou-se conhecer alguns dados da situação de cada UBS, da visão dos profissionais envolvidos sobre o papel de cada tipo de serviço no sistema o que verbalizam as pessoas atendidas no PS sobre o uso da unidade básica. Esse foi o caminho adotado para verificar possível causalidade entre o indice $\mathrm{HDEs} / \mathrm{HDs}$ demais e a situação da atenção básica, incorporando a análise qualitativa das situações e das motivações dos envolvidos. Procurou-se, também, o apoio de critérios lógicos para julgamento de causalidade de uma associação, como o da plausibilidade e da analogia com outras motivações de consumo de 
serviços de saúde, para um julgamento mais amplo e para controlar possíveis confundimentos na aparência dos dados.

A entrevista com uma amostra de 113 dos 625 atendidos e diagnosticados com uma das HDEs teve como intenção fundamental reconstituir os passos das pessoas na procura de assistência para o problema atual até chegarem a ser atendidas no PS. Foi interesse especial conhecer a relação mantida ou não com a UBS e as razões auto-referidas para as atitudes adotadas. A apreciação desses discursos revela a existência de consistências entre o motivo declarado da procura do PS e a situação da organização e da disponibilidade de atendimento em cada UBS.

A UBS Parque Paraíso, por exemplo, vinha sofrendo dificuldades havia algum tempo quanto à permanência da sua equipe médica, levando a certa descontinuidade da presença desse profissional. Isso transparece claramente nas indicações de motivos dos entrevistados. Também nos casos de problemas oriundos de orientações restritivas, as motivações concentram-se sobre as unidades que adotaram, por força de circunstâncias locais, que não são objeto do presente trabalho, formas de trancamento da agenda com abertura esporádica.

Observando-se alguns dados da UBS Valo Velho, percebe-se que essa unidade foi a que mais desenvolveu o processo de mudança focado na humanização dos cuidados (quadro 3). Não é a UBS com maior quantidade de horas médicas per capita, não é a que oferece maior quantidade de consultas médicas por habitante/ano, não obstante é a unidade com menor freqüência, dentre os entrevistados, de categorias discursivas que justificam a procura do PS motivada por problemas de falta de médico, vaga do dia, problemas de agendamento ou orientações restritivas. Tal situação aparentemente paradoxal corrobora a importância da compreensão da atenção básica não apenas como um somatório algébrico de recursos disponíveis, mas, também, como capacidade de organizá-la de forma a reconhecer o direito de acesso das pessoas.

Os discursos dos médicos de UBSs são também elementos importantes para a compreensão das visões coexistentes sobre os serviços básicos. Essas visões disputam, segundo variados interesses, o significado a ser atribuído, na prática, à abrangência da atenção básica. A maior força de uma ou de outra visão está ligada ao processo de condução das mudanças na direção do direito à saúde, da humanização dos serviços e da participação crítica de todos os profissionais. A atenção básica é um signo em disputa, e é 
positivo que assim o seja, pois a alternativa seria uma imposição por parte do pensamento hegemônico de limites para a atenção básica, na mesma direção tomada quando do enclausuramento da atenção primária como uma atenção primitiva para os pobres. Constata-se, assim, que os médicos das UBSs têm visões diferentes e por vezes contraditórias sobre o papel dos serviços básicos, e esses posicionamentos compõem o complexo de determinação de possibilidades ou restrições na reorientação do trabalho nas unidades básicas. No caso da UBS Valo Velho, os discursos dos médicos não apresentaram uma visão contrária à ampliação do papel tradicional dos antigos centros de saúde.

Os valores e opiniões apontados como mais relevantes na motivação para a procura do PS nos casos de HDE sugerem, com o apoio dos critérios lógicos, a existência de coerência entre os achados quantitativos de ocorrência diferencial das HDEs e a situação funcional da atenção básica em cada UBS. Essa interação dos fenômenos oferece argumentos consistentes de que a situação da atenção básica em cada área é um importante componente na determinação das ocorrências de HDE no PS.

\section{- A amostra dos entrevistados é representativa e probabilística de modo a permitir essas inferências sobre problemas na UBS que motivaram a procurar o PS?}

Não foi possível estabelecer uma amostra intencional probabilística. $\mathrm{O}$ processo de livre aceitação da pessoa atendida no PS em participar, a inclusão só das pessoas com um dos diagnósticos escolhidos, a vivência desse levantamento em ambiente de PS e logo após 0 atendimento e, ainda, as limitações estabelecidas pelo fato de as entrevistas terem sido realizadas só pelo pesquisador impuseram uma amostragem não probabilística. A amostra é relativamente bem representativa - 113 em $625(18,1 \%)$ - e permite trabalhar com expectativas de freqüência de $10 \%$, com erro de $5 \%$ ao nível de $95 \%$ de confiança, mas é não intencional, de conveniência, o que vale dizer que a sua capacidade de generalização para o universo dos 625 é limitada.

Diante dessa situação, procurou-se verificar algumas características da distribuição dessa amostra e sua semelhança com o universo de casos; em especial, verificou-se sua representatividade quanto à distribuição da variável área/UBS de procedência. Para essa característica é que havia maior interesse em que não se encontrassem diferenças entre amostra e universo. Não foi encontrada diferença estatística significativa nesse caso (tabela 22). 
- Será que as pessoas atendidas no PS por uma das HDEs, não são aquelas que não costumam utilizar as unidades básicas?

O levantamento de algumas caracteristicas dos entrevistados revelou que $88,5 \%$ deles costumam procurar atendimento na UBS, 90,3\% estão lá matriculados e 67,3\% estiveram na UBS no último ano para uma consulta médica. Portanto, certamente não se trata de pessoas que não utilizam a atenção básica. $O$ dado interessante, revelador da presença de obstáculos históricos ainda não totalmente removidos, é que, apesar ou talvez como fruto dessa proximidade com o funcionamento da UBS, apenas $22 \%$ dos entrevistados procuraram-na para tentar uma resposta ao problema que os levou ao PS.

Em uma pesquisa realizada pela Secretaria Municipal de Saúde de Itapecerica da Serra, em março de 2004, pessoas que deixavam o PS Central foram escolhidas por processo aleatório e entrevistadas, verificando-se que $88 \%$ utilizavam a UBS mais próxima da residência e que apenas $20 \%$ procuraram a UBS antes de ir ao PS pelo problema atual (ITAPECERICA DA SERRA 2004). Ou seja, tal como nos dados encontrados no presente levantamento, é alta a freqüência de uso da atenção básica, é alta a correspondência entre área de residência e UBS utilizada, e é baixa a procura da UBS pelo problema momentâneo que levou à procura do PS.

- As dez ocorrências escolhidas são as que mais refletem a situação local de saúde, são as mais importantes ou significativas para a atenção básica?

O procedimento usado, para a classificação da hipótese diagnóstica do atendimento realizado no PS, foi o registro de ocorrência única, aquela mais relacionada ao motivo da procura. Obviamente essa classificação não reflete a intensidade/gravidade da incidência ou da prevalência das doenças nas populações das áreas/UBSs estudadas. Muitos estudos de demanda têm fornecido importantes informações sobre perfil da clientela, motivos de consulta e procedimentos realizados para a parcela da população que consegue chegar aos serviços. Já os inquéritos populacionais têm permitido colher informações com alcance da totalidade da população, incluindo a parcela que não tem acesso aos serviços de saúde. Alguns estudos que comparam dados obtidos na unidade básica da mesma área de inquéritos concluem que há um nível de concordância que permite aos gerentes de saúde se apoiar em seus próprios registros para inferir sobre o perfil de morbidade da população e, portanto, utilizar-se dessa informação para o planejamento das ações (PUCCINI et al. 
2001; PUCCINI et al. 2002). O trabalho com evento sentinela em PS tem uma vantagem, pois ele permite também trabalhar com a população excluída ou que não faz uso rotineiro da atenção básica, e isso fornece uma maior abrangência na interpretação dessas ocorrências.

Em relação às ocorrências escolhidas, vale destacar que o diabetes $\mathrm{e}$ as vulvovaginites, como esperado, apresentaram freqüência zero no caso de pessoas atendidas e procedentes da menor área, o que enfraqueceu a análise dessas duas ocorrências. $\mathrm{Na}$ maioria das vezes seus valores de odds ratio apontaram uma tendência contrária à medidasumário (tabela 20). Isso leva a crer que, quando da construção de uma série histórica, na prática de um monitoramento nessas mesmas circunstâncias, talvez fosse mais interessante retirá-las dos cálculos. Em relação às outras ocorrências, elas contribuiram, segundo o limite de freqüência de cada uma, para o resultado da medida-sumário, permitindo uma análise comparativa.

Quanto à HAS, considerando que é parte de uma programação mais estruturada, recente e diferentemente viabilizada em cada área/UBS, foi a ocorrência que apresentou maior poder discriminatório. As ocorrências relacionadas à puericultura e à saúde da mulher, possivelmente por sua implantação e manuseio mais longínquo, apresentaram menor poder discriminatório do que a HAS, e as nasofaringites e demais doenças agudas permanecem como um grande desafio para todas as unidades num gradativo processo de assunção de responsabilidades com relação aos problemas de saúde-doença da população da área e dos que procuram a unidade.

Considerando-se o exemplo de outros estudos de demanda em PS, como os realizados nos PSs dos hospitais terceirizados para organizações sociais pela Secretaria de Estado da Saúde, observa-se que as ocorrências, na maior parte das hipóteses diagnósticas escolhidas, são muito semelhantes (YAMADA et al. 2000; CASTRO et al. 2002; YAMADA et al. 2002). Entretanto, há algumas diferenças para as quais a questão da padronização da classificação parece ser decisiva, e esse é um aspecto com o qual se deve ter muito cuidado na operação do monitoramento. Nesses hospitais as ocorrências de supervisão normal de gravidez foram bem freqüentes, e nesses casos a construção de um indicador de monitoramento necessariamente deveria incluí-las, conforme já discutido sobre a plasticidade que deve existir na definição do que comporá ou não o indicador, para que ele seja o mais sensivel, específico e discriminatório possível, em correspondência à realidade local de uma situação da atenção básica. 
- Alguns médicos das UBSs entrevistados não estariam com a razão ao defender que o atendimento de crises de HAS, diabetes e asma, não é papel da atenção básica, devido à gravidade da situação?

Em relação às situações de crise das doenças crônicas de acompanhamento incluídas no estudo (HAS, diabetes e asma), avalia-se que os médicos que questionam o papel da UBS nessas situações podem ter certa razão factual, mas estrategicamente essa posição não poderá ser aceita, se se pensar em uma busca de mudança. Entende-se que a grande utilidade de um indicador é justamente impulsionar mudanças, e não construir uma contemplação fenomênica. Uma rota de mudança e qualificação do sistema de saúde pressupõe identificação e superação de dificuldades dos serviços, visando à estruturação de uma nova atenção básica marcada pela integralidade, pela humanização e pelo dinamismo na definição de suas funções.

Assim é que essas ocorrências, além de seu aspecto momentâneo importante e verificado nos dados, devem sim ser incluídas em monitoramentos, também, pela imputação de responsabilidade por princípio originário na missão que a atenção básica deva ter para o adequado funcionamento do sistema de cuidado de saúde. Caso contrário, estar-se-ia transformando toda a concepção de evento sentinela proposta num indicador do funcionamento, melhor ou pior, da capacidade de prontamente atender da unidade básica. Não se pode deixar de considerar que é papel da atenção básica antecipar-se às crises das morbidades crônicas em acompanhamento. Como expressa um médico de UBS entrevistado:

"Em relação à hipertensão e ao diabetes, a realização de grupos de orientação e controle facilita muito e possibilita o encaminhamento para reavaliação médica dos casos descompensados, com maior agilidade, possibilitando ajuste de doses ou revisão do tratamento utilizado. Acredito que com adequada orientação multiprofissional muitas das ocorrências que atualmente se direcionam ao PS poderiam ser resolvidas na UBS."

Retirar as crises significaria deixar de obrigar que a atenção básica passe, de forma gradativa, a dar conta de um complexo mais amplo, continuado, pedagógico e comunicacional do cuidado das pessoas com essas morbidades. 
- E do senso comum a idéia defendida inclusive por alguns pesquisadores da área da saúde, de que a grande motivação das pessoas para procurarem o PS tem pouco a ver com a situação da atenção básica, sendo antes um comportamento cultural. Afirma-se: "o principal motivo para uma pessoa doente não procurar o serviço básico, onde está matriculada, é a preferência, o atrativo exercido pela unidade de maior densidade tecnológica” (KOVACS et al. 2005 p.258). Ou, ainda, “[...] a escolha do local de atendimento sugere que a confiança da população no serviço é diretamente proporcional à complexidade do mesmo. Essas situações ratificam o desconhecimento da população em relação à dinâmica do atendimento de saúde e aumentam a sobrecarga dos serviços de maior complexidade” (MARTINS e PASKULIN 1992 p.25). Se assim for, a situação da atenção básica não teria de fato um efeito desprezível na procura pelo PS?

Observa-se nos discursos das pessoas atendidas e entrevistadas que essa motivação está presente - "Vou lá porque tem RX, lá pedem exames, lá tem tudo". Entretanto, nem de longe essa é uma questão das mais importantes. Pode ser que no futuro, quando obstáculos objetivos de acesso à atenção básica forem removidos, esse problema ocupe uma posição importante, até para uma maior identidade entre o papel dos serviços e sua significação social. Mas, hoje, não é essa a situação local nem brasileira. Isto é, no que diz respeito ‘a saúde, o principal problema continua sendo a falta de abrangência do atendimento e de integralidade dos cuidados e não o fetiche pelo uso de tecnologia. A aposta exagerada nessa explicação é fruto de confusão de alguns posicionamentos sobre como a atenção básica se insere na materialização do direito à saúde. Por vezes essa argumentação é usada para justificar a redução e a simplificação da assistência no sistema, com base num discurso frágil e a-histórico sobre mitológicas "reais necessidades de saúde da população", outras vezes ela se coloca mais claramente na defesa da saúde para pobres contra a integralidade, e outras ainda como crítica genérica de cunho existencialista, à alienação dos profissionais de saúde, dos médicos em especial, como se estes fossem vítimas e algozes de uma total escravidão aos interesses mercantis do metabolismo social.

Porém, não é demais lembrar que quando essa "questão cultural" se firmar socialmente como o problema principal, resultado da recusa coletiva das manifestações do fetichismo da sociedade consumista, as pessoas se verão face a face com a górgone Medusa. Estará posto de forma ampla e radical para a sociedade o confronto transformador entre o valor de uso da saúde presente na concepção do direito à saúde contra a concepção da saúde como uma mercadoria, submetida aos interesses dos valores de troca. Ou seja, a 
formação de uma representação de mundo que uma pessoa estabelece não se processa no vácuo da psique, mas na vivência concreta e cotidiana do ser social do indivíduo. É sobre essa significação social em disputa que é, e sempre será, necessário que se desenvolva uma prática esclarecedora dos e pelos profissionais de saúde, em particular daqueles ligados à atenção básica. Mas para fazer isso é preciso que haja serviço - acessível -, no qual esteja presente o ideário da saúde como direito. Pode-se sugerir, portanto, que as questões culturais são inseparáveis daquelas mais concretas e objetivas. Ou seja, ao se considerar a práxis da atenção básica, são inseparáveis, para a sua realização, as questões concretas como estrutura de recursos, disponibilidade de oferta de serviços e garantia de acesso -, de outras questões, como as culturais, ou seja, da disputa social das significações. E, diga-se mais, isso é um fato tanto na consideração de uma práxis transformadora como naquela apenas reiterativa. $\mathrm{O}$ equívoco da posição exposta na indagação inicial não é apenas exagerar na consideração da "questão cultural", mas tentar destacá-la como algo independente da totalidade do funcionamento dos serviços e da vida cotidiana. Ao conduzir-se nessa direção erra-se duplamente, pois essa questão cultural torna-se algo com uma gênese mágica e, por outro lado, retira-se da atenção básica todo o seu conteúdo valorativo, convertendo-a de práxis em prática automática e repetitiva de procedimentos e atos assistenciais (VAZQUEZ 1990; KOSIK 1995).

- Aceitando que o uso substitutivo do PS em relação à UBS não pode ser explicado de forma simplista, reduzindo-o a uma questão cultural de veneração tecnológica e despregando-o da realidade concreta da atenção básica de cada área, então toda essa problemática não se resumiria à existência ou não de vaga no dia, isto é, à existência de um pronto-atendimento na unidade básica? Essa possibilidade não tornaria reducionista esse indicador de avaliação da atenção básica, quando ao final ele acaba se restringindo a monitorar a existência ou não de um pronto-atendimento médico?

Essa argumentação confunde a necessidade e o direito das pessoas a uma resposta imediata, quando necessário, dos serviços básicos de saúde com outro tipo de serviço historicamente distorcido, sobretudo da ação médica, restrito aos moldes de queixaconduta. Com essa confusão, todas as pessoas que se preocupam em pensar uma maneira concreta para responder à demanda do dia não agendada são, muitas vezes, classificadas como contrárias aos ideais da saúde coletiva, como pessoas que não valorizam a promoção da saúde por terem apego ou interesse em uma limitada prática clínica individual. 
O fato é que o pronto atender, e com médicos, é objetivamente fundamental para a atenção básica. A questão que se coloca é como fazer isso de forma racional, ampla, estável e articulada com os princípios gerais de defesa do direto de todos à saúde; como fazer isso de forma a ampliar o cuidado imediato, quando necessário, com a contribuição de variadas profissões de saúde; como reconhecer o momento da intervenção de um ou de outro profissional; como fixar e articular protocolos que possam permitir uma ampliação do trabalho interdisciplinar e um cuidado continuado.

Essas mudanças, considerando-se a experiência gerencial acumulada no SUS, não ocorrerão imaginando-se que surgirá subitamente no fluxo de uma longa história de unidades básicas, fragilmente organizadas, capengas de recursos e desumanizadas na sua ação, um pronto-atendimento qualificado. A mudança não é uma questão de discurso, de uma roda de acordos corporativos ou de imposição burocrática, pois a implantação nessa rota acaba funcionando por um período reduzido, como vitrine gerencial, sem estabilidade, finalidades e responsabilidades claramente assimiladas pelas pessoas envolvidas.

A resposta imediata que a população procura nos serviços básicos é uma mudança politicamente construída no gradativo reconhecimento do usuário como cidadão portador de um direito. Uma mudança que não é simples nem consensual, envolve interesses diversos, exige canais de participação crítica e decisão entre gerentes, equipe de saúde e cidadãos/usuários. Assim, para uma unidade capacitar-se a responder com acesso à procura das pessoas com problemas de saúde, no momento em que procuram atendimento à sua dor ou sofrimento, há que equacionar uma variedade de processos, que nem de longe se reduzem a uma simples existência formal de um pronto-atendimento médico (PUCCINI 2002).

- Mas o indicador proposto, ao valorizar 0 atendimento clínico realizado pelos profissionais de saúde e pelos médicos, em particular, não estaria favorecendo e ampliando uma medicalização dos problemas das pessoas que procuram o serviço?

Segundo COLLARES e MOYSES (1994), medicalização é o processo de transformar questões não médicas, eminentemente de origem social e política, em questões médicas, isto é, de tentar encontrar no campo médico as causas e soluções para esses problemas. Até há alguns anos esse processo era concretizado pelos profissionais médicos, e dessa circunstância advém o termo medicalização para nomear tal prática. Entretanto, 
mais recentemente, com a criação/ampliação de campos de conhecimento, novas áreas, com seus profissionais, estão envolvidas nesse processo. São nutricionistas, fisioterapeutas, terapeutas ocupacionais, psicólogos, fonoaudiólogos, enfermeiros, psicopedagogos que se vêm aliar aos médicos. Daí a proposta de substituir o termo medicalização por outro mais abrangente - patologização -, uma vez que o fenômeno tem-se ampliado, fugindo dos limites da prática médica. A patologização desloca as preocupações do coletivo para o particular. $\mathrm{O}$ que deveria ser objeto de mudança fica mascarado, ocultado pelo diagnosticar e tratar singularizados, e um fim desse processo é a culpabilização da vítima e a persistência do sistema de iniqüidades perverso, com alta efetividade ideológica, conseguindo que a própria vítima se sinta a culpada e se desespere à procura de socorro em algum serviço.

A patologização da sociedade não é mais um processo relativo somente à atuação do profissional médico. O interesse mercadológico na saúde, hoje, tem muitos mercadores. Transformam-se problemas e dramas de origem e resolução econômica e social em questões de saúde-doença, e a esse ocultamento da essência dos problemas estão sujeitos todos os profissionais, inclusive os agentes comunitários de saúde. Mas os problemas escolhidos para monitorar a atenção básica são ocorrências nosológicas criteriosamente identificadas e classificadas (conforme anexo 6), assim não se acredita que essa técnica de monitoramento seja um incentivo à patologização.

É certo que se verifica uma tendência crescente de uso de serviços de saúde por queixas/doenças que poderiam ser cuidadas com maior autonomia em casa ou com o simples apoio da comunidade, mas essa é outra questão, diferente em substância do ocultamento produzido pelo processo da patologização.

- Mas não haveria uma procura desmedida e exagerada pelo atendimento no dia, transformando desnecessariamente tudo em urgência, o que o indicador proposto só tende a ampliar?

Esse problema de fato existe, é uma situação real. A questão é como entender melhor sua determinação e como construir alternativas socialmente aceitáveis. A busca irrefreável, às vezes frenética por uma consulta médica no dia por parte dos usuários não pode ser plenamente entendida se reduzida à tendência de patologização ou à falta de conhecimento ou autonomia para enfrentar o adoecer. 
O Conselho Federal de Medicina (SÃO PAULO 1995) em sua resolução 1451/95, define como urgência "a ocorrência imprevista de agravo à saúde com ou sem risco potencial de vida, cujo portador necessita de assistência médica", e como emergência, "a constatação médica de condições de agravo à saúde que impliquem risco iminente de vida ou sofrimento intenso, exigindo, portanto, o tratamento médico imediato". O balizamento é dado pela irreversibilidade do dano, que é, também, o fundamento do significado jurídico do termo, isto é, significa o que uma situação tem a ver com a irreversibilidade de um dano ou prejuízo para alguém. A procura pela população de uma vaga na hora, imediata, a busca incontrolável por ser prontamente atendido não tem a ver com o conceito médico ou jurídico de urgência. Não é fruto de ignorância sobre gravidade, é experiência vivida nas condições de acesso à saúde do seu grupo social e do valor moral de tudo fazer para preservar a vida e a saúde própria ou a dos seus. A idéia de grave para o usuário tem a ver mais com o temor (que não é ilusório) de uma situação que pode ter conseqüências sérias ou trágicas para sua vida ou a de seus familiares, ao passo que para os profissionais de saúde a idéia de grave é mais sentida como razões importantes que levariam a um proceder técnico justificando a necessidade de uso de um serviço.

O depoimento das pessoas dá prova de que sabem o que estão fazendo, sabem quando o problema é grave o suficiente para passar na UBS. Quando não é, paradoxalmente sabem que é melhor ir direto ao PS, sabem da artimanha de alegar febre para ter mais chance de ser atendido, sabem que quando se chega "grave" à unidade há uma grita pelo porquê de não terem ido direto ao PS. Isso significa que não há uma mobilização pela consulta no dia por ignorância do corpo, nem por falta de autonomia no cuidar da saúde, nem tampouco por influência da patologização. $O$ fato é que historicamente se constituiu uma sensação de gravidade que está vinculada ao descaso a que o usuário dos serviços públicos de saúde foi submetido. Não é à toa que só a vivência de um atendimento, supervalorizada por toda a indução social e da corporação médica, em especial, parece encerrar a responsabilidade do acompanhante ou satisfaz uma expectativa. Parece que, mesmo quando seu problema não é grave, as pessoas não suportam deixar de ter uma palavra final no ato, no momento, no dia, a fim de aliviar-se de uma responsabilidade e não ter que suportar a suspeita própria ou de outrem de não ter feito tudo ao seu alcance.

Em poucas palavras é preciso reconhecer que a sensação de gravidade para as pessoas é prenhe de aprendizagem histórica da incerteza do acesso. 
Esse significado da gravidade de problemas de saúde torna-se mais complexo ainda quando aliado ao fato de que em problemas de saúde-doença as pessoas costumam resolvêlos não com um serviço qualquer de conveniência, mas com serviços para os quais as pessoas tendem a fazer o maior esforço possível para obter atendimento de forma rápida e na qualidade imaginada, segundo as experiências da classe social em que vivem (LAS CASAS 1991).

A questão do tempo é assim um elemento imanente a esse aspecto da irreversibilidade da busca do atendimento imediato. O tempo, elemento constituinte da atitude da procura no dia, é um importante aspecto do cuidado, ainda muito pouco compreendido ou resolvido pelos serviços. $\mathrm{O}$ tempo perdido, em qualquer situação, é uma vivência de dificil aceitação, pois envolve aspectos da inter-relação entre tempo, envelhecimento e morte. Mas na questão da saúde, o tempo é vivido de forma mais angustiada, pois a sua perda nesse caso é para notícia do consumo da vida, uma perda de tempo de vida exatamente para a revelação do aproximar da morte (MELLO FILHO 1973; LEVINSON 2000). Ferreira Gullar oferece um poema que muito ajuda a compreender tal situação:

\author{
[...] Ela veio chegando ao ritmo do pulso, \\ sem pressa nem vagar e sem perder o impulso \\ que empurra a vida para o desenlace, para \\ o ponto onde afinal o sistema dispara \\ cortando a luz do corpo - e a máquina pára. \\ Muito antes, porém, que ocorra esse colapso, \\ chega o aviso da morte, indecifrado, lapsus \\ linguae, sinal errado ou mal pronunciado \\ no código de sais, ou não compreendido \\ deliberadamente: a gente faz ouvido \\ de mercador à voz que a morte noticia \\ pra não ouvi-la, já que não tem serventia \\ ouvi-la e assim saber que a hora está marcada [...] \\ Nova Concepção da Morte, GULLAR (2000, p.464-66)
}

Refletindo nessas direções, a explicação das razões que se estabelecem para o uso substitutivo da atenção básica, levando às diferenças encontradas nos valores de chance de 
HDE de cada unidade, amplia-se e abrange um conjunto de questões que permeiam a implantação de mudanças. Esse conjunto não se reduz ao conhecimento de recursos disponíveis, aos processos normalizados burocraticamente ou ao volume de produção de atos e procedimentos, aspectos necessários, mas não suficientes para a compreensão do impacto da atenção básica em cada local.

É impossível compreender os problemas da atenção básica se o ser humano, no âmbito dessa totalidade, é considerado apenas objeto e se as relações entre as pessoas e seus grupos de interesse não são colocadas como parte dessa totalidade (KOSIK 1995).

- A necessidade de modificação dos processos de trabalho e, portanto, da situação dos trabalhadores da saúde é amplamente reconhecida. Isso não significa que valeria mais monitorar as ações de participação e motivação, de autogoverno do trabalhador, das condições da chamada “micropolítica do fazer”, lócus onde se processam as mudanças, do que ficar monitorando algo tão pontual e limitado, que pouco contribui para compreender os desejos de cada um dos envolvidos?

O indicador em discussão não é alternativo, não está sendo proposto para substituir qualquer outro esforço, nem ao menos se avalia que ele tenha uma abrangência suficiente para dar conta e monitorar os variados aspectos envolvidos na atenção básica e no seu processo de mudança.

A questão da subjetividade, como muitas vezes corretamente valorizada na literatura da área, é um componente indiscutível e muito presente no processo de cuidado em saúde. Mas há certa tendência a tratá-la como um aspecto independente no processo de realização do trabalho em saúde. Muitas vezes acaba-se operando com uma imagem excessivamente idealizada do subjetivo dos trabalhadores da saúde, quando se afirma, por exemplo, que recurso humano em saúde é gente que anseia proporcionar uma melhor qualidade de vida aos usuários ou, ainda, quando se adota o pressuposto de que processos participativos na organização do processo local de trabalho (micropolítica do trabalho) conduziriam a uma desalienação do trabalhador em saúde.

Nessa linha de pensamento, será mesmo, como sugerem MERHY (1997) e MISHIMA et al. (2003), que a subjetividade pode ser entendida como determinada por anseios e emoções individuais (o conceito do ser humano como "máquina desejante") e que a ela pode ser atribuída de forma autônoma o estabelecimento das inter-relações no 
momento do trabalho vivo? Qual a real potência que a vivência de processos participativos na atividade dos trabalhadores de saúde teria na superação da condição de trabalho alienado? Tratar a natureza global do processo de alienação de forma secundária, dedicando pouca atenção para suas conseqüências na totalidade da vida social não poderia resultar numa proposta com forte apelo corporativista e sindical?

É necessário valorizar as subjetividades sem ultrapassar o alcance de sua potência transformadora, evitando-se produzir uma "psicologização" dos processos de mudança ao não atentar para a essência sociológica desses fenômenos, "metê-los à força nos limites estreitos de um organismo individual e seu psiquismo" e explicar processos essencialmente sociais do ponto de vista da psicologia individual (BAKHTIN 2001, p.20). Discutindo aspectos da alienação, KONDER (1965) afirma que o refúgio na vida privada não impede que a dilaceração do humano sacrifique a unidade e promova a confusão. $O$ mundo psíquico atomiza-se tanto quanto o social e perde o sentido da totalidade, e esse choque é vivido de forma inautêntica sob a caricatura de um conflito entre a "razão e os sentimentos", como uma manifestação da cisão entre o singular e o universal, entre os indivíduos e a espécie no interior dos indivíduos. Assim, sem a percepção do que há de comum com os outros, as diferenciações individuais passam a ser observadas independentemente da história concreta e das condições materiais de vida dos homens.

A eleição da "micropolítica do fazer" como o centro do processo transformador do trabalho em saúde retira as pessoas da desesperança e do imobilismo, mas pode, também, criar um novo véu que se interpõe entre a realidade das coisas e os homens, mascarando-a, bem como às condições determinantes do que se pretende mudar (DURKHEIM 1978). Nesse contexto, é oportuno também considerar o exagero que existe em supor que processos de mudança centrados na autogestão dos serviços de saúde pelos seus trabalhadores, no interior do sistema capitalista, isolados, setoriais e, portanto, marcadamente coorporativos, tenham condições de romper a lógica capitalista e comprometer-se com a lógica dos usuários. Ademais, seria interessante definir mais claramente que lógica é essa dos usuários e quem a elegeria como tal. Seria a lógica limitada às necessidades necessárias conforme criticada por HELLER (1978)? Estabelecer o centro diretor de mudanças alicerçado no dissecar da "micropolítica do fazer" traz contribuições e, também, apresenta grandes limitações, pois essa estratégia perde sua potência transformadora quando desarticulada da construção de projetos contrahegemônicos amplos. É preciso considerar todas as partes num todo em mudança. 
Em uma análise critica, essas indagações conduzem a um necessário posicionamento sobre o núcleo da alienação do trabalhador em saúde. Seria uma alienação produto da disputa genérica entre trabalho morto e sua tendência de capturar o trabalho vivo numa dada racionalidade instituída? Seria, por outro lado, fruto do confronto entre valores de uso e valores de troca e da supremacia deste que se estabelece em particular no sistema capitalista, penetrando na totalidade da vida social, tal como propõe o conceito de reificação? Reificação é aqui entendida como a situação resultante do tipo de processo produtivo da sociedade, e por ele caracterizada sobretudo no sistema capitalista, em que o trabalho humano, cuja base é uma relação entre pessoas, se realiza de modo que produza coisas que são separadas dos homens, para se transformarem em mercadorias independentes ou imaginadas como tal e que, em vez de serem intermediárias entre indivíduos, convertem-se em realidades soberanas que passam a governar a vida social, submetendo a atividade humana, a qual se torna estranha ao próprio homem (LUKÁCS 1974).

Essa condição de submissão da atividade humana tem que ser considerada como uma característica geral da sociedade capitalista. Assim, idealizar o usuário do serviço público de saúde como se fosse uma pessoa estruturalmente mais generosa também pode levar a não reconhecer um conflito, para o qual esse usuário contribui numa inter-relação muitas vezes ríspida, repleta de preconceitos e do egoísmo individualista tão cultuado na sociedade, expressando uma revolta dispersa que é sentida particularmente pelos mais comprometidos profissionais de saúde. Uma certa fricção é inevitável e até pedagogicamente produtiva, impulsiona mudanças, mas não há como negar um conflito desagregador crescente entre usuários e profissionais dos serviços públicos. Esse quadro histórico-social recebe o combustível do descaso pelas pessoas que procuram atendimento nos serviços públicos. Toda essa situação destrutiva vai levando a população a criar um conceito, ou um preconceito, a respeito dos serviços de saúde e amplia a agressividade e o desprezo mútuo entre as pessoas.

KONDER (2000, p.29), discutindo o tipo humano burguês, o tipo humano da nossa sociedade e seus dilemas éticos, afirma:

"Querem ser bons, no entanto precisam aprender a ser maus. Querem ser solidários, mas não conseguem deixar de ser egoístas. Um certo calculismo se infiltra, gélido, até mesmo na cálida intimidade dos afetos. Virtudes e vícios se misturam, qualidades e defeitos se confundem. Inteligência e 
esperteza se transformam em malandragem e matreirice. Generosidade vira burrice. O homem burguês é um ser eticamente irresolvido."

Walter Benjamim, apud KONDER (1988, p.40), com uma apreciação aguda, reforça a dilaceração do humano no sistema produtor de valores de troca, afirmando que

“o dinheiro ocupou 'militarmente' o centro das conversas e das relações entre as pessoas, empobrecendo brutalmente a arte de conversar e conviver e obrigando as pessoas a só falarem nos preços das mercadorias."

Assim, procura-se alertar para o fato que, para fazer mudanças, é preciso atentar coletivamente, e não apenas corporativamente, para o peso da força do passado e dos interesses do presente na totalidade social. Nos processos de reforma, em especial setoriais, o passado e a racionalidade instituída de uma sociedade nunca são definitivamente isolados, eles estão sempre presentes em todos nós, continuam agindo em nós com toda a força da tradição a favor e contra o humano do homem. Como afirma Walter Benjamin (apud KONDER 2000, p.106): “Todos os terrenos precisam ser tornados transitáveis pela razão, precisam ser limpos da galharia, da loucura e do mito".

Com essas preocupações não se quer menosprezar a necessidade de novos caminhos na gestão do trabalho em saúde, nem tampouco afirmar que não se devam incentivar e monitorar avanços de participação e democratização do processo de trabalho. Entretanto, a complexidade e os condicionamentos para uma transformação radical dos processos de trabalho impõem que se considere de forma mais modesta as possibilidades de mudanças num dado regramento econômico-social. Assim, algumas avaliações sobre mudanças conquistadas por meio de processos participativos dos trabalhadores na "micropolítica do fazer", embora motivadoras, estão mais próximas de declarações de fé, pois em choque com a totalidade social concreta esgotam-se, são fugazes, descontínuas, significativamente distantes de vislumbrada transformação dos trabalhadores em "sujeito social coletivo".

$\mathrm{O}$ indicador proposto, ainda que somente tenha potencialidade para monitorar algo bem mais singelo e pontual, é concreto e está ao alcance de uma intervenção, o que pode contribuir para a defesa continuada da implementação de mudanças gradativas na atenção básica, colaborando com a resistência às políticas públicas mínimas. $\mathrm{O}$ indicador, de forma concentrada, repercute os processos de trabalho, o compromisso e a participação dos 
profissionais e o que pensam e como reagem os usuários, maiores interessados na missão do sistema de saúde, embora não seja o instrumento mais apropriado para monitorar, especificamente, cada um desses aspectos.

\section{- Será possível ao gestor local manter o indicador analisado? Não haverá grande gasto de} tempo dos profissionais, resultando numa relação custo-benefício pouco favorável?

$\mathrm{O}$ instrumental de monitoramento analisado não será montado sem algum esforço adicional da equipe local de saúde. Mas é algo muito sintonizado com a atividade cotidiana de gestão. A maioria dos municípios conta com profissionais que assumem responsabilidades no acompanhamento das atividades de saúde integral da criança, da mulher e do adulto, e as UBSs também podem contribuir periodicamente com pessoas para viabilizar a coleta e a análise dos dados. Entretanto, seria bom que houvesse uma equipe mais fixa, pois isso permite melhor padronização das classificações nosológicas e na realização das entrevistas. Acredita-se que, para um município do porte do estudado, três profissionais, após uma capacitação feita em não mais que uma semana, incluindo o treinamento para o programa de metanálise, possam operar toda a idéia de coleta e cálculos aqui apresentadas. Os profissionais que manteriam esse instrumento estariam envolvidos nessa atividade durante uma quinzena a cada trimestre, por exemplo, mas não é uma atividade distante do que fazem, é um momento de contato com a situação real, muito interessante para a observação e o reconhecimento de problemas. Trata-se de uma atividade pedagógica para quem se propõe a organizar programas integrais de saúde.

A viabilidade do indicador aqui analisado não está, portanto, só no pouco tempo de trabalho que exige, mas no fato de que não constituirá um gasto de tempo paralelo às funções da equipe local de gestão ou de coordenação programática, a qual muitas vezes não sabe como sair do escritório e ter um contato mais concreto com o que está acontecendo e com as dificuldades na linha da execução.

Um grave problema que pode acontecer na gestão local é o indicador vir a tomar ares de pavão e tentar substituir a politica. A gestão começará, então, a correr atrás de metas de indicadores como se estas tivessem ligação linear e natural com as prioridades gerenciais a serem enfrentadas, na sedução do enquadramento do real por única política possível e infalível. 


\section{- Mas não seria mais prático e simples acompanhar indicadores relacionados com a tríade clássica - estrutura, processo e resultados?}

Acompanhar estrutura, processo e resultado não é incompatível com o proposto. Ao contrário, os dados de estrutura e processo podem, em contato com o indicador em análise, ilustrarem-se mutuamente. Por exemplo, é muito importante saber as horas/médico disponíveis em cada local, ou a porcentagem das mulheres matriculadas no pré-natal de uma localidade, ou o número de hipertensos sob cuidado contínuo; mas esses dados, aliados ao indicador em análise, mudam de qualidade e passam em conjunto a dizer muito mais.

Ademais, é bom lembrar que a técnica de acompanhar estrutura e processo, isoladamente, pressupõe uma cadeia de determinações com uma estabilidade modelar que na prática dos cuidados de saúde é dificilmente verificada (VUORI 1991; SILVA e FORMIGLI 1994; MEDINA et al. 2000).

Uma UBS pode, por exemplo, ter uma cadeia de frio exemplar, perfeita, pode ter seus vacinadores bem capacitados, estoque de vacinas controladas por novíssimos computadores e não obstante apresentar baixa cobertura vacinal. Essa desconexão concreta entre estrutura, processo e resultado alerta para as dificuldades de garantir o extenso rol de pressupostos envolvidos na linearidade sistêmica do modelo da tríade.

Aparentemente é lógico que, dada uma boa estrutura e adequados processos, haja bons resultados. Mas nessa linha de raciocínio há pelo menos três grandes questões: a primeira diz respeito à condição estruturalmente heterogênea na prestação de serviços pessoais especializados, nos quais é forte a dependência da realização do trabalho da pessoa do profissional, o que produz grande variabilidade e instabilidade na adesão a um conjunto de normas ou padrões dos processos de atendimento estabelecidos (LAS CASAS 1991); o segundo diz respeito à natureza consciente e ativa do objeto do sistema. Não é útil ou mesmo ético esperar que uma pessoa que adentra ao sistema de serviços de saúde comporte-se tal qual um lingote de ferro numa siderúrgica. Ou seja, não há como realizar uma práxis de saúde sem o convívio, sem atentar para as singularidades do ato cuidador como interação entre pessoas, sempre mais dinâmico e flexivel do que qualquer extenso detalhamento modelar. A terceira questão diz respeito à dificuldade na definiç̧ão do que seja um bom resultado. Quantos equívocos são diariamente cometidos em nome de "bons" resultados. Pode-se lembrar o uso da talidomida, a recente reposição hormonal, que 
resultou numa epidemia de câncer de mama, o uso do medicamento Viox e tantas outras questões. O fato é que mesmo resultados aparentemente respeitáveis e altamente qualificados podem, muitas vezes, se transformar até em iatrogenia, porque a idéia de resultado é sempre diferente no tempo e no espaço, ela muda de forma permanente, está sujeita às imposições dos valores de troca, e isso embaralha a pretensa estabilidade avaliativa de eficácia baseada em estrutura e processo.

Do ponto de vista mais geral, essas são questões que apontam os limites do modelo da análise sistêmica quando aplicada às práticas sociais não mecanizáveis, para as quais o modelo sistêmico tem reduzida capacidade de compreendê-las criticamente no seu processo de transformação.

Essa mesma limitação do modelo sistêmico é, também, uma razão da confrontação, na prática gerencial, entre a adoção de uma diretriz de humanização radical dos serviços, o que pressupõe reconhecer e mergulhar no fluxo das transformações para disputar um direcionamento, e a adoção de uma diretriz da "qualidade total", cujo fundamento orienta a gerência para a obsessão de normalizar, de pré-fixar estratégias e de cravá-las na margem, procurando ancorar o fluxo das coisas, resistindo e contrapondo-se ao movimento geral de mudanças. Quando, com o passar do tempo, um turbilhão arrasta as convicções mecânicas mais certeiras, de súbito conclui-se que a falha decorreu do fato de a realidade não ter sido fincada mais firme e estancada como devia. Ou, pior, a preguiça intelectual e o pânico diante de incertezas tomam conta e, em toque de retirada, adota-se a idéia de que as coisas são assim mesmo, pois é impossível explicar as coisas, já que na vida tudo é relativo, depende da interpretação individual, e não existe conhecimento: as certezas, não sendo eternas, são inúteis, e no fundo só o acaso explica a realidade...

O indicador analisado não é um indicador de estrutura ou de processo, mas ele reflete essas dimensões das atividades e dos serviços. Ele também não é um resultado esperado, ele é o resultado negativo, o anti-resultado, a tentativa de negação do sistema modelado em cada local e pode, assim, cumprir um papel, estabelecido na metodologia científica, de contribuir na refutação do estabelecido e fixado. 


\section{Conclusões}

Definir indicador é um caminho para se aproximar da compreensão do funcionamento do todo. Seja para avaliação, seja para monitoramento, os indicadores não podem ser entendidos como objetivos de uma ação ou da gestão, desvio muito comum com indicadores de avaliação, os quais os niveis hierárquicos com menor poder obrigam-se a colocar no centro da sua missão, por sentirem-se vulneráveis a cobranças externas, estas, muitas vezes, sem sentido operacional real.

RATTNER (2003), criticando a tendência de transformar indicadores em centro da problemática de desenvolvimento de uma política social ou econômica, afirma que esse caminho pressupõe erradamente que indicadores estatísticos constituiriam um retrato fiel da realidade e que a tarefa mais importante passaria a ser o aperfeiçoamento do sistema de informações, ou seja, melhores indicadores levariam automaticamente a uma política social mais eficaz e justa, orientada e controlada pelos tecnocratas cujo modelo de organização social seria um sistema baseado no consenso. Enfatiza ainda que para evitar esse caminho seria aconselhável que a explicação das relações sócio-políticas, subjacentes aos planos, metas e programas, precedesse a elaboração dos sistemas de informação ou dos indicadores.

Nenhum indicador pode ser entendido como absoluto, trata-se apenas de mais um instrumento. Os indicadores não explicam nada: fornecem informações para uma explicação. A fragilidade histórica dos indicadores foi discutida, e sua neutralidade renegada, uma vez que sua construção envolve juízos de valor, opções prévias de valores e visões de mundo, que no presente trabalho estão fixados e expressos nos princípios que procuram qualificar a abrangência e a extensão do direito de todos à saúde.

É preciso estar vigilante quanto a tendências que procuram ultrapassar a potencialidade real dos indicadores, transformando-os em biombos que escondem os problemas concretos. Sempre há uma tendência de transformar indicador em meta, e aí ele acaba reduzido a um controlador de volume de atos, sem produzir alterações no processo de trabalho. Essa alternativa, que não tem permanência, é muito valorizada numa visão campanhista. Fornece projeção na mídia e em nada contribui para a ordenação estável dos serviços e de um sistema de saúde. 
O indicador estudado tem uma importante característica a se destacar como princípio para a sua operação futura. $O$ levantamento dos discursos dos envolvidos deverá ser mantido e aperfeiçoado, ainda que em menor periodicidade que o levantamento quantitativo das ocorrências. Esse procedimento pode ser uma vacina eficaz contra a tendência do indicador de degenerar para uma matemática gerencial, mantendo sua capacidade crítica ao assimilar variações qualitativas.

Mas para concretizar princípios não basta declará-los, são necessárias informações objetivas que digam sobre uma prática executada, não apenas sobre instrumentos tecnológicos da prática, sobre atividades meio, pois para embasar as discussões da equipe no processo de mudança há necessidade da objetividade do conhecimento da situação concreta. Há necessidade de dados que não sejam, apenas, auto-referidos, mas que tenham um certo distanciamento para poder avaliar o que está resultando determinada prática de um grupo. $\mathrm{O}$ dado do indicador de monitoramento cumpre um papel por vezes semelhante àquele desempenhado por um consultor externo. Com suas vantagens e limites, é uma colaboração crítica para uma equipe de trabalho propiciada por algo não diretamente implicado nas inter-relações cotidianas.

Indicadores, na óptica do monitoramento, são instrumentos que ajudam a observar uma característica ou um conjunto, sempre limitado, de características. Eles nos aproximam da compreensão do todo de um sistema complexo, como é o de saúde, com base na decomposição de suas partes, julgando-as segundo valores presentes no devir projetado para uma prática social. Assim, eles permitem acompanhar mais de perto as ações e as atividades, colaborando com subsídios para o planejamento e a gerência.

Do ponto de vista prático, o emprego de indicadores exige consideração detalhada de algumas características ou requisitos para o cumprimento da sua função. As características discutidas a seguir foram estabelecidas com base em conhecidos critérios para a escolha de indicadores de saúde e, também, com base na intencionalidade de induzir os princípios da reforma sanitária. Assim, com esses critérios avalia-se a qualidade do indicador de monitoramento em estudo:

- Simples: facilidade na obtenção dos dados, fácil de ser calculado e compreendido pelas pessoas diretamente envolvidas e interessadas em se apropriar das informações, constituindo-se em instrumento prático, voltado à realidade local e que pode apoiar tomadas de decisão. 
- Robusto: pouco sensível à defíciência de dados (sobretudo dados de população) necessários à sua construção. Essa foi uma das razões da utilização do conceito de chance na análise.

- Específico: associa-se mais fortemente com a situação da atenção básica a ser monitorada.

- Sintético: expressa um complexo de possíveis fatores determinantes da situação da atenção básica.

- Relevante: retrata aspectos essenciais da atenção básica que se deseja monitorar, exigindo definições mais claras sobre os objetivos e os papéis da atenção básica no sistema.

- Evolui ao longo do uso: existe a possibilidade de aprimoramento do indicador; ele tem condições de se adequar a diferentes condições da atenção básica.

- Discriminante: pode diferenciar níveis e indicar alterações que ocorram com o tempo, pois varia em razão de mudanças nos processos ou sistemas de interesse do monitoramento. Mas essa capacidade depende de esforço adaptativo permanente e de um certo volume de variação para ser detectada.

- Cobertura: pode ser disponível para diferentes áreas/UBSs e localidades, permitindo amplas comparações.

- Útil à tomada de decisão: facilita a priorização de ações corretivas, na medida em que pode manter um acompanhamento de cada unidade e entre unidades ao longo do tempo.

- Utilizável para o controle social: pode ser comunicado e apropriado pela população, fortalecendo o processo de participação dos conselhos de saúde e do usuário em geral.

- Custo aceitável: não exige grandes dispêndios para obtenção das informações, cálculo e manutenção periódica. 
- Respeito ético: não suscita nenhum problema de ordem ética, além de necessitar da opinião periódica dos envolvidos, sendo plenamente possível manter a confidência das informações levantadas.

Considerando as limitações apontadas, as vantagens $\mathrm{e}$ as qualidades do indicador analisado, finalmente conclui-se que:

- a freqüência das ocorrências escolhidas foi influenciada pelas áreas/UBSs de procedência das pessoas;

- foi possível sugerir com razoável plausibilidade que essa influência detectada é, em parte, determinada pela situação da atenção básica em cada área/UBS;

- a téenica de levantamento de evento sentinela em pronto-socorro para o monitoramento da atenção básica mostrou-se tecnicamente possível;

- o instrumental de monitoramento estudado pode ser produzido e mantido com uma operação simples e viável para o gestor municipal;

- o indicador satisfaz de forma aceitável um conjunto de requisitos que o qualifica para a função de monitorar o que se propõe;

- o indicar não revela todos os aspectos e dificuldades da atenção básica, mas propicia um maior diálogo com o cotidiano mais imediato dos serviços e pode somar-se e conviver com outros indicadores, propiciando a sua parte de contribuição.

Para a materialização dessas qualidades será preciso desenvolvê-lo, levá-lo à prática. $\mathrm{O}$ indicador proposto precisa ser aprimorado, receber contribuições de novas pesquisas acadêmicas e, sobretudo, ser testado e revisto com seu uso na ação prática de monitorar. 


\section{Bibliografia}

Anadão CA, Alvarenga EHL. Otite média. In: Borges DR, Rothschild HA, editores. Atualização terapêutica - 2003. São Paulo: Artes Médicas; 2003. p.1211-4.

Assis MMA, Gonçalves ML, Matos MS. Atenção primária de saúde x sistema único de saúde: apontamento para um debate. Rev baiana enfermagem 1993; 6:78-88.

Bakhtin M. O freudismo. São Paulo: Perspectiva; 2001. 110p.

Baracat EC, Bonduki CE, Albuquerque Neto LC, Lima GR. Sangramento uterino disfuncional. In: Borges DR, Rothschild HA, editores. Atualização terapêutica - 2003. São Paulo: Artes Médicas; 2003a. p.623-4.

Baracat EC, Haidar MA, Costa AMM, Lima GR. Amenorréia. In: Borges DR, Rothschild HÁ, editores. Atualização terapêutica - 2003. São Paulo: Artes Médicas, 2003b. p.61320.

Bardin L. Análise de conteúdo. Lisboa: Edições 70; 2000. 226p.

Bellei NCJ. Gripes e resfriados. In: Borges DR, Rothschild HA, editores. Atualização terapêutica - 2003. São Paulo: Artes Médicas; 2003. p.285-88.

Bodstein R. Atenção básica na agenda da saúde. Ciênc saúde coletiva 2002; 7:401-12.

Brasil. Ministério da Saúde. Portaria No 3925 de 1998. Aprova o Manual para Organização da Atenção Básica no Sistema Único de Saúde. [Online] Brasilia, 1998. Disponível em: <http//www.saude.gov.br/sus/portarias/Port 1998>[set 2004].

Brasil. Ministério da Saúde. Portaria No 476 de 1999. Regulamenta o processo de acompanhamento e avaliação da atenção básica - Pacto de indicadores da atenção básica. [Online] Brasília, 1999. Disponível em: <Http//www.saude.gov.br/sus/portarias/Port1999> [set 2004]. 
Brasil. Ministério da Saúde. Secretaria de Atenção à Saúde. Departamento de Atenção Básica. Pacto de Indicadores da Atenção Básica: instrumento de negociação qualificador do processo de gestão do SUS. Rev Bras Saúde Matern Infant 2003; 3:221:4.

Braverman H. Trabalho e capital monopolista: a degradação do trabalho no século XX. $3^{a}$ ed. São Paulo: Livros Técnicos e Científicos; 1987. 379p.

Bruyne P, Herman J, Shoutheete M. Dinâmica da pesquisa em ciências sociais. Rio de Janeiro: Francisco Alves; 1977. 251p.

Bueno WS. Betim: construindo um gestor único Pleno. In: Merhy EE, Onocko R, organizadores. Agir em saúde. São Paulo: Hucitec; 1997. p.169-95.

Carvalho MCBC, Barreira MCRN. Apresentação In: Carvalho MCBC organizadora. Tendências e perspectivas na avaliação de políticas e programas sociais. São Paulo: [EE/PUC-SP; 2001. p.7-12.

Castro CGJ, Almeida MF, Cardoso MRL, Bertolino ME, Puccini PT. Estudo do perfil da demanda do serviço de pronto-socorro do Hospital Geral de Itapecerica da Serra. São Paulo: Faculdade de Saúde Pública da Universidade de São Paulo, 2001. 151p.

Castro CGJ, Almeida MF, Yamada ATT, Garbin W, Oliveira NA, Oliveira MS, Sá ENC, Gomes MC. Estudo do perfil da demanda do serviço de pronto socorro do Hospital de Itaim Paulista. [Online] São Paulo: Faculdade de Saúde Pública da Universidade de São Paulo, 2002. Disponivel em <http://www.bvs-sp.fsp.usp.br/tecom/docs/2002/cas003.pdf> [20 jun 2004].

Cecilio LCO. Modelos tecno-assistencias em saúde: da pirâmide ao círculo, uma possibilidade a ser explorada. Cad Saúde Pública 1997; 13:469-78.

Cecílio LCO. As necessidades de saúde como conceito estruturante na luta pela integralidade e eqüidade na atenção. Campinas. In: Araújo R, Pinheiro R, organizadores. Os sentidos da integralidade na atenção e no cuidado à saúde. Rio de Janeiro: IMS/UERJ - ABRASCO; 2001. p.113-26. 
Cesar CL, Tanaka OY. Inquérito domiciliar como instrumento de avaliação de serviços de saúde: um estudo de caso na região sudoeste da área metropolitana de São Paulo, 19891990. Cad Saúde Pública 1996; 12(supl 2):59-70.

Collares CAL, Moyses MAA. A transformação do espaço pedagógico em espaço clínico (a patologização da educação) [Online]. São Paulo: FDE, 1994. Disponível em $<$ http://www.crmariocovas.sp.gov.br> [nov 2004].

Consenso Brasileiro no Manejo da Asma - III. J Pneumol 2002; 28(supl 1):S1-S28.

Conill EM. Complementando a discussão sobre a atenção básica: podem o acesso, a integralidade e o controle social se constituírem em temáticas de consenso para a avaliação da reforma brasileira? Ciênc saúde coletiva 2002; 7:421-23.

Correa L, Pignatari ACC. Infecção por cocos gram-positivos. In: Borges DR, Rothschild HA, editores. Atualização terapêutica - 2003. São Paulo: Artes Médicas; 2003. p.253-61.

Coutinho ESF. Metanálise. In: Medronho RA, Carvalho DM, Bloch KV, Luiz RR, Werneck GL. Epidemiologia. São Paulo: Atheneu; 2003. p.447-55.

Dawson B, Trapp RG. Bioestatística básica e clínica. $3^{\text {a }}$. ed. Rio de Janeiro: McGrawHill; 2003. 364p.

Deslandes SF. Concepções em pesquisa social: articulações com o campo da avaliação em serviços de saúde. Cad Saúde Pública 1997;13(1):103-7.

Donabedian A. Basic approaches to assessment: structure, process and outcome. In: Donabedian A. Exploration in quality assessment and monitoring. Ann Arbor, Michigan: Health Administration Press, 1980. p.77-125.

Donato AF. Traçando redes de comunicação: releitura de uma práxis da educação no contexto da saúde. São Paulo; 2000 [Tese - Doutorado - Universidade de São Paulo Faculdade de Saúde Pública].

Durkheim E. O que é um fato social? In: Durkheim E. As regras do método sociológico. São Paulo: Abril Cultural; 1978. p.87-109. (Coleção os Pensadores). 
Gallo E, Nascimento PC. Hegemonia, bloco histórico e movimento sanitário. In: Fleury S, coordenador. Reforma sanitária em busca de uma teoria. $2^{\mathrm{a}}$ ed. São Paulo: Cortez; 1995, p.91-118.

Genov IR, Roxo Júnior P. Otite média recorrente na infância. Medicina (Ribeirão Preto) 2001; 34: 297-300.

Goldenberg P, Shenkman S, Franco LJ. Prevalência de diabetes mellitus: diferenças de gênero e igualdade entre os sexos. Rev Bras Epidemiol 2003; 6(1):18-28.

Gullar F. Toda poesia. $9^{a}$. ed. Rio de Janeiro: José Olympio; 2000. p.464-6.

Gutierrez MR, Barbieri MA. Sistema Único de Saúde e demanda ambulatorial - Os pacientes do Hospital das Clínicas da Faculdade de Medicina de Ribeirão Preto - USP. Medicina (Ribeirão Preto) 1998; 31(1):81-98.

Haidar MA, Albuquerque Neto LC, Nunes MG, Baracat EC. Dismenorréia. In: Borges DR, Rothschild HA, editores. Atualização terapêutica - 2003. São Paulo: Artes Médicas; 2003. p.608-9.

Hartz ZMA. Mortalidade infantil "evitável" em duas cidades do Nordeste do Brasil: indicador de qualidade do sistema local de saúde. Rev Saúde Pública 1996; 30:310-18.

Hartz ZMA. Avaliação em saúde: dos modelos conceituais à prática na análise de implantação de programas. $1^{\circ}$ reimp. Rio de Janeiro: FIOCRUZ; 2000a. 132p.

Hartz ZMA. Pesquisa em avaliação da atenção básica: a necessária complementação do monitoramento. Divulg saúde deb 2000b; 21:29-35.

Hartz ZMA. Institucionalizar e qualificar a avaliação: outros desafios para a atenção básica. Ciênc saúde coletiva 2002; 7:419-21.

Hartz ZMA, Camacho LAB. Formação de recursos humanos em epidemiologia e avaliação dos programas de saúde. Cad Saúde Pública 1996; 12(supl. 2):13-20.

Heller A. Teoria de las necesidades en Marx. Barcelona: Península; 1978. 182p. 
Heller A. O cotidiano e a história. $6^{\text {a }}$ ed. São Paulo: Paz e Terra; 2000. 121p.

Novaes HMD. Avaliação de programas, serviços e tecnologias em saúde. Rev Saúde Pública 2000; 34:546-59.

Hochman G. A era do saneamento. São Paulo: Hucitec; 1998. 261p.

Hortale VA, Conill EM, Pedroza M. Desafios na construção de um modelo para análise comparada da organização de serviços de saúde. Cad Saúde Pública 1999; 15:79-88.

Itapecerica da Serra. Secretaria Municipal da Saúde. Projeto de humanização do atendimento nos serviços públicos de saúde de Itapecerica da Serra. 1998 (mimeo).

Itapecerica da Serra. Secretaria Municipal da Saúde. Relatório de avaliação 1997-2003. 2003 (mimeo).

Itapecerica da Serra. Secretaria Municipal da Saúde. Relatório de pesquisa 2004. (mimeo).

Kessner DM, Kalk C, Singer J. Assessing health quality - a case for tracer. N Engl J Med $1973 ; 288: 189-94$.

Kobinger MEBA, Bresolin AMB, Novaes HMD. Afecções de vias aéreas superiores. In: Sucupira ACSL, Bricks LF, Kobinger MEBA, Saito MI, Zuccolotto SMC. Pediatria em consultório. $4^{\mathrm{a}}$ ed. São Paulo: Sarvier; 2000. p.267-93.

Konder L. Walter Benjamin: o marxismo da melancolia. Rio de Janeiro: Campus; 1988.

Konder L. Os sofrimentos do “homem burguês”. São Paulo: SENAC; 2000.

Kosik K. Dialética do concreto. São Paulo: Paz e Terra; 1995.

Kovacs MH, Feliciano KV, Sarinho SW, Veras AA. Acessibilidade às ações básicas entre zrianças atendidas em serviços de pronto-socorro. J Pediatr 2005; 81:251-8.

Lukács G. Existencialismo ou marxismo? São Paulo: Senzala; 1967. 252p. 
Lukács G. História e consciência de classe. Porto (PO): Escorpião; 1974.

Levinson GK. Psicanálise e tempo: a busca de um viver pleno. Rev Bras Psicanál 2000; $34(2): 367-78$

Las Casas AL. Marketing de serviços. São Paulo: Atlas; 1991. 163p.

Luz MT. Notas sobre as políticas de saúde no Brasil de "transição democrática" - anos 80. In: Santana JP, coordenador. Desenvolvimento gerencial de unidades básicas do sistema único de saúde. Brasília: OPAS; 1997. p.138-54.

Marsiglia RG. Relação ensino-serviços: dez anos de integração docente-assistencial no Brasil. São Paulo: Hucitec; 1995.

Martin JFV, Higashiama E, Garcia E, Luizon MR, Cipullo JP. Perfil de crise hipertensiva. Prevalência e apresentação clínica. Arq. Bras Cardiol 2004; 83(2):125-30.

Martins NGR, Paskulin LMG. Emergência: fatores que levam a população infantil a recorrer a este serviço. Rev bras enfermagem 1992; 45(1):21-7.

Matus C. Adeus, senhor presidente: governantes e governados. São Paulo: FUNDAP; 1997. 381p.

Medina MG, Aquino R, Carvalho ALB. Avaliação da atenção básica: construindo ferramentas para o SUS. Divulg saúde debate 2000; 21:15-28.

Mello Filho J. Luto pelo self e angústia do tempo perdido. Rev Bras Psicanál 1973; 7 (2):197-218.

Mendes EV. O dilema do SUS. Radis - Fiocruz 2004; 25:35.

Mendes HWB. Regionalização da assistência à saúde: análise de demanda ao serviço de urgência/emergência de um hospital universitário. São Paulo; 2003. [Tese de doutorado - Universidade de São Paulo - Faculdade de Saúde Pública].

Merhy EE, Queiroz MS. Saúde pública, rede básica e o sistema de saúde brasileiro. Cad Saúde Pública 1993; 9:177-84. 
Merhy EE. Em busca do tempo perdido: a micropolítica do trabalho vivo em saúde. In: Merhy EE, Onocko R, organizadores. Agir em saúde. São Paulo: Hucitec; 1997. p.71-112.

Mishima SM, Pereira MJB, Fortuna CM, Matumoto S. Trabalhadores de saúde: problema ou possibilidade de reformulação do trabalho em saúde? - Alguns aspectos do trabalho em saúde e da relação gestor/trabalhador. In: Brasil. Ministério da Saúde. Observatório de recursos humanos de saúde no Brasil: estudos e análises. Rio de Janeiro: FIOCRUZ, 2003. p.137-156.

Nogueira RP. O trabalho em serviços de saúde. In: Santana JP, coordenador. Desenvolvimento gerencial de unidades básicas do sistema único de saúde. Brasília: OPAS; 1997, p.129-36.

Oliveira F. Os direitos do antivalor: a economia política da hegemonia imperfeita. Petrópolis: Vozes; 1998. 231p.

Oliveira ZNP, Rivitti EA. Dermatologia pediátrica - noções básicas para o pediatra. In: Sucupira ACSL, Bricks LF, Kobinger MEBA, Saito MI, Zuccolotto SMC. Pediatria em consultório. $4^{\mathrm{a}}$ ed. São Paulo: Sarvier; 2000. p.645-57.

Paim JS. Políticas de descentralização e atenção primária à saúde. In: Rouquayrol MZ, Almeida Filho N. Epidemiologia e Saúde. $5^{\text {a }}$. ed. Rio de Janeiro: Medsi; 1999. p.489-503.

Penna MLF. Condição marcadora e evento sentinela na avaliação de serviço de saúde. In: Santana JP, coordenador. Desenvolvimento gerencial de unidades básicas do sistema único de saúde. Brasília: OPAS; 1997. p.121-28.

Pereira MG. Epidemiologia: teoria e prática. Rio de Janeiro: Guanabara Koogan; 2002. $596 \mathrm{p}$.

Potyara APP. Necessidades humanas: subsídios à crítica dos mínimos sociais. São Paulo: Cortez; 2000. 215p.

Puccini PT. Limites e possibilidades da proposta de humanização dos serviços e satisfação dos usuários na disputa pelo direito à saúde. Campinas; 2002. [Dissertação de mestrado - Universidade Estadual de Campinas - Faculdade de Ciências Médicas]. 
Puccini PT, Cecilio LCO. A humanização dos serviços e o direito à saúde. Cad Saúde Pública 2004; 20(5):1342-53.

Puccini RF, Goihman S, Sigulem D, Ramos MP, Manfred N. Morbidade em unidades básicas de saúde. Rev Paul Pediatria 2001; 19:7-14

Puccini RF, Pedroso GC, Silva EMK, Araújo MS. Morbidade referida em crianças e utilização de serviços de saúde - Inquérito domiciliar em área da região metropolitana de São Paulo, 1996. Rev Paul Pediatria 2002; 20:111-121.

Rattner H. Indicadores sociais e planificação do desenvolvimento. São Paulo, 2003. Disponivel em $<$ http//www.espacoacademico.com.br/030/30rattner.htm $>$ [nov 2004]

Ribeiro JM. Atenção básica em saúde e a busca por uma conceituação. Ciênc saúde coletiva 2002; 7:413-15.

Rodrigues Neto E. A via do parlamento. In: Fleury S. organizadora. Saúde e democracia. São Paulo: Lemos; 1997. p.63-92.

Rouquayrol MZ, Almeida Filho N. Epidemiologia e saúde. 5a ed. Rio de Janeiro: Medsi; 1999. 600p.

Rutstein DD, Berenberg W, Chalmers TC, Child CG, Fishman AP, Perrin EB. Measuring the quality of medical care - A clinical method. N Engl J Med 1976; 294:582-8.

Sala A, Nemes MIB, Cohen DD. Metodologia de avaliação do trabalho em atenção primária à saúde. Cad Saúde Pública 1998; 14:741-51.

Salla J, Ghellar M, Kaufman ML, Ilha NS, Frandoloso PR. Perfil da demanda de um serviço de pronto-socorro, Santa Maria. Saúde (Santa Maria) 1989; 15:71-80.

Sano LL. Histórico do sistema de saúde de Itapecerica da Serra. 1999 (mimeo).

Santos RP, Weckx LLM. Sinusopatia. In: Borges DR, Rothschild HA, editores. Atualização terapêutica - 2003. São Paulo: Artes Médicas; 2003. p.1236-8. 
Santos NR. Um novo pacto para o SUS. Rio de Janeiro: FIOCRUZ, 2002. Disponível em: $<$ http//WWW.fiocruz.br/eventos/6seminelson.htm> [set 2003].

São Paulo. Conselho Federal de Medicina (CFM). Resolução CFM Nº 1451 de 10/3/1995. Disponivel em <http://www.portalmedico.org.br/resolucoes/cfm/ $>$ [mar 2005]

Schor E, Sato H, Freitas V, Girão MJBC. Algia pélvica crônica. In: Borges DR, Rothschild HA, editores. Atualização terapêutica - 2003. São Paulo: Artes Médicas; 2003. p.609-10.

Silva LMV, Formigli VLA. Avaliação em saúde: limites e perspectivas. Cad Saúde Pública 1994; 10:80-91.

Sociedade Brasileira de Cardiologia. IV Diretrizes Brasileiras de Hipertensão Arterial. Arq Bras Cardiol 2004; 82(supl. IV):1-14.

Sociedade Brasileira de Diabetes. Consenso Brasileiro sobre Diabetes 2001. 50p. (mimeo).

Starfield B. Atenção primária: equilíbrio de saúde, serviços e tecnologia. Brasília: UNESCO, Ministério da Saúde; 2002. 726p.

Sucupira ACSL, Novaes HMD. A prática pediátrica no consultório. In: Sucupira ACSL, Bricks LF, Kobinger MEBA, Saito MI, Zuccolotto SMC. Pediatria em consultório. $4^{\text {a }}$. ed. São Paulo: Sarvier; 2000. p.3-7.

Teixeira GT, Barreto ML, Costa MCN, Strina A, Martins Junior D, Prado M. Áreas sentinela: uma estratégia de monitoramento em saúde pública. Epidemiol serv saúde $2003 ; 12: 21-28$.

Testa M. Pensar em saúde. Porto Alegre: Artes Médicas; 1992. 226p.

Valente CA, Nunes MG, Haidar MA. Síndrome pré-menstrual. In: Borges DR, Rothschild HA, editores. Atualização terapêutica - 2003. São Paulo: Artes Médicas; 2003. p.612-3.

Vázquez AS. Filosofia da práxis. 4a . ed. São Paulo: Paz e Terra; 1990. 454p.

Vuori H. A qualidade da saúde. Divulg Saúde em Debate 1991; 3:17-25. 
Yamada ATT, Castro CGJ, Almeida MF, Nakazaki RMD, Garbin W, Sá ENC, Yamamoto EK. Estudo do perfil da demanda do serviço de pronto-socorro do Hospital Geral de Pedreira. São Paulo: Faculdade de Saúde Pública. São Paulo: Faculdade de Saúde Pública da Universidade de São Paulo, 2000. Disponível em <http://www.bvssp.fsp.usp.br/tecom/docs/2000/yam001.pdf>. [jun 2004].

Yamada ATT, Castro CGJ, Almeida MF, Nakazaki RMD, Garbin W, Sá ENC, Gomes MC. Estudo do perfil da demanda do serviço de pronto-socorro do Hospital Geral de Grajaú. São Paulo: Faculdade de Saúde Pública da Universidade de São Paulo, 2001. Disponivel em <http://www.bvs-sp.fsp.usp.br/tecom/docs/2001/yam001.pdf > [jun 2004].

Yamada ATT, Castro CGJ, Almeida MF, Garbin W, Sá ENC, Gomes MC. Estudo do perfil da demanda do serviço de pronto-socorro do Hospital Geral de Itaquaquecetuba. São Paulo: Faculdade de Saúde Pública da Universidade de São Paulo, 2002. Disponível em <http://www.bvs-sp.fsp.usp.br/tecom/docs/2002/yam001.pdf> [jun 2004].

Zamith R, Nazário ACP, Nicolau SM, Baracat EC. Corrimento genital. In: Borges DR, Rothschild HA, editores. Atualização terapêutica - 2003. São Paulo: Artes Médicas; 2003. p. 585-8. 
8. Anexos 


\section{ANEXO 1:}

\section{Questionário para entrevista dos médicos do pronto-socorro.}

\section{Questionário - médico socorrista}

Este é um levantamento que faz parte de um projeto de pesquisa da Faculdade de Saúde Pública/USP, que visa analisar a integração da rede de serviços de saúde. Solicitamos sua participação voluntária e anônima no sentido de responder a duas questões sobre o papel dos serviços. Sua experiência é um conhecimento importante para a avaliação da situação. Obrigado!

- PS:

- Data

- Sexo___ \#. Idade

- Tempo de formado
- Especialidade

- Tempo de Trabalho neste PS

- Atua no PS atendendo: Pediatria __ Clínica geral Gineco-obstetrícia ___ Ortopedia

1. Na sua avaliação, quais ocorrências/doenças atendidas por você freqüentemente, neste PS, deveriam estar sendo resolvidas ou acompanhadas em unidades básicas de saúde, por não necessitarem de atendimento de urgência ou emergência?

$1^{\circ}$.

$2^{\circ}$.

$3^{\circ}$.

$4^{\circ}$.

$5^{\circ}$

$6^{\circ}$.

$7^{\circ}$.

$8^{\circ}$

$9^{\circ}$.

$10^{\circ}$ 
2. 0 que você acha que determina esse tipo de procura?

A - 3 


年




\section{ANEXO 3:}

\section{Formulário para entrevista das pessoas atendidas no PS.}

\section{Formulário de entrevista}

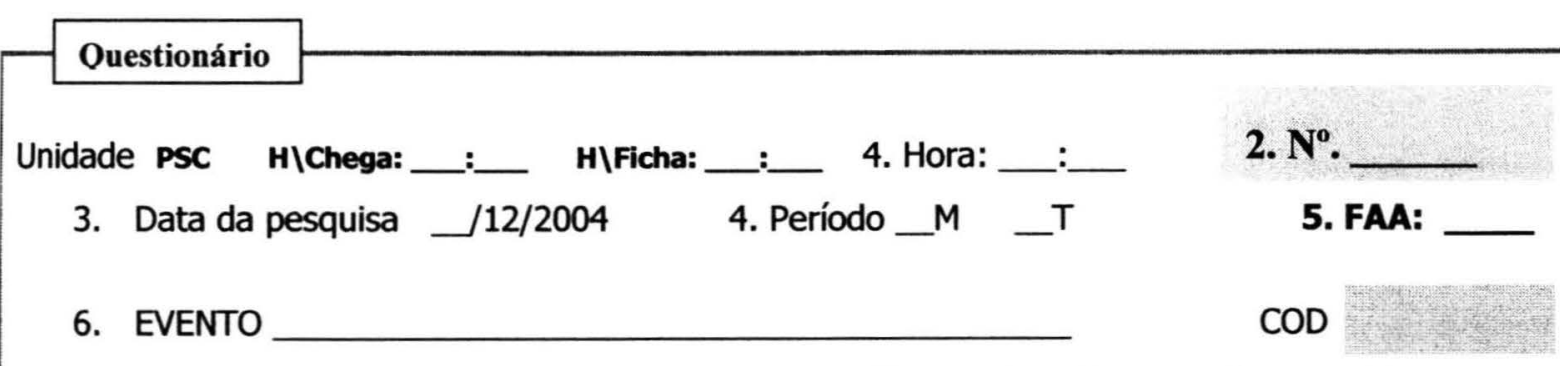

\section{Identificacão do paciente}

7. Nome

8. Sexo _ $M$

9. Idade

a

m

9. Bairro

11. Município

12. Tempo de residência no endereço atual meses

\section{Complemento do paciente ou do acompanhante (criança)}

13. __Paciente Acompanhante

14. Ocupação (atual)

15. Escolaridade série ${ }^{F} \_\mathrm{M}-\mathrm{S}$ Anos de estudos

16. A qual serviço você costuma ir para cuidar da (sua) saúde (da criança)? médico particular _ médico do convênio _pronto-socorro _ hospital _ UBS

17. Você vai (leva a criança) a alguma unidade básica, posto ou centro de saúde? $\ldots \operatorname{sim}$ não (

18. Vai (leva a criança) para usar que tipo de serviço?

__só vacina_só remédios consulta/atendimento marcado quando doente

19. Qual ubs/posto?

20. Município:

21. É o posto mais próximo da sua casa (da casa da criança)?

sim não 
22. Você (a criança) tem matrícula lá?

_sim

não

23. Você (a criança) neste ano esteve no posto para consulta marcada? (só para vacina, assinalar "não")

sim não

no mês de

próxima no mês de

24. Quando começou o atual problema de saúde?

Há __ dias_ queixa:

25. Você chegou a procurar atendimento lá no posto, por este problema?

_sim não (

26. Quando esteve lá? 1

27. Periodo T

28. O que aconteceu nesse atendimento lá no posto?

Fale um pouco como foi esse atendimento lá. (APÓS, IR PARA A QUESTÃo 30)

29. O que motivou você a não procurar o posto pelo problema atual? Fale um pouco sobre isso.

A - 6 
30. Procurou algum outro atendimento, pelo problema atual, antes de vir aqui? _sim, qual? não

31. Veio aqui, hoje, por causa de encaminhamento de outro serviço ou profissional? _sim, quem, qual? não

32. Se sim, trouxe alguma informação do atendimento anterior?

guia/impressos exames

33. Nos últimos 3 meses, quantas vezes a mais você (a criança) procurou atendimento neste PS? vezes (sem contar a atual) Queixas:

34. E agora, foi encaminhado(a) para outro serviço para continuar o tratamento?

_sim, qual? não

35. Como foi o atendimento recebido aqui no PS?

sujeitos da pesquisa que não costumam freqüentar UBS

36. Você conhece o posto mais próximo da sua casa (da casa da criança)?

$\operatorname{sim}$ não

37. Se "sim", qual é?

38. Alguma vez você (a criança) procurou atendimento lá?

sim não Por quê? (SE "NÃO" IR PARA A QUESTÃO 41).

30. Quando foi isso? Há meses

40. Fale um pouco como foi esse atendimento?

41. Quando começou o atual problema de saúde? (APÓS, VOLTAR PARA A QUESTÃO 30).

Há dias 


\section{ANEXO 4:}

\section{Questionário para observar a UBS e entrevistar o diretor.}

\section{Questionário}

\section{Identificacão da UBS}

1. Unidade

4. População que abrange

2. Data observação ______________

5. Anos de existência

3. Funciona das às

6. Município

\section{Disponibilidade de recursos}

Instalações

7. _ N No de cadeiras odontológicas

9. N_ No de assentos na sala de espera
8. ㄴ_ No de consultórios

10. ___ sala própria para reunião

\section{Horas semanais}
11. ___ Cirurgião dentista
12. Pediatria
13.
14. Clínico
15. G__ Generalista
16. Enfermeiros
17. __ Psicólogo
18. ___ Fonoaudiólogo
19. ___ Aux. Enfermagem
20.
ACS
21.
THD
22. ACD

Periodos sem profissional nas últimas duas semanas

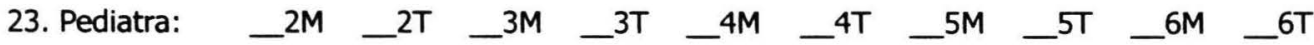

24. GO:

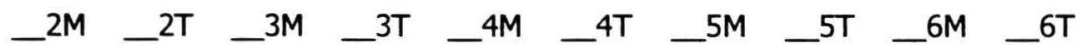

25. Clínico:

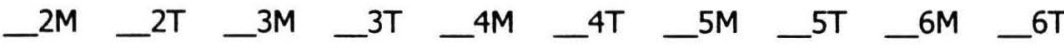

26. Generalista:

$2 M-2 T$

$-3 M-3 T$

27. Enfermeiro:

$-2 M \quad{ }^{2 T}-^{3 M}-^{3 T}{ }^{3 M}$

$4 M-4 T-5 M-5 T-6 M-6 T$

28. Ocorreram problemas com atrasos ou absenteísmo dos médicos, nos últimos 15 dias? _ sim, quais dias/períodos 


\section{Materiais e Medicamentos}

29. Faltou medicamento básico nos últimos 15 dias?

sim, quais?

não

30. Existe falta repetida de quais medicamentos básicos?

_sim, quais?

_ não

31. Faltou material, causando retardo ou cancelamento de atendimento, nos últimos 15 dias? _ sim, quais?

— não

32. Faltou instrumental, causando retardo ou cancelamento de atendimento, nos últimos 15 dias? _ sim, quais?

não

33. Ocorreu falha no funcionamento de equipamento, causando retardo ou cancelamento de atendimento, nos últimos 15 dias?

_. sim, quais?

Infra-estrutura geral

34. Os profissionais estão uniformizados e identificados?

$\operatorname{sim}$ não

35. A limpeza da unidade é satisfatória?<smiles>C[SnH3]</smiles>
— não

36. A conservação predial é satisfatória? $\ldots \operatorname{sim}$ —não
37. A sinalização interna é satisfatória?

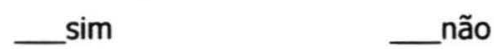

38. Há bebedouro de água para os usuários?<smiles>C[SnH2]CC[SeH2]</smiles>

39. Há banheiros para os usuários?

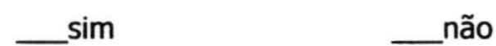




\section{Organização dos serviços e dos processos de trabalho}

Acesso, Recepção, Escuta, Fluxo

37. Há grades, guichês, balcões isolando usuário de profissional?

_sim

n não

38. No atendimento na recepção o usuário tem que permanecer em pé?

_ $\operatorname{sim}$ não

39. Quanto à dinâmica de acesso à consulta médica? agendados e extras agendados e vagas do dia (reserva vagas para a demanda do dia)

40. Sistema de trabalho prontuário: cadastramento de família por equipe mínima matrícula no serviço

41. Qual o tempo médio de espera para uma consulta médica? minutos

42. Como é orientada a hora de chegada do paciente agendado? na primeira hora/atende antes quem chega antes em dois horários por hora

Tempo médio de demora (em dias) para conseguir uma data agendada de consulta:
43. Pediatria
44.
45. Clínico
46.
47. Enfermeiro

Há restrição de dia ou de horánio para realizar:

49. ___ agendamento

50.

coleta de exames

51. __ vacina

52. A recepção agenda a pedido do paciente em qualquer situação?

_sim

— não

53. A recepção/balcão dispensa usuários quando não há mais vaga extra?

sim não 
54. Quem controla e decide sobre o uso das vagas do dia para a consulta médica? _ Recepção técnica acolhedora _ Recepção/balcão Ordem de chegada

55. Há alguma pessoa orientando o fluxo na entrada da unidade?

sim — não

56. A espera para recepção/acolhimento é ordenada por meio de:

filas senha numerada

\section{Questões 57 a 65 para o caso do serviço realizar recepção técnica acolhedora}

57. O local é exclusivo para o acolhimento?

sim não

58. O local possibilita atendimento individualizado?

_sim —não

59. Qual o horário de funcionamento dessa atividade:

60. Há responsável formal pela supervisão, apoio ao acolhimento? _sim, quem? ——não

61. 0 acolhimento faz registro dos atendimentos? Quais?

62. Qual tipo de profissional realiza o acolhimento?

63. Participou de algum treinamento específico para isso?

$\ldots \operatorname{sim}$

_ـ não

64. Qual o tempo médio de espera para o acolhimento?

65. Qual a relação/fluxo do acolhimento com a recpçã? 
66. $O$ enfermeiro realizou atividade de consulta, nos últimos 15 dias?

—não _só esporadicamente___agendado__agendado/continuidade imediata

67. Ocorreram atividades em grupo (últimos 15 dias):

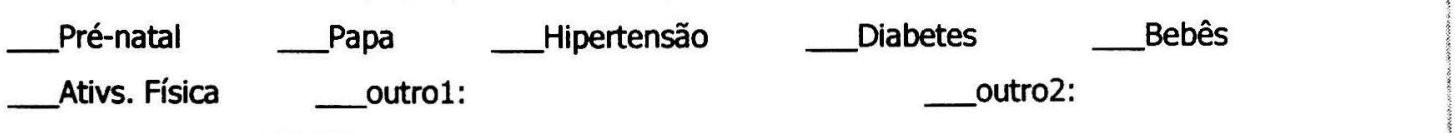

68. Ocorreram ações de visita domiciliar (faltosos)?

—sim —não

69. Ocorreram ações de visita domiciliar por equipe técnica, nos últimos 15 dias?

—sim —não

70. Existe supervisão de farmacêutico na unidade?

_diária _ semanal _mensal _bimensal _raro

71. Há problemas freqüentes (todo mês) com erros de coleta e resultados de exames?

— $\operatorname{sim} \quad$ _não

72. Qual o tempo médio (em dias) para receber resultados dos exames de:

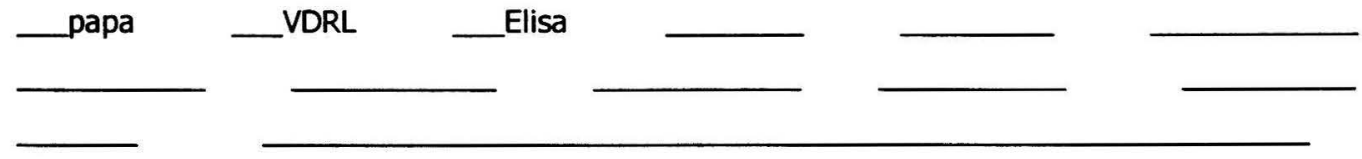

73. Porcentagem de encaminhamento para o PS?

_\%

74. O encaminhamento para o PS é feito com guia/impresso?

—sim _ não

75. Quais as maiores dificuldades com serviços de referências? 


\section{Participação dos usuários e controle social}

76. Há caixa de sugestão?

$\operatorname{sim}$ não

77. Quais as principais redamações?

78. Há Conselho Gestor?

__ sim, com reunião mensal _ não

79. Há mecanismos de participação dos conselheiros/usuários na definição de prioridades da unidade? _im, quais?

—_não

80. Houve pré-conferências na área da unidade, preparatórias para a última Conferência municipal? sim n não

81. Realizou ações de promoção de saúde com a comunidade, neste ano?

sim não

82. Realizou ações intersetoriais, neste ano?

sim não 


\section{ANEXO 5:}

Questionário de entrevista dos médicos das unidades básicas.

\section{Questionário - médicos de UBS}

Este é um levantamento que faz parte de um projeto de pesquisa da Faculdade de Saúde Pública/USP, que visa analisar a integração da rede de serviços de saúde. Solicitamos sua participação voluntária e anônima no sentido de responder a duas questões sobre o papel dos serviços. Sua experiência é um conhecimento importante para a avaliação da situação. Obrigado!

UBS:

- Data

- Sexo \# Idade

- Tempo de formado

- Especialidade

- Tempo na unidade
- Atua atendendo:

Pediatria __ Clínica geral Gineco-obstetrícia __ Outra

- Trabalha ou trabalhou em prontosocorro? _ Sim Não

1. Considerando sua experiência profissional, quais ocorrências/doenças que com freqüência chegam às unidades básicas de saúde e que poderiam ser melhor resolvidas se procurassem diretamente os prontos-socorros?

$1^{\circ}$

$2^{\circ}$.

$3^{\circ}$.

$4^{\circ}$.

$5^{\circ}$

$6^{\circ}$.

$7^{\circ}$.

$8^{\circ}$.

$9^{\circ}$

$10^{\circ}$. 
2. Considerando a necessidade de melhor delimitar as funções das unidades básicas de saúde e dos prontos-socorros, nos casos de febre, pródromos de IVAS, broncoespasmo, sintomas de descontrole de hipertensão ou diabetes, para qual desses dois serviços as pessoas, em geral, deveriam ser orientadas a procurar atendimento? Comente um pouco sobre sua indicação. 


\section{ANEXO 6: \\ Classificação e descrição das ocorrências escolhidas para estudo}

Nasofaringite (CID: J00) - inclui catarro nasal agudo, coriza (aguda), rinofaringite e rinite aguda ou infecciosa. É uma doença infecciosa viral, de curso autolimitado, de larga ocorrência na população, afetando pessoas em qualquer idade ou sexo, e, apesar da baixa gravidade, algumas vezes o mal-estar geral que ocasiona obriga as crianças a faltarem à escola e os adultos ao trabalho. Estima-se que uma criança tenha de 3 a 8 episódios dessa infecção ao ano, com maior freqüência entre lactentes e pré-escolares do que no grupo em idade escolar. Depois de um período de incubação que varia de um a dois dias, os sintomas predominantes do resfriado comum são rinorréia, obstrução nasal e espirros, tosse, dor de garganta, cefaléia, febre e mal-estar geral. Embora os sintomas mencionados refiram-se ao trato respiratório superior, podem-se observar queixas de outros sistemas, razão pela qual a pessoa pode apresentar males como dor torácica, irritação ocular, vômitos, diarréia, mialgias e dor abdominal. Evolui naturalmente para a cura após cerca de 7 dias do início dos sintomas. Gripe (CID: J11) - a gripe é uma infecção respiratória aguda muito semelhante ao resfriado comum, mas devido a características dos agentes etiológicos envolvidos apresenta sintomas mais graves com maior comprometimento do estado geral e das vias aéreas inferiores. Dentre as principais complicações, a mais freqüente e de maior relevância é a pneumonia. Os registros do atendimento deste PS não apresentavam especificidade suficiente para separar essas duas ocorrências, nasofaringite (resfriado comum) e influenza (gripe), incluindo-se, também, outras denominações para estes dois diagnósticos, como, por exemplo: faringite, IVAS e sinais e sintomas de infecção das vias aéreas superiores, sem a prescrição de antibioticoterapia (KOBINGER et al. 2000; BELLEI 2003).

Sinusite (CID: J01) - inclui sinusite maxilar aguda, sinusite frontal aguda, sinusite etmoidal aguda, sinusite esfenoidal aguda, pansinusite aguda, outras sinusites agudas, sinusite aguda não especificada. A sinusite é a inflamação das mucosas dos seios da face, região do crânio formada por cavidades ósseas ao redor do nariz, maçãs do rosto e olhos. É doença de grande incidência entre adultos e crianças. Com grande freqüência é precedida de rinite e decorre da complicação em até $10 \%$ das infecções de vias aéreas superiores. Se 
somarmos aos diagnósticos de gripe e resfriado comuns os de sinusite, a incidência por habitante dessas três morbidades chegará a duas por ano em adultos e até quatro ao ano em crianças. As sinusites podem ser divididas em agudas e crônicas. Na sinusite aguda, costuma ocorrer dor de cabeça, na área do seio da face mais comprometido, em pontada, pulsátil ou sensação de pressão ou peso na cabeça. Na grande maioria dos casos, surge obstrução nasal com presença de secreção amarela ou esverdeada, sanguinolenta, que dificulta a respiração. Febre, cansaço, coriza, tosse, dores musculares e perda de apetite costumam estar presentes. Na sinusite crônica, os sintomas são os mesmos, porém variam muito de intensidade. A tosse, geralmente noturna, costuma ser o sintoma preponderante. Neste item foram considerados todos os diagnósticos de sinusite, aguda ou crônica, especificados ou não como bacterianos (KOBINGER et al. 2000; SANTOS e WECKX 2003).

Otite média aguda não supurativa (CID: H65) - inclui: otite média serosa, otite média aguda não supurativa, otite média serosa crônica, otite média mucóide crônica, outras otites médias crônicas não supurativas, otites médias não supurativas não especificadas. Otite média supurativa e as não-especificadas (CID: H66) - inclui otite média aguda supurativa, otite média tubotimpânica supurativa crônica, otite média ático-antral supurativa crônica, otite média supurativa não especificada, otite média não especificada. A otite média aguda (OMA) é uma das doenças mais comuns na infância. Alta prevalência, elevada morbidade e baixa letalidade caracterizam a OMA. Estima-se que $75 \%$ de todas as crianças com menos de cinco anos tiveram, pelo menos, uma consulta devido a tal diagnóstico. Aproximadamente $70 \%$ das crianças terão um episódio antes de completarem cinco anos de idade. Avalia-se que cerca de $40 \%$ dos antibióticos prescritos na prática pediátrica ambulatorial são dirigidos para tratamento da OMA. Ela é um importante problema de saúde pública, afetando a criança, a família e o sistema de assistência médica. É definida como a existência de fluido na orelha média, em associação com sinais e sintomas de doença aguda, local ou sistêmica, que podem ser específicos, como otalgia e otorréia, ou inespecíficos como febre. Além dos sinais e sintomas clássicos (febre, inapetência, dor à compressão do trágus, otalgia e otorréia em algumas ocasiões), as manifestações clínicas nos processos crônicos e recorrentes da OMA podem levar a efeitos adversos na fala, na linguagem e no desenvolvimento cognitivo, que são, provavelmente, 
causados pela perda flutuante da audição. Neste item foram considerados todos os diagnósticos de otite média aguda ou crônica, supurados ou não, identificados como bacterianos ou não (KOBINGER et al. 2000; GENOV e ROXO JUNIOR 2001; ANADÃO e ALVARENGA 2003).

Amigdalite (CID: J03) - inclui amigdalite estreptocócica, amigdalite devido a outros microorganismos e amigdalite não especificada. O quadro clínico caracteriza-se pela presença de sinais inflamatórios nas amígdalas e na parede da orofaringe, e ocorrem dor de garganta, hiperemia, exsudação e ulceração do palato, amígdalas e orofaringe, acompanhados por disfagia, febre, cefaléia, mal-estar geral e anorexia. Os vírus são os agentes causais mais importantes. As infecções bacterianas são responsáveis por $15 \%$ a $20 \%$ dos quadros e quase a totalidade $(90 \%)$ destas são causadas pelo estreptococo betahemolítico do grupo A. Em crianças menores de dois anos predomina a origem viral, enquanto entre 5 e 8 anos a infecção estreptocóccica corresponde à cerca de $50 \%$. O tratamento de escolha para a amigdalite estreptocóccica é a penicilina benzatina, por sua eficácia, baixo custo e adequação para prevenção das complicações da doença. Neste item foram considerados todos os casos com diagnóstico de amigdalite ou faringite discriminados como de origem bacteriana ou para os quais havia sido prescrito antibioticoterapia (KOBINGER et al. 2000; CORREA e PIGNATARI 2003).

Asma brônquica (CID: J45) - inclui asma predominantemente alérgica, asma alérgica (extrínseca, atópica), mista, não especificada. É definida como uma doença crônica das vias aéreas inferiores caracterizada por: obstrução ao fluxo aéreo reversível (embora não completamente, em algumas pessoas), espontaneamente ou com tratamento; inflamação; aumento da reatividade das vias aéreas a uma variedade de estímulos; e episódios recidivantes de sibilância, dispnéia, aperto no peito e tosse, particularmente à noite e pela manhã ao acordar. O diagnóstico clínico tem como base: presença de sintomas compatíveis, sintomas episódicos, resposta favorável à terapia específica para a asma e exclusão de diagnósticos alternativos. De acordo com o III Consenso Brasileiro para o Manejo da Asma, a doença pode ser classificada em: intermitente e persistente (leve, moderada e grave). Aproximadamente $75 \%$ dos casos são de asma intermitente ou leve, $20 \%$ de moderada e cerca de $5 \%$ grave. Os principais objetivos do tratamento são: reduzir a freqüência e a gravidade das exacerbações, a morbidade e a mortalidade; controlar a hiper- 
reatividade brônquica; normalizar a inflamação crônica; propiciar uma qualidade de vida adequada. Nas crises ou exacerbações, na dependência da gravidade do quadro, o tratamento inclui: oxigenoterapia, hidratação, medicação por via inalatória ou endovenosa e internação, sendo a medicação por via inalatória suficiente na maioria dos casos, procedimento seguramente realizável na unidade básica de saúde. Um ponto importante na primeira abordagem realizável, também, na atenção básica é a identificação do asmático de risco para o devido encaminhamento a serviço especializado e para o estabelecimento do plano de cuidado dos demais na unidade básica. São critérios de gravidade: três ou mais visitas a serviços de emergência ou duas ou mais internações por asma nos últimos dois meses; uso freqüente de corticóide sistêmico; crise prévia grave (necessitando de intubação); uso de dois ou mais tubos de aerossóis dosimetrados de broncodilatador por mês; co-morbidades; asma lábil; má percepção do grau de obstrução (CONSENSO BRASILEIRO NO MANEJO DA ASMA 2002).

\section{Exame geral, investigação de pessoa sem queixa ou diagnóstico relatado em} Puericultura até um ano de idade (CID: Z00) - inclui exame médico geral, exame de rotina da criança para vigilância do crescimento e do desenvolvimento, exame na fase de crescimento rápido da criança. Foram codificadas nesse grupo situações freqüentes em consultas de puericultura - preocupações em relação ao crescimento e do desenvolvimento da criança, à alimentação, dificuldades quanto à amamentação, cólicas e obstrução nasal no lactente ou quando o diagnóstico do médico registrado na ficha tenha sido de higidez. Dermatite das fraldas (CID: L22) - ocorre devido ao contato constante e prolongado com urina e fezes das fraldas e caracteriza-se pela presença de eritema na região afetada. Esse diagnóstico (também, até um ano de idade) foi considerado em conjunto com a puericultura, por ser, também, queixa comum em consultas de rotina do lactente na atenção básica (OLIVEIRA e RIVITTI 2000; SUCUPIRA e NOVAES 2000).

Outras afecções inflamatórias da vagina e da vulva - vulvovaginite (CID: N76) - inclui vaginite ou vulvovaginite aguda, subaguda e crônica, vulvite aguda, subaguda e crônica, abscesso vulvar, ulceração vaginal ou vulvar, outras inflamações especificadas da vagina e da vulva. Estas são muito comuns e correspondem a um terço das consultas em ginecologia. A causa é variada, sobressaindo os agentes de natureza infecciosa. A infecção pode se originar do crescimento da flora normal da vagina, assim como da colonização de novos 
microorganismos. $\mathrm{O}$ diagnóstico diferencial em relação aos agentes etiológicos tem como base o exame clínico, o exame microscópico e, em alguns casos, outros exames subsidiários, que no seu conjunto irão determinar a terapêutica adequada e específica; esta deve ser sempre acompanhada de medidas gerais de higiene, redução de fatores predisponentes e alívio dos sintomas. Neste item foram considerados todos os diagnósticos de vulvovaginite, vaginose, leucorréia e corrimento vaginal. As hipóteses diagnósticas de vulvovaginites apareceram numa freqüência inferior ao mínimo estabelecido $(0,8 \%)$, mas decidiu-se por deixá-las tendo em vista que a retirada diminuiria a presença e a análise dos agravos específicos da assistência à mulher. Considerou-se, ainda, que essa reduzida mas não ausente freqüência pode ser um instrumento de monitoramento no futuro imediato, ao permitir o acompanhamento das unidades maiores. É bom lembrar que de forma semelhante deverá ser entendido um eventual surgimento de casos de supervisão de gravidez normal (pré-natal) no pronto-socorro estudado, que no período da pesquisa teve freqüência nula (ZAMITH et al. 2003).

Menstruação ausente, escassa e pouco freqüente (CID: N91) - inclui amenorréia primária, secundária e não especificada e oligomenorréia primária, secundária e não especificada. Define-se amenorréia como a falta de menstruação no menacme. Classifica-se em primária e secundária. É primária quando a pessoa relata não ter tido nenhuma menstruação prévia espontânea; é secundária quando, após período variável de tempo em que ocorrem fluxos normais ou anormais, a mulher deixa de menstruar. Considera-se amenorréia se o período em que faltam as menstruações for igual ou exceder, cronologicamente, três intervalos menstruais prévios ou 180 dias; antes disso considera-se atraso menstrual. Nesse grupo foram, também, incluídos os atrasos menstruais, portanto, as suspeitas de gravidez. Menstruação excessiva, freqüente e irregular (CID: N92) - inclui menstruação excessiva e freqüente com ciclo regular e irregular, menstruação excessiva na puberdade, sangramento na ovulação, sangramento abundante na pré-menopausa, outros tipos de irregularidades menstruais. Define-se como sangramento uterino disfuncional toda perda sangüínea de origem uterina, na ausência de gravidez ou de qualquer afecção orgânica do trato genital. Dor e outras afecções associadas com os órgãos genitais femininos e com o ciclo menstrual (CID: N94) - inclui ovulação dolorosa, dispaurenia, vaginismo, síndrome de tensão pré-menstrual, dismenorréia primária, secundária e não 
especificada e outras afecções relacionadas ao ciclo menstrual. A algia pélvica crônica é caracterizada por dor nos segmentos inferiores do abdômen de caráter contínuo e com duração superior a seis meses. Pode se manifestar como dismenorréia, dispaurenia ou dor em qualquer fase do ciclo menstrual. A dificuldade no diagnóstico etiológico se deve à complexidade da inervação da pelve e à existência de diversos tecidos (urogenitais, neurovasculares, gastrintestinais e músculo-esqueléticos). Estima-se que $10 \%$ a $15 \%$ das mulheres sofram ou já tenham sofrido de dor pélvica crônica. Dismenorréia são dores abdominais relacionadas ao fluxo menstrual que surgem preferencialmente em jovens. A maioria dos autores estima que cerca de 50\% das adolescentes apresentem dismenorréia. Em porcentagem elevada de casos associa-se à síndrome pré-menstrual. A síndrome prémenstrual é afecção de grande importância, devido à alta freqüência e ao comprometimento das funções habituais da mulher. O quadro clínico é variado e polimorfo, sendo relacionados mais de 150 sintomas, destacando-se ansiedade, irritabilidade, depressão, alterações do apetite, transtornos do sono, agressividade, cefaléia, dor e aumento do volume de mamas, taquicardia, dispnéia, náuseas e vômitos. Estima-se que acometa $40 \%$ das mulheres. $O$ tratamento inclui orientação dietética, incentivo a atividades físicas, administração de medicamentos (em alguns casos) e, sobretudo, uma abordagem global da pessoa, com acompanhamento e apoio. As doenças constituintes desses três grupos da CID foram agrupadas tendo em vista a limitação do diagnóstico diferencial dessas morbidades no atendimento do pronto-socorro e o tipo de abordagem requerido que exige prolongado acompanhamento, detalhamento da anamnese, exame físico, exames subsidiários e, sobretudo, uma compreensão da pessoa no seu contexto familiar e social (BARACAT et al. 2003a; BARACAT et al. 2003b; HAIDAR et al. 2003; SCHOR et al. 2003; VALENTE et al. 2003)

Hipertensão arterial sistêmica - HAS (CID: E14) - inclui hipertensão arterial benigna ou maligna, primária sistêmica, pressão arterial sangüínea alta, hipertensão essencial (primária). Exclui as situações caracterizadas como emergências hipertensivas, isto é, com deterioração rápida de órgãos e risco imediato de vida. Dentre elas pode-se citar encofalopatia hipertensiva, acidente vascular encefálico, hemorragia intracraniana, edema agudo de pulmão, dissecção de aorta, etc. Consideraram-se como HAS duas condições: pessoas que desconheciam o problema e foram diagnosticadas no atendimento realizado e 
situações de crise hipertensiva. Adotou-se como definição de crise hipertensiva a proposta pelo consenso estabelecido no VI Joint National Commitee e pelo VI Encontro Brasileiro sobre crises hipertensivas, 2001, que também definem urgência hipertensiva como situação na qual uma pessoa apresenta pressão arterial diastólica maior ou igual a $120 \mathrm{~mm}$ de HG e com sintomas, diferenciando-a da situação de emergência, aqui não considerada, pois não apresentavam evidências de lesão em órgão-alvo podendo, portanto, a redução de pressão arterial ser feita em horas. As doenças cardiovasculares representam importante problema de saúde pública, constituindo-se na primeira causa de morte no Brasil. Dentre essas doenças encontra-se a hipertensão arterial sistêmica (HAS) com prevalência estimada entre $20 \%$ a $30 \%$ da população adulta. Hipertensão arterial e diabetes estão fortemente relacionadas como co-morbidades. A hipertensão arterial e o diabetes mellitus constituem os principais fatores de risco para as doenças do aparelho circulatório. Dentre suas complicações mais freqüentes decorrentes encontram-se o infarto agudo do miocárdio, o acidente vascular cerebral, a insuficiência renal crônica, a insuficiência cardíaca, as amputações de pés e pernas, a cegueira definitiva, os abortos e as mortes perinatais. A identificação precoce das pessoas portadoras e o estabelecimento do vínculo entre os elas e as unidades básicas de saúde são elementos imprescindíveis para o sucesso do controle desses agravos. O acompanhamento e o controle da hipertensão arterial e do diabetes mellitus no âmbito da atenção básica poderão evitar o surgimento e a progressão das complicações, reduzindo o número de internações hospitalares, bem como a mortalidade resultante desses agravos. (MARTIN et al. 2004; SOCIEDADE BRASILEIRA DE CARDIOLOGIA 2004).

Diabetes mellitus (CID: I10) - inclui diabetes sem outra especificação com ou sem complicações. O diabetes é uma síndrome decorrente da falta de insulina, ou da incapacidade da insulina em exercer adequadamente seus efeitos, ou de ambas as situações, com múltiplas e graves conseqüências para a saúde das pessoas em longo prazo. Estudo multicêntrico sobre Prevalência de Diabetes no Brasil, realizado em nove capitais no periodo de 1986 a 1988, na população de 30 a 69 anos de idade, evidenciou a prevalência de $7,6 \%$ para o conjunto da amostra, sendo de $9,7 \%$ a prevalência estimada para a cidade de São Paulo, que apresentou o maior valor entre as áreas estudadas. Num estudo circunscrito ao Diabetes Mellitus Auto-Referido - DMAR4, que respondeu por 50,5\% da prevalência na 
cidade de São Paulo, as estimativas encontradas apontaram para maior prevalência dentre as mulheres - 5,7\% -, enquanto dentre os homens essa prevalência foi de 3,5\%. Entretanto, estudos têm revelado que com a busca ativa de casos tende a desaparecer a diferença de prevalência entre os sexos. No diabetes tipo 2 a HAS faz parte do espectro da síndrome metabólica, estando presente em cerca de $50 \%$ dos pacientes no momento do diagnóstico de diabetes. Em termos gerais, a HAS é cerca de duas vezes mais freqüente entre indivíduos diabéticos que entre a população em geral. Diante dessa co-morbidade entre diabetes e HAS, consideraram-se diabetes apenas os quadros cujos sintomas eram característicos dessa morbidade ou em que os níveis de pressão arterial eram normais. Quando da presença das duas alterações e de sintomas mistos, e diante da necessidade de considerar apenas um diagnóstico, optou-se por classificar essa situação como HAS. Embora a freqüência do diabetes tenha sido baixa, optou-se por mantê-la, dado as circunstâncias expostas sobre a interação entre HAS e diabetes (SOCIEDADE BRASILEIRA DE DIABETES 2001; GOLDENBERG et al. 2003). 


\section{ANEXO 7: \\ Termo de consentimento dos médicos entrevistados}

\section{TERMO DE CONSENTIMENTO LIVRE E ESCLARECIDO PARA PARTICIPAÇÃO EM TRABALHO CIENTIFICO}

Projeto de pesquisa: Análise de instrumentos de apoio ao monitoramento dos serviços de atenção básica.

O objetivo da presente pesquisa é analisar a população atendida no serviço de pronto socorro do PS Central de Itapecerica da Serra.

Solicito seu consentimento para participar de entrevista, respondendo a perguntas sobre os atendimentos realizados nesse serviço.

Tendo sido satisfatoriamente informado sobre a pesquisa "Análise de instrumentos de apoio ao monitoramento dos serviços de atenção básica", sob responsabilidade do aluno do curso de pós-graduação da Faculdade de Saúde Pública da Universidade São Paulo, Paulo de Tarso Puccini, orientado pela Professora Vitória Kedy Cornetta, declaro que concordo em participar da mesma, respondendo a perguntas apresentadas em questionário-entrevista.

Estou ciente de que as informações serão utilizadas exclusivamente pelo pesquisador, preservando-se o sigilo; que o mesmo está disponivel para responder a quaisquer perguntas e que poderei retirar este consentimento a qualquer tempo.

de de 2004 


\section{ANEXO 8:}

Termo de consentimento das pessoas atendidas no PS entrevistadas

\section{TERMO DE CONSENTIMENTO LIVRE E ESCLARECIDO PARA PARTICIPAÇÃO EM TRABALHO CIENTÍFICO}

Projeto de pesquisa: Atenção básica à saúde: análise de instrumentos de apoio ao monitoramento dos serviços

O objetivo da presente pesquisa é analisar a população atendida no serviço de pronto socorro do PS Central de Itapecerica da Serra.

Solicito seu consentimento para participar de entrevista, respondendo perguntas sobre os motivos que o levaram a procurar esse serviço e sobre o atendimento prestado no seu bairro e no seu município.

Tendo sido satisfatoriamente informado sobre a pesquisa "Atenção básica à saúde: análise de instrumentos de apoio ao monitoramento dos serviços", sob responsabilidade do aluno do curso de pós-graduação da Faculdade de Saúde Pública da Universidade São Paulo, Paulo de Tarso Puccini, orientado pela Professora Vitória Kedy Cornetta, declaro que concordo em participar da mesma, respondendo a perguntas apresentadas em entrevista.

Estou ciente de que as informações serão utilizadas exclusivamente pelo pesquisador, preservando-se o sigilo; que o mesmo está disponível para responder a quaisquer perguntas e que poderei retirar este consentimento a qualquer tempo.

de de 2004 


\section{ANEXO 9:}

\section{Concordância do gestor local com a realização da pesquisa}

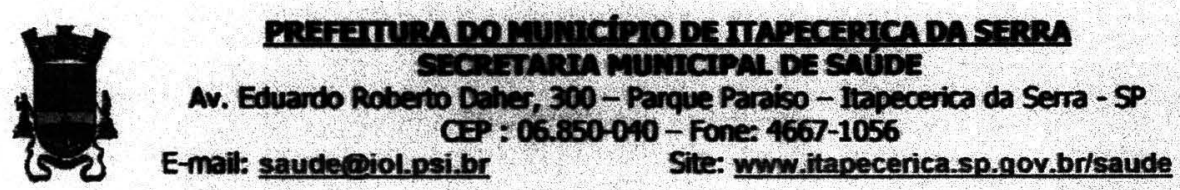

DECLARAÇÃO DE CONCORDÂNCIA

Declaro, para os devidos fins, que o Projeto de Pesquisa "Análise de instrumentos de apoio ao monitoramento dos servigos de atençäo básica", de autoria de Paulo de Tarso Puccini, sob orientapao da Professora Associada Vitória Kedy Cornetta da Faculdade de Saúde Pública da Universidade de Săo Paulo, tem a concordância para ser desenvolvido neste município.

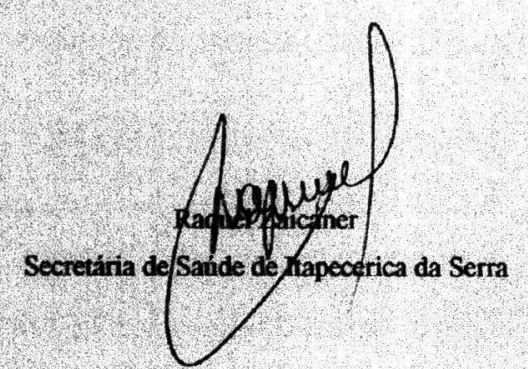

